Portland State University

PDXScholar

$1-1-2011$

\title{
The Realization of the Cathlapotle Plankhouse: Reflections on Cross-Cultural Collaboration in the Post-NAGPRA Era
}

Erica Lynn Boyne

Portland State University

Follow this and additional works at: https://pdxscholar.library.pdx.edu/open_access_etds

Let us know how access to this document benefits you.

Recommended Citation

Boyne, Erica Lynn, "The Realization of the Cathlapotle Plankhouse: Reflections on Cross-Cultural Collaboration in the Post-NAGPRA Era" (2011). Dissertations and Theses. Paper 692.

https://doi.org/10.15760/etd.692

This Thesis is brought to you for free and open access. It has been accepted for inclusion in Dissertations and Theses by an authorized administrator of PDXScholar. Please contact us if we can make this document more accessible: pdxscholar@pdx.edu. 
The Realization of the Cathlapotle Plankhouse: Reflections on Cross-Cultural Collaboration in the Post-NAPGRA Era

by

Erica Lynn Boyne

A thesis submitted in partial fulfillment of the requirements for the degree of

Master of Arts

in

History

Thesis Committee:

Katrine Barber, Chair

David A. Horowitz

William Lang

Portland State University

(C)2011 


\begin{abstract}
In the last two decades, a shift in the museological paradigm has changed the way in which Native American history and culture is interpreted and represented to the general public. As legal mandates and growing institutional pressures increasingly call for the integration of tribal representatives into the decision-making bodies of museums and authoritative institutions, cross-cultural collaboration and partnerships have increased significantly. With little precedent guiding public historians and museum professionals through this new and complex system of collaboration, the path unfolding in the journey towards the "indigenization" of museums has been marked with achievements and challenges that have both taught and tested historical professionals. The following is a case study that examines the ways in which this unfolding shift in Native American representation manifested itself in the reconstruction of a Chinookan plankhouse in the early $21^{\text {st }}$ century.
\end{abstract}

With a common objective of educating visitors about the significant cultural and natural history of the former site of the Cathlapotle village, the U.S. Fish and Wildlife Service and the Chinook Indian Nation teamed up to design, fund, construct and interpret the Cathlapotle Plankhouse in Ridgefield, Washington. Despite sharing a common goal for the reconstruction of a full-scale Chinookan plankhouse, different motivations and agendas guided the decision-making process and required both partners to make compromises that challenged each other's understanding and expectations of the project. In this work, I analyze how these two organizations navigated the rewarding yet challenging realm of cross-cultural collaboration to create a meaningful and significant 
heritage site for a wide range of user groups. From this analysis, I hope to provide public historians and museum professionals a detailed example of a cross-cultural partnership that will assist them as they move forward through a continuously unfolding and largely uncharted system of collaboration. 


\section{ACKNOWLEDGEMENTS}

A number of people supported me both personally and professionally as I worked to complete this challenging yet rewarding study of cross-cultural collaboration. First and foremost, I would like to thank my thesis advisor and public history mentor, Katrine Barber, for all of the assistance and support she provided in the research and writing process. Through oddly-timed Skype calls, the long-distance cheerleading, and the reference of unending bodies of literature and knowledge, Katy eliminated the thousands of miles that separated us for most of the thesis process. Her passion for public history is an inspiration to all of the students who are lucky enough to take classes from her, and I cannot repay her for the valuable lessons I have learned about the profession over the past three years.

I would also like to thank my husband for his patience, his motivation and the sharing of his intellectual genius. It was he who was most affected by my pursuit of a graduate degree, and he did a tremendous job at not making me feel guilty for the nights and weekends he was left alone while I was at the library or locked in another room. When I hit roadblocks in motivation or thought, he was always there to provide me with encouragement or a fresh perspective, and our hour-long discussions about different elements of my thesis expanded my analysis in ways that would not have been possible without him. I am eternally grateful for his support of my educational and professional pursuits.

There are many others who have also supported me as I worked to complete this study over the past three years. While not a comprehensive list, I wish to thank: 
- $\quad$ My mother, Ann Lacks, for giving me life and always supporting my educational pursuits. You never questioned the path I have chosen for myself, and I cannot thank you enough for that.

- $\quad$ My father, D. Mark Stevenson, for instilling the love of history in me. Although I rolled my eyes at the historical stories that accompanied every road trip or educational outing as a kid, I am now the person telling the stories to anyone who will listen.

- $\quad$ Members of the Chinook Indian Nation Culture Committee, especially Tony and Gary Johnson, who took time out of their very busy schedules to share their historical and cultural knowledge with myself and other classmates.

- Jessie McClendon, who knew exactly when to engage me in historical discussion and when to talk about anything else. Our Raccoon Lodge meet ups gave me sanity in a very busy and life-transforming time.

- Donna Sinclair, who always took the time to talk about public history or life, even when she did not have any. Her passion for history and the Pacific Northwest is absolutely contagious. 


\section{CONTENTS}

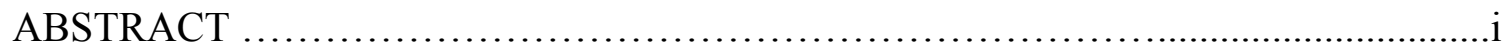

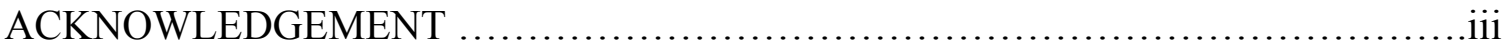

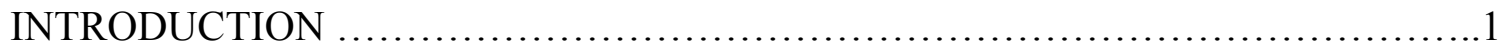

Historical Representations of Native Americans .............................. 3

Authenticity and the Representation of Native Americans ...................... 12

Literature Review .................................................... 14

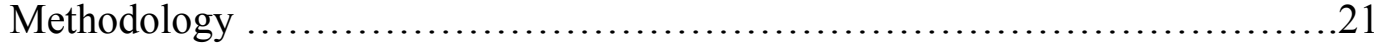

Issues of Federal Recognition ...........................................24

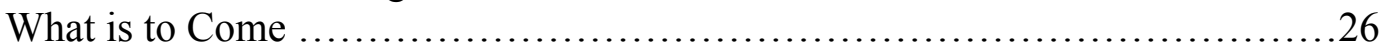

CHAPTER I - UNEARTHING THE CATHLAPOTLE PLANKHOUSE...............29

History of the Cathlapotle Site ..........................................................................29

Pre-Contact and Contact History of the Cathlapotle Village ..............29

Post-Contact History of the Cathlapotle Site ..........................33

The Carty Generations .............................................. 38

The Site as the Ridgefield National Wildlife Refuge ....................40

The Cathlapotle Archaeology Project .......................................41

Partners .......................................................43

Portland State University ...............................43

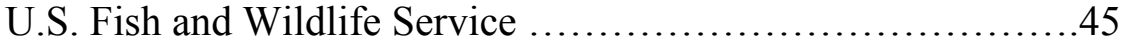

Chinook Indian Nation ....................................46

Results of the Project ..........................................52

CHAPTER II - PLANKHOUSE DESIGN AND CONSTRUCTION .................58

The Beginnings of the Cathlapotle Plankhouse Reconstruction Project ..........59

The Lewis and Clark Bicentennial Commemoration ....................59

The Original Vision of the Cathlapotle Plankhouse ...................62

Phase I - The Conceptual Design of the Cathlapotle Plankhouse ...............66 66

Challenges to Design Authenticity ....................................68

Phase II - The Erection of Cathlapotle Plankhouse ..........................74

The Cowlitz Indian Tribe ............................................83

The Result .......................................................... 86

\section{CHAPTER III - CATHLAPOTLE IS: INTERPRETIVE IMPLICATIONS OF A}

HERITAGE SITE...........................................................89

The Cathlapotle Plankhouse as an Outdoor Educational Center ................90

Interpretive Implications ......................................96

The Cathlapotle Plankhouse as a Cultural Anchor ............................. 98

Interpretive Implications ...................................... 107

The Cathlapotle Plankhouse as a Political Arena ............................110 


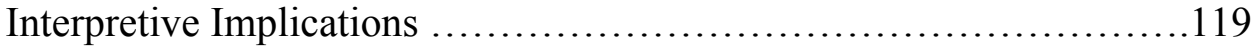

Cathlapotle Is... .................................................... 122

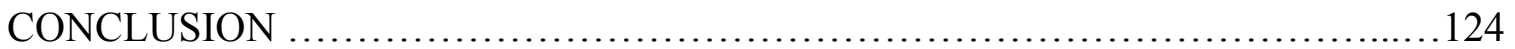

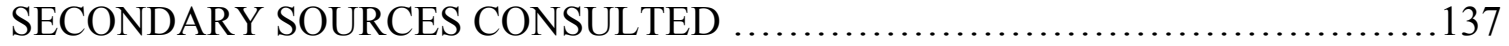

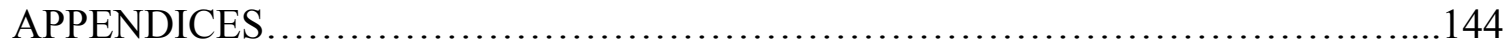

Appendix A - Public History Component..................................... 144

Appendix B - Images of the Cathlapotle Plankhouse ....................... 182 


\section{INTRODUCTION}

In the last two decades, public historians and museum professionals have increasingly modified the way in which they approach the representation of Native Americans. Responding to both legal mandates and growing institutional pressures to consult the indigenous groups they represent, museums and authoritative institutions are gradually integrating tribal representatives into steering groups, committees and other decision-making bodies that have a say in collections management policy and exhibition content. While this shift in the museological paradigm has produced well-rounded, culturally comprehensive products that confront historic misrepresentations of Native Americans and provide an active voice to modern tribal entities, cross-cultural collaboration remains a relatively new concept that is still being incorporated into museum policy and procedure. ${ }^{1}$ Additionally, public historians and museum professionals with little experience are compelled to move forward in the collaborative process with little guidance or precedent. As such, the path leading to the "indigenization" of museums has been and will continue to be marked with achievements and challenges that both teach and test historical professionals in unprecedented ways. ${ }^{2}$ As argued by Ruth B. Phillips, "we are now a mere two decades down the road in a

\footnotetext{
${ }^{1}$ When I use the term "cross-cultural" in this paper, I imply interactivity between two or more cultural groups requiring communication and exchange beyond the boundaries of each group's culture.

${ }^{2}$ Patricia Pierce Erikson, with Thelma Ward and Kirk Wachendorf, Voices of a Thousand People, (Lincoln, NE: University of Nebraska Press, 2002), as quoted in Karen Coody Cooper, Spirited Encounters: American Indians Protest Museum Policies and Practices, (Lanham, MD: AltaMira Press, 2008), xvi.
} 
process that is still unfolding and will continue to unfold for years come." ${ }^{3}$ The following is a case study that examines the ways in which this unfolding shift in Native American representation manifests itself in a Pacific Northwest heritage site.

Nestled on the shores of Duck Lake in Washington's Ridgefield National Wildlife Refuge, a reconstructed Chinookan plankhouse reminds Refuge visitors of a history equally concealed by thick overgrowth and the colonial pioneer narrative. Better known as a stopover for the Lewis and Clark Expedition in 1806, the site of the Cathlapotle village now hosts a twenty foot tall, thirty-seven foot wide, and seventy-eight foot long plankhouse that represents the innovation, wealth and grandeur of Chinookan culture prior to European contact. Responsible for this towering structure, its rich materiality, and its cultural detailing is a unique partnership between the U.S. Fish and Wildlife Service and the Chinook Indian Nation. Following years of archaeological research that revealed extraordinary details about daily life at the village, these partners capitalized on funding opportunities made available for the commemoration of the Lewis and Clark Bicentennial in 2005 and 2006 to reconstruct an example of the accommodation that was central to Chinookan economic, political and social life on the Columbia River. With the common objective of educating visitors about the significant cultural and natural history of the area, partners designed, constructed and interpreted a full-scale plankhouse on the federally owned Ridgefield National Wildlife Refuge from 2002 to 2005.

Despite sharing the common goal of building a full-scale Chinookan plankhouse, the principal partners of the Cathlapotle Plankhouse Reconstruction Project had different

\footnotetext{
${ }^{3}$ Ruth B. Phillips, review of "Looking Several Ways: Anthropology and Native Heritage in Alaska," by James Clifford, Current Anthropology, 45, no. 1 (February 2004): 25.
} 
goals guiding them in the decision-making process. The U.S. Fish and Wildlife Service, for example, envisioned the Plankhouse to be a "living" interpretive center that would allow visitors to interact with physical representations of the past in a unique and educational manner. The Chinook Indian Nation, on the other hand, envisioned the Plankhouse to be a cultural center that would confront colonial misrepresentations of Native Americans and provide the Tribe a place for private ceremony and cultural renewal. With varying agendas underlying a similar objective, both stakeholders were required to make compromises that challenged each other's expectations of the project. In this thesis, I will detail and analyze how these partners collaboratively navigated the design, construction and interpretation of the Cathlapotle Plankhouse to create a meaningful and significant place for a diverse cross-section of stakeholders. From this analysis, I hope to provide public historians and museum professionals an example of a cross-cultural partnership that will assist them as they move forward through a continuously unfolding and largely uncharted system of collaboration.

\section{Historical Representations of Native Americans}

To adequately understand the reasons for and the significance of the Cathlapotle Plankhouse's development in the early $21^{\text {st }}$ century, it is important to place the structure's evolution within the larger context of historic representations of Native Americans. From the arrival of white settlers to the American West to the civil rights movement of the 1960s, anthropological, ethnographic, historical and artistic authorities have instructed Americans to view the nation's westward expansion as a heroic pioneer saga based on the values of progress and civilization. According to historian Fergus Bordewich, Native 
Americans reside at the center of a pioneer myth as both "noble and barbaric, man of nature and bloodthirsty savage, and destined for tragic extinction." ${ }^{44}$ The origin of this multifaceted perception of Native Americans can be traced back to the early European representations of the "New World" in the $16^{\text {th }}$ century. Illustrations, paintings and written accounts depicted indigenous Native Americans to be handsome, brown, and athletic "creatures of nature" with no formal political or social structure. ${ }^{5}$ As representations of this manner continued throughout the $17^{\text {th }}$ and $18^{\text {th }}$ centuries, Native American artifacts became objects of curiosity, created by a group of people perceived to represent earlier stages of human development. ${ }^{6}$ World fairs perpetuated this notion of pre-civilized Native groups in the $19^{\text {th }}$ century, as Europeans and Euro-Americans contrasted the technological achievements of Western civilization against the primitive, nature-based lifestyle of indigenous groups. ${ }^{7}$ The presentation of Native Americans as "noble savages" was an important part in the formation of American identity, as settlers wanted to gain a Native-like natural affinity with the continent while also controlling the landscape in a manner that required the elimination of its original inhabitants. ${ }^{8}$

Even as time moved forward and national political agendas shifted, indigenous culture was "frozen in time" by history textbooks, museums, and academic authorities

\footnotetext{
${ }^{4}$ Fergus M. Bordewich, Killing the White Man's Indian: Reinventing Native Americans at the End of the Twentieth Century, (New York, NY: Doubleday, 1996), 18.

${ }^{5}$ Evan Maurer, "Presenting the American Indian: From Europe to America," in The Changing Presentation of the American Indian: Museums and Native Cultures, National Museum of the American Indian, (Washington, D.C.: National Museum of the American Indian, 2000): 16.

${ }^{6}$ Ibid.

${ }^{7}$ Kathleen Fine-Dare, Grave Injustice: The American Indian Repatriation Movement and NAGPRA (Lincoln, Nebraska: University of Nebraska Press, 2002).

${ }^{8}$ Philip J. Deloria, Playing Indian, (New Haven, CT: Yale University Press, 1998), 5.
} 
that failed to represent Native America's existence in and bearing on modern life. ${ }^{9}$ Museum professional and Cherokee tribal member Karen Coody Cooper contends the general public was fed a "steady diet of cultural pabulum" throughout the $20^{\text {th }}$ century regarding Native American history and culture that harmed Native communities and shortchanged the American public with "scanty information and ensuring conjectures.", While many Native groups voiced interest in determining how their culture was represented to wider audiences in the first half of the $20^{\text {th }}$ century, their requests found few listeners and even fewer individuals willing to engage in active and constructive responses. ${ }^{11}$ Instead, institutions charged with defining public knowledge asserted authoritative expertise and unilateral control in the representation of culture that was not their own, rendering it ahistorical and devoid of any subjectivity and dynamism. ${ }^{12}$ Native American objects stored within these institutions were viewed to have little significance beyond their aesthetic value, and interpretation presented these artifacts as the few rare remnants of an extinct culture. ${ }^{13}$

Beginning in the 1960s and extending well into the 1980s, "an upheaval of epic proportions" in America's social and political consciousness provided Native Americans an unprecedented opportunity to challenge the traditional power structure of museums

\footnotetext{
${ }^{9}$ Maurer, "From Europe to America," 25; James Nason, "'Our' Indians: The Unidimensional Indian in the Disembodied Local Past," in The Changing Presentation of the American Indian: Museums and Native Cultures, National Museum of the American Indian, (Washington, D.C.: National Museum of the American Indian, 2000): 37. ${ }^{10}$ Cooper, Spirited Encounters, xiv, xvi.

${ }^{11}$ Ibid., 2.

12 Brenda Trofanenko, "Displayed Objects, Indigenous Identities, and Public Pedagogy," Anthropology Education Quarterly 37, no. 4 (2006): 309, 324.

${ }^{13}$ Evan M. Maurer discusses the rise in the representation of Native artifacts as art in "From Europe to America" (24-25). Karen Coody Cooper discusses the implications of this artistic representation in Spiritual Encounters (49-59).
} 
and other authoritative institutions. ${ }^{14}$ As one of the many ethnic groups that heightened its political efforts during the Civil Rights Movement, Native American activists used demonstrations and increased media coverage to publicize everyday issues affecting modern-day tribes including inadequate health care, housing, and education. ${ }^{15}$ Public protests also confronted museums and historic sites for the "usurpation of the right [for Native Americans] to define themselves to the world at large." ${ }^{\prime 16}$ From specific exhibitions to universal museum policies, Native demonstrations addressed the longstanding frustrations of indigenous Americans regarding the insensitive misrepresentation of their culture, the inappropriate collection and display of sacred objects and human remains, and the lack of consultation with tribal bodies in the interpretive process. ${ }^{17}$ As argued by anthropologist Kathleen Fine-Dare, this activism laid the groundwork for intense legal and political activity in the 1980 s that dramatically altered the way in which public institutions and academics approached the historical interpretation of Native Americans. ${ }^{18}$

Supplementing the heightened political activity of Native Americans, a new museology movement emerged in the 1970s that challenged the conventional notions of museum policy and practices. ${ }^{19}$ Historically justified by scientific and nationalistic discourse, the systematic collection of human remains and artifacts by museums

\footnotetext{
${ }^{14}$ Bordewich, Killing the White Man's Indian, 11.

${ }^{15}$ Fine-Dare, Grave Injustice.

${ }^{16}$ Cooper, Spirited Encounters, x.

${ }^{17}$ For further reading on specific Native American protests of museum exhibition and collection policy, refer to Karen Coody Cooper, Spirited Encounters (2007).

${ }^{18}$ Fine-Dare, Grave Injustice, 84.

${ }^{19}$ Christina Kreps, Liberating Culture: Cross-Cultural Perspectives on Museums, Curation, and Heritage Preservation (New York, NY: Routledge, 2003 ), 9.
} 
remained unquestioned by mainstream society during the first half of the $20^{\text {th }}$ century. ${ }^{20}$ The increased discussion of human and civil rights that accompanied the Civil Rights Movement, however, initiated conversations among museum professionals regarding the role of museums in representing indigenous culture and preserving their cultural material. ${ }^{21}$ The introduction of ethnohistory in the 1950 s also inspired critical conversations amongst museologists, as the union of history and ethnology produced scholarship that possessed the diachronic dimensions of history and the synchronic sensitivity of ethnology. ${ }^{22}$ While the exact origin of this shift in thought is difficult to identify, museologists significantly modified their attitude towards cross-cultural collaboration as a result. ${ }^{23}$ Referred to as the "decolonization" of museums by Patricia Pierce Erikson, museum professionals increasingly framed repatriation as a human rights issue in the 1980s, with human remains having the status of a living person. ${ }^{24}$ These same professionals also began to consider and embrace a variety of forms and meaning in

\footnotetext{
${ }^{20}$ Miranda Brady, "A Dialogic Response to the Problematized Past" in Contesting Knowledge: Museums and Indigenous Perspectives, ed: Susan Sleeper-Smith, Contesting knowledge museums and indigenous perspectives (Lincoln: University of Nebraska Press, 2009).

${ }^{21}$ T. J. Sullivan, M. Abraham, and D.J.G. Griffin, "NAGPRA: Effective Repatriation Programs and Cultural Change in Museums," CURATOR 43, No. 3 (July 2000): 232.

${ }^{22}$ James Axtell, "Ethnohistory: A Historian's Viewpoint," in James Axtell's The European and the Indian: Essays in the Ethnohistory of Colonial North America, (Oxford, 1981): 5, as cited in Anna Green and Kathleen Troup, The Houses of History: A Critical Reader in the Twentieth-Century History and Theory, (Washington Square, NY: New York University Press, 1999), 175.

${ }^{23}$ Kreps, Liberating Culture, 9.

${ }^{24}$ Patricia Pierce Erikson, 'Decolonizing the 'Nation's Attic': The National Museum of the American Indian and the Politics of Knowledge-Making in a National Space," in The National Museum of the American Indian: Critical Conversations, ed: Amy Lonetree and Amanda Cobb, (Lincoln, NE: University of Nebraska Press, 2008): 47, 66.
} 
the presentation of living indigenous culture and heritage. ${ }^{25}$ Combined with the political action of Native Americans in the 1960s and 1970s, this new way of thinking initiated a shift in the museum paradigm that altered the way in which public institutions approached and continue to approach the cross-cultural interpretation of indigenous cultures.

In the late 1980s and early 1990s, the United States government passed two significant pieces of legislation that reflected the changing attitudes of the museum profession towards Native American representation. The National Museum of the American Indian Act of 1989 (NMAIA) established the National Museum of the American Indian (NMAI) under the authority of the Smithsonian. As part of this Act, the collection at New York's Museum of the American Indian was inventoried and transferred to the Smithsonian in Washington D.C. Human remains and funerary objects identified in this inventory were then made available for repatriation to the lineal descendents and members of tribes that could prove cultural affiliation to specific artifacts. ${ }^{26}$ The NMAI expanded this repatriation policy in 1991 to include common objects, duplicate objects, illegally acquired objects and communally owned objects. ${ }^{27}$ More significant, however, was the passage of the Native American Graves Protection and Repatriation Act (NAGPRA). This legislation, passed in 1990, extended the repatriation mandate of the National Museum of the American Indian Act to all museums that received federal funding and established a legal framework for consultation on

\footnotetext{
${ }^{25}$ Kreps, Liberating Culture, 9.

${ }^{26}$ Bordewich, Killing the White Man's Indian, 170.

${ }^{27}$ Ibid, 171.
} 
repatriation claims. ${ }^{28}$ Additionally, NAGPRA protected burial sites and assigned all objects found in excavations to be the automatic property of tribal groups affiliated with the site. ${ }^{29}$ Such legislation required museums to significantly adjust their existing policies and procedures regarding the collection, storage, preservation, and display of Native American material culture. It also encouraged consensual decision-making and cross-cultural collaboration as a means of equalizing the balance of power between tribes, museums and the scientific community in the representation of Native American culture. $^{3031}$

Since the passage of legislation like the NMAIA and NAGPRA, an obvious shift in the way in which museum professionals approach the interpretation of Native American history and culture can be identified. Anthropologist Michael Ames argues collaboration has become the accepted standard in the presentation of indigenous cultures to mainstream society by public institutions. New interpretation strategies increasingly demonstrate a growing sense of respect for Native American communities and their cultural and historical knowledge, as more and more museums, historic sites, and public institutions incorporate Native voice into exhibition design, development and artifact

\footnotetext{
${ }^{28}$ Ibid., 170-171.

${ }^{29}$ Bordewich, Killing the White Man's Indian, 171; Kreps, Liberating Culture, 3.

${ }^{30}$ Nason, "'Our Indians'," 41.

${ }^{31}$ While certainly an impressive step forward in the integration of indigenous cultures into conservation and interpretive activity, M. Sullivan, M. Abraham, and D.J.G. Griffin argue in "Cultural Change in Museums" (231) that NAGPRA only inspired communication and consultation, commitment of resources, and the sharing of authority with indigenous people in the areas where legal mandate requires it to happen (collections of human remains and secret/scared material). In Grave Injustice (143-171), Kathleen Fine-Dare discusses "eleven elemental problems" of NAGPRA, including debilitating demands on Native tribes to prove cultural affiliation with objects.
} 
preservation. ${ }^{32}$ Tribal representatives are commonly members of museum steering committees, advisory boards, and conservation teams, and a majority of public products on indigenous peoples now illustrate cultural vitality and continuity. ${ }^{33}$ This paradigmatic shift in museum representation is best articulated by art historian and anthropologist Janet Berlo and Aldona Jonaitis, who comment that "it is virtually unthinkable for a museum to create an exhibit about Native people without including Native peoples themselves in the planning and curatorial process. ${ }^{, 34}$ It is important to note that this shift in indigenous representation was not confined to the United States of America. Museums and authoritative institutions around the globe encouraged the integration of indigenous representatives into interpretive processes using diverse mechanisms. ${ }^{35}$ Canada, for example, issued a constructive set of voluntary and mutually agreed upon principles for indigenous representation instead of pursuing legal mandates as a means of equalizing the relationship between museums and First Nation Peoples. ${ }^{36}$

While the "indigenization" of museums has given Native Americans the right to be custodians of their own culture for the first time in over a century, anthropologists,

${ }^{32}$ Michael Ames, "Are Changing Representations of First Peoples in Canadian Museums and Galleries Challenging the Curatorial Prerogative?," in The Changing Presentation of the American Indian: Museums and Native Cultures, National Museum of the American Indian, (Washington, D.C.: National Museum of the American Indian, 2000): 73.

${ }^{33}$ Joy Hendry, Reclaiming Culture: Indigenous People and Self-Representation, First Edition. (New York, NY: Palgrave MacMillian, 2005), 32.

${ }^{34}$ Aldona Jonaitis and Janet Catherine Berlo, "'Indian Country' on the National Mall: The Mainstream Press versus the National Museum of the American Indian," in The National Museum of the American Indian: Critical Conversations, ed. Amy Lonetree and Amanda J. Cobb, (Lincoln, NE: University of Nebraska Press, 2008), 210.

${ }^{35}$ For a closer examination of the way in which world museums, culture centers, and other representational institutions are changing the way in which they approach indigenous representation, refer to Joy Hendry, Reclaiming Culture (2005) and Christina Krep, Liberating Culture (2003).

${ }^{36}$ Ames, "Curatorial Prerogative?," 85. 
museum professionals and public historians have also struggled to adjust to the new expectations associated with Native American representation. ${ }^{37}$ Museum curator David W. Penney explains that "most museum professionals acknowledge the importance of the 'Native voice,' though they are often not sure how to respond to what that 'voice' may say." ${ }^{38}$ Different methods of story telling, meaning making and cultural representation, for example, have tested museums' traditional forms of cultural representation and visitor education in a manner that has steered museum professionals away from the policies and procedures known and familiar to them. While this challenge to museums' colonialbased representation model has produced significant opportunities for rich and inclusive interpretation, it has also left anthropologists, public historians and museum professionals to navigate the tenuous waters of cross-cultural collaboration and representation with little guidance or precedent. Beyond additional time, money and resources that are often not pragmatic realities for museums and public institutions, interpretative professionals are also grappling with cultural misunderstandings and differing agendas that often accompany cross-cultural collaborative efforts in the post-NAGPRA era. ${ }^{39}$ As more

${ }^{37}$ Erikson, Voices of a Thousand People, as quoted in Cooper, Spirited Encounters, xvi; Kreps, Liberating Culture, 3.

${ }^{38}$ David W. Penney, "The Poetics of Museum Representation: Tropes of Recent American Indian Art Exhibitions," in The Changing Presentation of the American Indian: Museums and Native Cultures, National Museum of the American Indian, (Washington, D.C.: National Museum of the American Indian, 2000): 47.

${ }_{38}^{38}$ Berlo and Jonaitis, "'Indian Country' on the National Mall," 210.

${ }^{39}$ Although beyond the scope of this examination, it is important to note that many Native Americans tribes with sufficient resources choose to develop their own cultural centers and conduct their own cultural resource management activities. Further information on this subject can be found in Joy Hendry's Reclaiming Culture (81 - 104), Karen Coody Cooper's Spirited Encounters (137-170) and Janice Clements "The Integration of Traditional Indian Beliefs into the Museum at Warm Springs" (67-71) in The Changing Presentation of the American Indian. 
successful and unsuccessful examples of cross-cultural collaboration emerge, museum professionals are identifying appropriate methods and strategies for partnerships with Native groups. In "an ongoing process of reevaluation and redirection," however, these curatorial professionals are still learning and adjusting to a new but important method of interpretation. ${ }^{40}$ The unsteady navigation of these collaborative challenges will become evident in my examination of the partnership that produced the Cathlapotle Plankhouse from 2002 to 2005 .

\section{Authenticity and the Representation of Native Americans}

As part of the paradigmatic shift that occurred in Native American representation in the late 1980s and early 1990s, debates over issues of authority and voice challenged the existing power structures within the museum environment. Paralleling these issues was also the issue of authenticity, as Native peoples' quest to define themselves for the world at large included the power to define themselves as "authentic Indians". ${ }^{41}$

Beginning in the late $19^{\text {th }}$ century, salvage anthropologists attempting to document Native life prior to white contact defined the attributes of traditional Native life in publications and museum displays based on fieldwork. ${ }^{42}$ With anthropology's aura of legitimacy and the "long-term invisibility" of Native Americans as modern beings in museums, this colonial definition of Indians as uncivilized, barbaric and extinct has remained intact

\footnotetext{
${ }^{40}$ Maurer, "From Europe to America," 15.

${ }^{41}$ Laura Peers, Playing Ourselves: Interpreting Native Histories at Historic Reconstructions (Altamira Press, 2007), xviii.

${ }^{42}$ Paige Raibmon, Authentic Indians: Episodes of Encounter from the Late-NineteenthCentury Northwest Coast (Duke University Press Books, 2005), 5.
} 
despite the significant changes that have occurred in Native culture. ${ }^{43}$ Whether this definition was romanticized in imperialist nostalgia or used in the context of policy, religion, amusement and science, historian Paige Raibmon contends colonizers developed a definition of Native authenticity that rendered tribes irrelevant in modern society. ${ }^{44}$ If Native Americans reflected the $19^{\text {th }}$ century image of a traditional Indian, they were uncivilized and not suited for the future. If they adapted to the contemporary environment, they had assimilated into mainstream society and their culture was effectively extinct. ${ }^{45}$ This binary framework is best reflected in the common expectations of tourists who seek purist representations of Native Americans and question indications of adaptation and evolution. ${ }^{46}$

In the last quarter of the $20^{\text {th }}$ century, Native Americans and museum professionals questioned the colonial-based notions of Native authenticity that had limited their growth and commodified their culture since the late $19^{\text {th }}$ century. By demanding the right to act as authorities in the representation of their cultures, Native Americans also demanded a say in what stories were told, what objects were used, how they were used, and what was excluded from display. In other words, Native peoples commanded the power to deem what was culturally authentic to mainstream society. This desire for control in defining authenticity is best expressed by Native American R. A. Warrior, who asserts Native peoples "must firmly insist that [their] own experience is no less authentic than that of [their] ancestors, even if [their] existence has changed

\footnotetext{
${ }^{43}$ Ibid.; Cooper, Spirited Encounters, xiii-xiv.

${ }^{44}$ Raibmon, Authentic Indians, 6-7.

${ }^{45}$ Ibid., 9.

${ }^{46}$ Hendry, Reclaiming Culture, 58-59.
} 
considerably from theirs. ${ }^{, 47}$ While Native Americans are currently participating in the process of redefining what an "authentic Indian" is through collaboration and selfproduced public products, they are also competing against a century of misrepresentation that supports the colonial myths underpinning majority society. As argued by Philip J. Deloria, stereotypes about Native Americans have been important tools in understanding the relationship between representations and the concrete exercise of power. ${ }^{48}$ Revising the stereotypes of Native Americans means revising the way in which mainstream American society makes sense of their history and their identity. ${ }^{49}$ This has been a challenge in the two decades subsequent to the paradigmatic shift in Native representation. This worthwhile struggle becomes evident in the examination of the design, construction and interpretation of the Cathlapotle Plankhouse, as issues surrounding authenticity and authority threatened the partnership that made the Plankhouse so unique.

\section{Literature Review}

In my review and analysis of the Cathlapotle Plankhouse's design, construction, and interpretation, I draw upon a breadth of scholarship focused on the cultural and historical (mis)representation of Native Americans. Because the Plankhouse does not function strictly as an educational center, a museum, a historic reconstruction, or an indigenous cultural center, locating secondary literature that directly addresses

${ }^{47}$ R.A. Warrior, “A Marginal Voice”, Native Peoples, Vol. 1, No. 3 (1991), 30.

${ }^{48}$ Philip J. Deloria, Indians in Unexpected Places, (Lawrence, KS: University Press of Kansas, 2004), 8.

${ }^{49}$ Peers, Playing Ourselves, xv. 
complexities similar to that found at the Plankhouse proved to be a significant challenge in my research. Instead of sourcing one or two focused bodies of knowledge, I have sourced a wide range of scholarship rooted in the disciplines of anthropology, museology, public history, architecture, ethnohistory, pedagogy, and aboriginal studies. From each of these disciplines, I extracted discussions centered on aboriginal identity, Native American representation, museum collection and preservation policies, Native American architecture, Pacific Northwest history and indigenous collaboration to establish a foundation from which to analyze the design, construction and interpretation of the Cathlapotle Plankhouse.

While guided by a wide range of scholarly literature, ethnohistorian Laura Peers' study on the process and implications of inserting indigenous history into reconstructed historic sites provides the central framework for my examination of the Cathlapotle Plankhouse. In Playing Ourselves: Interpreting Native Histories at Historic Reconstructions, Laura Peers explores the issues of power, authority and voice embedded in the various forms of cultural representation present in historical reconstructions. ${ }^{50}$ Through the examination of five historic sites and their integration of Native history and historical re-enactors into their interpretive programs, Peers identifies historic reconstructions to be forums for cross-cultural relations that challenge representations and power structures steeped in colonial ideology. Expanding upon Mary Louise Pratt's

${ }^{50}$ In Playing Ourselves (xiv), Laura Peers defines historic sites to be those that evoke and teach about the past by using period buildings, furnishings and staff dressed in replica period clothing to interpret aspects of life in the past to visitors. 
notion of "contact zones," where different cultures meet, clash and grapple with each other. ${ }^{52}$ Often places of confrontation and contestation, Peers argues contact zones can also be places of stimulation where people from different backgrounds can understand and learn from each other. $^{53}$ The insertion of Native staff and themes into reconstructed historic sites, for example, creates contact zones that empower Native peoples in significant and unprecedented ways:

For Native interpreters, the arena created by these sites offers a space within which to articulate identity and cultural difference: to assert, in the face of centuries of scholarly and popular historical narratives, their ancestors' worth and dignity; to contest stereotypes and misinformation and to insist on the right to tell their own stories, in their own voices. ${ }^{54}$

My assertion that Cathlapotle Plankhouse is an arena where the myths and power structures that underpin majority society are challenged and Native identity is strengthened stems from this analytical framework. While the Cathlapotle Plankhouse does not strictly adhere to the characteristics of a reconstructed historic site, the building similarly acts as a contact zone where many visitors encounter Chinookan historians and Pacific Northwest history from the Native American perspective for the first time.

Equally significant to my examination of the Cathlapotle Plankhouse Construction Project is the work of Jon D. Daehnke. As an archaeology student in the

\footnotetext{
${ }^{51}$ In Imperial Eyes, Mary Louise Pratt uses the term "contact zone" to "invoke the spatial and temporary copresence of subjects previously separated by geographic and historical disjunctures, and whose trajectories now intersect." For Pratt, "contact zones" are synonymous with the "colonial frontier," as they emphasize how subjects are constituted in and by their relations to each other.

${ }^{52}$ Mary Louise Pratt, Imperial Eyes: Travel Writing and Transculturation, (London: Routledge, 1992), 6 - 7, as quoted in Peers, Playing Ourselves, xx.

${ }^{53}$ Peers, Playing Ourselves, xx.

54 Ibid.
} 
Masters program at Portland State University, Daehnke participated in the Cathlapotle Archaeology Project and wrote his Masters thesis on the values and challenges to public outreach within archaeology. In Public Outreach and the "Hows" of Archaeology: Archaeology as a Model for Education, Daehnke argues that public outreach is an important aspect to archaeology that must go beyond the provision of findings to present the methodology and process of archaeology. ${ }^{55}$ As part of his thesis, Daehnke produced an informational booklet, Cathlapotle...Catching Time's Secrets, as an example of the public outreach he endorses. Running forty-eight pages long, this booklet provides an indepth history of the Cathlapotle site. Within his explanation of Chinookan social, political and economic life, Daehnke integrates discussions, photographs and drawings related to archaeological methods and processes to convey how archaeologists know and understand so much about daily life at Cathlapotle. This booklet played an important role in my research, as it familiarized me with the site and its history.

Daehnke also published an article on the Cathlapotle Plankhouse in the Journal of Social Archaeology titled “A ‘Strange Multiplicity’ of Voices: Heritage Stewardship, Contested Sites and Colonial Legacies on the Columbia River." Focusing on the complexities of cultural resource stewardship that are the product of continuing manifestations of colonialism, Daehnke examines the issues that arose at the Cathlapotle Plankhouse when both the unrecognized Chinook Indian Nation and the recognized

${ }^{55}$ Jon D. Daehnke, "Public Outreach and the "Hows" of Archaeology: Archaeology as a Model for Education," (M.A. thesis, Portland State University, 2002), abstract. 
Cowlitz Indian Tribe staked a cultural claim in the site. ${ }^{56}$ Federal mandates embedded in colonial legacies forced the U.S. Fish and Wildlife Service to negotiate a complicated three-party relationship that designated a long-time partner of the Service legally inferior to a short-term stakeholder in the site. Such a situation, Daehnke argues, was a product of continuing colonial entanglements that make stewardship collaborations impossible to conduct on equal ground. ${ }^{57}$ While my work also discusses the role that colonialism continues to play at the Cathlapotle Plankhouse, I choose to focus on the way in which the legacy of colonialism affects, guides and complicates the partnership between the U.S. Fish and Wildlife Service and the Chinook Indian Nation and the representation of Native Americans at the Ridgefield National Wildlife Refuge. ${ }^{58}$

The work of Native historian and museologist Karen Coody Cooper also significantly informs my examination of the ways in which the shift in the paradigm of Native American representation manifest itself in the Cathlapotle Plankhouse Reconstruction Project. In Spirited Encounters: American Indians Protest Museum Policies and Practices, Cooper examines different instances of Native American protest against museums in the 1970s, 1980, and early 1990s. While each of these protests reflected different concerns amongst a diverse range of Native American tribes, Cooper argues they collectively articulated the mounting frustration of Native groups concerning

${ }^{56}$ Jon D. Daehnke, "A 'Strange Multiplicity' of Voices: Heritage Stewardship, Contested Sites and Colonial Legacies on the Columbia River," Journal of Social Archaeology 7 (2007), 250.

${ }^{57}$ Daehnke, "A 'Strange Multiplicity' of Voices," 271.

${ }^{58}$ Jon Daehnke has written another article on the Cathlapotle Plankhouse, set to be released in the Spring 2012 edition of Wicazo Sa. In this article, Daehnke separately comes to many of the same conclusions I have about the various uses the Plankhouse and the complications that arise from those uses. 
their lack of control in the representation of their own culture. Through the in-depth examination of these protests, Cooper provides great insight into the origins and the development of external pressures that led museums to change the way in which they stored and displayed Native American artifacts and interpreted Native history. This scholarship proved crucial to my assessment of the Cathlapotle Plankhouse, as it allowed me to compare the concerns of the Chinook Indian Nation in the early $21^{\text {st }}$ century to Native American concerns prior to the late 1980s. Were they the same or were they different? Had the process of Native American representation shifted, and if so, how was that reflected in the Cathlapotle Plankhouse Construction Project?

The Smithsonian Institution's anthology The Changing Presentation of the American Indian: Museums and Native Culture was also pivotal in developing my understanding of the paradigm shift experienced by museums in the late 1980s and the early 1990s. While a number of the essays in the anthology provide a historical context for the changes experienced by museums during this time period, several also examine the ways in which museums responded to the demands for change in the decade that followed the paradigm shift. Anthropologist Michael Ames, for example, appraises both the intent and the delivery of integrating the principles of Canada's Task Force Report on Museums and First Peoples into interpretive processes. Arguing that existing structural factors inhibit the goodwill and intent for museums to change, Ames identifies obstacles that public historians and museum professionals need to overcome if they want to collaborate with indigenous North Americans in a meaningful way. ${ }^{59}$ Some of these obstacles include the increased budgets and longer timelines required for collaborative

${ }^{59}$ Ames, "Curatorial Prerogative?" 85-86. 
projects. James Nason's article within this anthology also identifies obstacles to crosscultural collaboration, in addition to offering suggestions for overcoming the centuries of tradition engrained in museum policy and structure. Finally, art curator David W. Penny identifies similar obstacles to cross-cultural collaboration and reminds museum professionals that they need patience in this changing process, as are were challenging "habitual ways of thinking that are not easily changed." challenges and the provision of suggestions for the future provided by The Changing Presentation of the American Indian prove to be pivotal in my examination of the challenges faced by the Cathlapotle Plankhouse, as they provide a foundation for comparison and reflection that placed in the Plankhouse within the larger context of national change in Native American representation.

Finally, the work of architectural historian Carol Herselle Krinsky significantly informed my discussion of the Cathlapotle Plankhouse's significance to the tribal identity of the Chinook Indian Nation. In her book Contemporary Native American Architecture: Cultural Regeneration and Creativity, Krinsky closely connects the surge in modern Indian architecture in the last quarter century to the widespread movement amongst Native Americans to renew and enhance their culture. ${ }^{61}$ Through the examination of various structures built throughout the United States in the last few decades, Krinsky conveys "AmeriIndian" architecture to be a key source of cultural healing and regeneration. ${ }^{62}$ Beyond the provision of shelter that accommodates group meetings,

${ }^{60}$ Nason, "'Our' Indians," 41-45; Penney, "The Poetics of Museum Representation,” 61. ${ }^{61}$ Carol H. Krinsky, Contemporary Native American Architecture: Cultural Regeneration and Creativity, (New York, NY: Oxford University Press, 1996). 33. ${ }^{62}$ Ibid., 33. 
Krinsky argues a well-designed Native American building "abstracts elements of the damaged culture, refreshing it and preparing it for use in a more optimistic future. ${ }^{\prime 63}$ This discussion of the significance of modern Native American architecture served as a foundation for my argument that the Cathlapotle Plankhouse is a cultural anchor for the Chinook Indian Nation that affirms, develops, and celebrates their modern identity. While the Plankhouse looked back to the past for traditional construction methods and authenticity in design, its results are very similar to that of the modern Native American buildings described by Krinsky.

\section{Methodology}

A majority of the primary material used to inform my study of the design, construction and interpretation process of the Cathlapotle Plankhouse derives from inactive file drawers within various offices of the U.S. Fish and Wildlife Service. While performing an internship at the Plankhouse, I gained access to files housed in the Ridgefield National Wildlife Refuge office in Ridgefield, Washington. These files contain materials that are mostly applicable to the post-construction operations of the Plankhouse. A subsequent Freedom of Information Act request to the U.S. Fish and Wildlife Service led me to the personal files of Region 1 archaeologist Anan Raymond in Sherwood, Oregon. These documents consist of professional correspondence, meeting minutes, official documents and their drafts, and personal notes related to the Cathlapotle site from 1993 to 2007 . While thorough in the documentation of many decisions made during the design, construction and interpretation of the Cathlapotle Plankhouse, these

${ }^{63}$ Ibid. 
files were not a comprehensive account of the entire process. A significant hole existed regarding the decisions and compromises made by the Project Management Team in 2004, when tensions were at their highest and the Chinook Indian Nation was threatening to pull out of the Project. To gain further insight into the important decisions and compromises made during this time, I examined Project Management Team member Greg Hranac's personal files from the U.S. Fish and Wildlife Service Regional Office in Portland, Oregon. These documents include meeting minutes and professional correspondence from various stakeholders that directly pertain to the Plankhouse's structural safety and code issues. While these three archives do not document every element of the design, construction and interpretation of the Cathlapotle Plankhouse, I feel they provide a sturdy foundation upon which to understand and analyze the process and the partnership. Further investigation might reveal documents in other inactive file drawers within the U.S. Fish and Wildlife Service, including those of Virginia Parks, Tom Melanson, and Thomas Smiley.

To gain a better understanding of the motivations behind the decisions and compromises reflected in the documents stored in U.S. Fish and Wildlife Service offices, I conducted informational interviews with Anan Raymond and members of the Chinook Indian Nation Culture Committee. While the main intention of these interviews was to fill in informational gaps not addressed in archival documents, the retrospective reflections of the interviewees regarding the Project and the collaborative process that guided it are extremely beneficial to my analysis of the significance of the Plankhouse and cross-cultural collaboration. It is important to note that the statements provided by individuals in these interviews are expressions of personal feelings and recollections and 
do not necessarily reflect the opinion of the organization that they represent. It is also important to note that former Culture Committee Chairman, Gary Johnson, provided me a stack of personal files he kept on the Plankhouse following my interview with the Culture Committee. These documents included publicity articles, official documents, and pieces of internal tribal correspondence that provide insight into the motivations, reactions and responses of the Chinook Indian Nation throughout the design, construction, and interpretation process. ${ }^{64}$

Finally, I use personal reflections from my time as an intern and visits to the Cathlapotle Plankhouse as a member of the general public to inform my discussion of the interpretive effectiveness and implications of the Plankhouse. From September to December of 2009, I assisted Plankhouse Coordinator Katie Harrison with the development of a collections management policy for Cathlapotle. The intention of this policy was to lay the foundations for understanding, maintaining and expanding the collection in a direction that would further the Plankhouse's goal of interpreting the rich natural and cultural heritage preserved on the Ridgefield National Wildlife Refuge. Through the research of preservation techniques, the development of a draft collections management policy, and the generation of accessioning worksheets and legal documents associated with the donation and/or loan of artifacts, I gained familiarity with the interpretive processes being applied to the Plankhouse interior and the Chinook Indian Nation's role within that process. Outside of my internship, I visited the Plankhouse on a number of different occasions for cultural events, personal recreation, and a classroom

\footnotetext{
${ }^{64}$ I submitted a full thesis draft for comment to the Chinook Indian Nation Culture Committee.
} 
site visit. During these visits, I participated in a guided hike to the original archaeology site, toured the Plankhouse with a docent, self-toured the Plankhouse with friends, and attended a cultural event during the annual Birdfest and Bluegrass celebrations at the Refuge. I draw upon my reflections and the reflections of others during these visits in my analysis of the interpretive effectiveness of the Plankhouse and the implications that accompany its various uses by different stakeholders.

\section{Issues of Federal Recognition}

In the following examination of the design, construction and interpretation of the Cathlapotle Plankhouse, my primary objective is to explore how the U.S. Fish and Wildlife Service, a large government agency, and the Chinook Indian Nation, a small and federally unrecognized tribal body, navigate the new and constantly evolving paradigm of Native American representation and cross-cultural collaboration. Within this paradigm, the legal recognition of tribes is increasingly important, as tribes recognized by the federal government receive elevated legal status, institutional authority and financial resources that greatly advance their ability to participate in cultural resource management activities. ${ }^{65}$ When the idea of the Cathlapotle Plankhouse Reconstruction Project was first presented to the Chinook Indian Nation in 2002, the Tribe had recently been granted federal recognition by US Assistant Secretary of the Interior, Kevin Gover, during the last days of the Clinton administration. Recognition meant the Chinook Indian Nation would have access to unprecedented manpower and financial resources for participation in the Cathlapotle Plankhouse Reconstruction Project and other cultural resource

${ }^{65}$ Daehnke, “A 'Strange Multiplicity' of Voices", 263-264. 
management activities. The Tribe's recognition was rescinded in July of 2002, however, after the Bush administration ruled the Chinook Indian Nation had not adequately addressed the seven mandatory criteria for recognition. ${ }^{66}$ Left without the resources the Tribe anticipated for the Plankhouse Project, the Chinook Indian Nation questioned their ability to continue as partners in the reconstruction of a Chinookan plankhouse. ${ }^{67}$ Eventually agreeing to move forward with the Project, the Chinook Indian Nation did so as an unrecognized tribal body that relied heavily upon the goodwill and dedication of volunteers. As I argue in this paper, this unrecognized status has a significant affect on the way in which the Chinook Indian Nation uses the Plankhouse and the publicity that stems from the Project.

A lack of financial capacity and resources was not the only challenge the Cathlapotle Plankhouse Reconstruction Project faced as a result of the Chinook Indian Nation's status as an unrecognized tribe. As detailed in the work of archaeologist Jon D. Daehnke, the Cathlapotle Plankhouse became a "site of contested heritage" in December of 2003, when the newly recognized Cowlitz Indian Tribe challenged the cultural affiliation of the Cathlapotle village and demanded a voice in the Project. Consultation with two tribes that held differing views on the same history proved to be especially difficult for the U.S. Fish and Wildlife Service, as the agency found itself in the middle of a dispute between an unrecognized but highly respected tribal partner and an unfamiliar tribe with legal rights to consultation. A comprehensive discussion of this conflict has already been performed by Daehnke and is beyond the scope of this paper. I do,

${ }^{66}$ Ibid., $260-261$.

${ }^{67}$ Dean Baker, "Plankhouse Project Kicks Off Saturday," (Vancouver, WA) Columbian, 3 September 2002, C1. 
however, address key details of the dispute within the paper that directly affect the progress of the Reconstruction Project and the relationship between the U.S. Fish and Wildlife Service and the Chinook Indian Nation.

\section{What is to Come}

In Chapter One, I discuss the history of the Cathlapotle site from the time of Chinookan inhabitance to the early 1990s. Prior to European contact in the late $17^{\text {th }}$ and early $18^{\text {th }}$ century, portions of what is now the Ridgefield National Wildlife Refuge was home to the thriving Chinookan village of Cathlapotle. As part of an elaborate trade network that extended up and down the Columbia River, this village of approximately 900 complex hunter-gathers maintained a sophisticated economic and social system that converted the area's various natural resources into extraordinary material wealth. The arrival of Europeans to the Columbia River, however, introduced disease to the Pacific Northwest that devastated Native American populations and caused the abandonment of the Cathlapotle in the 1830s. Following a brief period of reinhabitance by interior tribes in the 1840 s and 1850 s, the village was left to decompose under the cover of vegetation for the next century and a half. Deeded to a private settler in 1851 and eventually sold to the U.S. Fish and Wildlife Service in 1965, the land that concealed the remnants of Cathlapotle lay fallow until U.S. Fish and Wildlife Service and Portland State University archaeologists discovered plankhouse depressions in 1992. So began a six-year archaeology project that uncovered thousands of artifacts and revealed key elements of Chinookan daily life at the site. More importantly, an award winning partnership between the U.S. Fish and Wildlife Service, Portland State University, and the Chinook 
Nation was established under the Cathlapotle Archaeology Project that would make the reconstruction of the Cathlapotle Plankhouse possible in the early 2000s.

In Chapter Two, I detail the origins and the implementation of the Cathlapotle Plankhouse Reconstruction Project. With a large amount of funding available for the upcoming Lewis and Clark Bicentennial commemoration, the dream of Cathlapotle Archaeology Project partners to reconstruct a Chinookan plankhouse at the Ridgefield National Wildlife Refuge became a likely reality in the early $21^{\text {st }}$ century. With the support of the U.S. Fish and Wildlife Service, the Lewis and Clark Bicentennial Committee for Vancouver / Clark County, and the Chinook Indian Nation, the Cathlapotle Plankhouse Reconstruction Project commenced in 2002. With the goal of building a full-scale plankhouse that would serve as an educational center for Refuge visitors and a place of ceremony for the Chinook Indian Nation, project partners hired Native architect Art Peterson to design a plankhouse that would reflect what Lewis and Clark saw upon their arrival at Cathlapotle and fulfill the practical needs of the various stakeholders. Safety requirements of the $21^{\text {st }}$ century, however, threatened the authenticity of the structure and the stability of the Reconstruction Project. Cultural tensions mounted between the Chinook Indian Nation and the U.S. Fish and Wildlife Service in late 2003 and early 2004, as both partners had priorities for the Project that conflicted with one other. After a yearlong struggle over safety code compliance and their ramifications to the building's authenticity, mutual compromise allowed the Plankhouse to be completed in March 2005.

Finally, Chapter Three analyzes the outcomes of the Cathlapotle Plankhouse Reconstruction Project and the way in which different stakeholders use the structure. 
First and foremost, the Cathlapotle Plankhouse operates as a unique educational facility for the U.S. Fish and Wildlife Service. In an attempt to preserve the structure's authentic feel, the U.S. Fish and Wildlife Service employ oral and tactile methods of instruction to educate visitors about the Refuge's natural and cultural heritage as opposed to interpretive panels and display cases. The need to accommodate large groups of people, however, has practical limitations on the Plankhouse's authenticity, as bench seating was installed in one half of the structure to accommodate instructional situations and a higher occupancy allowance required the addition of modern safety features like egress lighting and exit doors.

These features, while undesirable, do not stop the Chinook Indian Nation from using the Plankhouse as a cultural anchor that affirms, develops, and celebrates the Chinook Indian Nation's modern identity. Through the process of cultural retrieval and ceremony, the Chinook Indian Nation uses the Plankhouse to honor the ancestors of Cathlapotle, to instill a sense of pride in the modern-day Tribe, and to guarantee tribal survival through cultural repatriation and regeneration activities. Acting as a ceremonial site, however, has interpretive consequences that challenge the U.S. Fish and Wildlife Service staff who develop and run the Plankhouse's interpretive programs. Plankhouse interpreters must find unique and effective forms of instruction that allow the structure to act as a meaningful place for both the general public and the Tribe, which is not always easy or within the Plankhouse's financial capabilities.

Finally, the Plankhouse is used as a political arena by the Chinook Indian Nation to challenge historical misrepresentations of Native Americans and existing structures of power. Using the heightened media attention drawn to the Lewis and Clark Bicentennial 
and the Cathlapotle Plankhouse Reconstruction Project, the Chinook Nation publicized their struggle for recognition and directly challenged the federal government structure that defined them as such. The mere existence of the structure also challenges the colonial-based notions of Native American barbarianism, extinction, and the heroic myth of progress associated with the Lewis and Clark Expedition. Such political statements have implications on the interpretation of the Plankhouse, however, as visitors who base their understanding of American identity on the myths being challenged by the Plankhouse will be confronted in uncomfortable and off-putting manner. Through the analysis of these various uses of the Plankhouse and their interpretive ramifications, I argue the cross-cultural collaboration that occurred between the U.S. Fish and Wildlife Service and the Chinook Indian Nation resulted in a unique and significant structure that fulfills the diverse needs of a wide range of user groups at the Ridgefield National Wildlife Refuge. 


\section{CHAPTER I}

\section{UNEARTHING THE CATHLAPOTLE PLANKHOUSE}

\section{History of the Cathlapotle Site}

\section{Pre-Contact and Contact History of the Cathlapotle Village}

While serene and relatively uninhabited today, the Carty Dairy Unit on the Ridgefield National Wildlife Refuge in Southwest Washington was once home to a thriving trading center that operated within a complex regional network of commerce. Based at the confluence of the Lake, the Lewis and the Columbia Rivers since AD 1000, the village of Cathlapotle ${ }^{68}$ was one of many Chinookan towns situated along the banks of the Columbia River. ${ }^{69}$ Acting as stopping points in the exchange of goods between the coastal and interior groups of the Pacific Northwest, these towns formed a large-scale Chinookan trade network that stretched between Canada, California and into the interior plateau. $^{70}$ While unified in culture, language, and kinship networks, each of these villages operated as individual political and economic entities. ${ }^{71}$ A local village's success in trade weighed heavily upon its political influence along the River, which was

${ }^{68}$ Historical evidence suggests the town was called "Nahpooitle" by its original inhabitants. Alternate spellings of the village in historic documents include "Cath-lahpoh-tle," "Quathlahpohtle," "Quathlapohtle," "Katlapoutle," and "Kattlepootle." ${ }^{69}$ Michael Silverstein, "Chinookans of the Lower Columbia River," in Handbook of North American Indians, Volume 7: Northwest Coast, ed: Wayne Suttles and William Sturtevant (Smithsonian Institution, 1990), 534; Kenneth M. Ames et al., Archaeological Investigations at 45CL1 Cathlapotle (1991-1996), Ridgefield National Refuge, Clark County, Washington - A Preliminary Report (U.S. Fish and Wildlife Service, 1999), i. ${ }^{70}$ Jon Daehnke, Cathlapotle ... Catching Time's Secrets (Sherwood OR: U.S. Fish \& Wildlife Service Cultural Resources Team Region 1, 2002), 17.

${ }^{71}$ Verne Frederick Ray, Lower Chinook Ethnographic Notes, (Seattle, WA: University of Washington, 1938). 
determined by its size and the wealth and power of its leaders. ${ }^{72}$ With abundant natural resources, a large population and highly influential chiefs, Cathlapotle proved to be one of the largest and wealthiest Chinookan towns along the Columbia River. ${ }^{73}$

In addition to the wealth acquired through trade on the Pacific Northwest's "liquid highway," the village of Cathlapotle maintained a sophisticated economic system that effectively converted the area's various natural resources into material and cultural wealth. ${ }^{74}$ As "complex hunter-gatherers," inhabitants of Cathlapotle lived a sedentary lifestyle that relied heavily upon the utilization, trade, and storage of the environment's many natural resources, including salmon, waterfowl, deer, elk, and wapato. ${ }^{75}$ As observed by Meriwether Lewis during the Expedition's visit to the village on 29 March 1806:

They had also an abundance of sturgeon and wappetoe; the latter they take in great quantities from the neighbouring bonds, which are numerous and extensive in the river bottoms and islands. the wappetoe furnishes the principal article of traffic with these people which they dispose of to the nations below in exchange for beads cloth and various articles. the natives of the Sea coast and lower part of the river will dispose of their most valuable articles to obtain this root. ${ }^{76}$

Additionally, stone, wood and bone were used to make weapons, fishing tools, glue and armor, while plants were used to make fishing nets, dyes, clothing, baskets, and medicine. ${ }^{77}$ As articulated by archaeologist Jon Daehnke, "if a resource was in the

\footnotetext{
${ }^{72}$ Daehnke, Cathlapotle ... Catching Time's Secrets, 17.

${ }^{73}$ Kenneth M. Ames et al., Archaeological Investigations, 14.

${ }^{74}$ Daehnke, Cathlapotle ... Catching Time's Secrets, $2,7$.

${ }^{75}$ Kenneth M. Ames and Herbert D. G. Maschner, Peoples of the Northwest Coast: Their Archaeology and Prehistory, (New York, NY: Thames \& Hudson, 1999), 24.

76 "March 29, 1806," The Journals of the Lewis and Clark Expedition, http://lewisandclarkjournals.unl.edu/read/? xmlsrc=1806-03-29\& xslsrc=LCstyles.xsl (accessed 15 July 2011).

${ }^{77}$ Daehnke, Cathlapotle ... Catching Time's Secrets, 8-10.
} 
environment, the people of Cathlapotle found a way to use it.. ${ }^{, 78}$ The Cathlapotle villagers are also thought to have actively managed the condition of the land through controlled burns and strategic harvesting, and the division of labor into occupational specialties allowed the village to maximize its economic efficiency. ${ }^{79}$ Such efficiency resulted in material prosperity and wealth that fostered one of the highest population densities in North America. ${ }^{80}$

In order to house Cathlapotle's large and compact population, cedar plankhouses of varying sizes were erected to accommodate large numbers of inhabitants. With large cedar logs composing the house frame and cedar planks lashed with cedar-bark and cordage comprising the walls and the roof, these plankhouses served as the primary source of shelter for Chinookan villages along the Columbia River. ${ }^{81}$ As detailed by fur trader Gabriel Franchére in the early $19^{\text {th }}$ century:

The native houses, built of cedar, are remarkable for their form and, above all, their size. They are nearly a hundred feet long and thirty to forty feet wide...Fires are made in the middle of the house and smoke escapes through a hole in the roof. Several families, separated from each other by partitions, live in one of these large buildings. The doors, raised well above ground level, are oval and very small. ${ }^{82}$

The partitions described by Franchére were carved walls or mats that separated the structure into compartments that housed approximately two families each. ${ }^{83}$ Within each compartment, these families had access to one of the many hearths running through the middle of the house, as well as elevated sleeping platforms and excavated storage cellars

\footnotetext{
${ }^{78}$ Ibid., 12.

${ }^{79}$ Ibid., 12-13.

${ }^{80}$ Ibid., 17.

${ }^{81}$ Silverstein, "Chinookans of the Lower Columbia," 538.

${ }^{82}$ Gabriel Franchere, Adventures at Astoria, 1810-1814, edited and translated by Hoyt Franchere, (Norman, OK: University of Oklahoma Press, 1967), 114.

${ }^{83}$ Daehnke, Cathlapotle...Catching Time's Secrets, 24.
} 
that ran along the structure's exterior walls. Depending on the size of the plankhouse, anthropologists predict these structures housed between 20 and 100 individuals at a time. ${ }^{84}$ Adorned with highly detailed, carved sculptures and finely painted figures, these plankhouses are believed to have stood for nearly 400 years at a time. ${ }^{85}$

Beyond the provision of shelter, plankhouses were also significant to Chinookan economic, political and social life. ${ }^{86}$ Due to the damp conditions of the Pacific Northwest climate, a majority of productive and communal activities occurred under plankhouse roofs, including cooking, food processing, eating, socializing, storytelling and craft making. ${ }^{87}$ This made the plankhouse the center of community life and production. These structures also reflected the organization of Chinookan society, in which the population was divided along strict class lines. Members of the elite class, consisting mostly of chiefs, warriors and traders, resided at the back of the house away from the entrance. Free commoners, who were mostly responsible for art, crafts, and gathering, resided towards the center of the house. Finally, slaves acquired from raids or trade were segregated from the free members of Cathlapotle society and resided near the entrance. ${ }^{88}$ The size of each plankhouse reflected the influence and wealth of its individual chief, and the highest ranked house of the village was in the rear row of dwellings, away from the riverbank. $^{89}$

${ }^{84}$ Ames et al., Archaeological Investigations, 14.

${ }^{85}$ Daehnke, Cathlapotle ... Catching Time's Secrets, 28.

${ }^{86}$ Ames et al., Archaeological Investigations, 14.

${ }^{87}$ Daehnke, Cathlapotle ... Catching Time's Secrets, 26.

${ }^{88}$ Ibid., 17, 19, 24.

${ }^{89}$ Ibid., 24. 


\section{Post-Contact History of the Cathlapotle Site}

The town of Cathlapotle existed long before Lewis and Clark ever came to the Pacific Northwest with the Corps of Discovery. Having lived along the banks of the Columbia River for thousands of years, Chinookans continuously adapted to the changing natural and political environment. Upon the arrival of foreign influences in the late $18^{\text {th }}$ and early $19^{\text {th }}$ centuries, Chinookans from the Pacific Coast to The Dalles continued this process of adaptation through the integration of European explorers into their trade network. Chinookans were not able to adapt to disease brought to the region by these foreigners, however. Only fifty years after the arrival of Captain Robert Gray to the mouth of the Columbia River, epidemics of small pox, measles, malaria, and influenza decimated the Native population of the Pacific Northwest, and the town of Cathlapotle was abandoned. ${ }^{90}$ The plankhouses that once stood as indicators of power and affluence were left to decompose, and survivors fled to kinship networks in the mountains or on the Pacific Coast.

From the first sighting of Captain Robert Gray's Columbia Rediviva in the mouth of the Columbia River in 1792, Chinookans from the coast to the interior plateau worked to integrate Western explorers into their elaborate network of trade. Through the eventual development of a simplified trading language known as Chinook Jargon, Chinookans were able to negotiate transactions with foreign explorers interested in acquiring popular trade goods like otter pelts and various forms of sustenance. At

${ }^{90}$ Robert T. Boyd, The Coming of the Spirit of Pestilence: Introduced Infectious Diseases and Population Decline Among Northwest Coast Indians, 1774-1874, (Seattle, WA: University of Washington Press, 1999), 240-241. 
Cathlapotle, residents welcomed this new source of trade, as it gave the town greater independence from Chinookan villages upstream. ${ }^{91}$ The site's location next to a Fort Vancouver fur trade trail made Cathlapotle a key center for the exchange of goods with explorers, and residents used this opportunity to acquire a wide variety of novelty and utility items including glass beads, buttons, coins, guns, knives, ceramics and clothing. ${ }^{92}$ By the time the Corps of Discovery passed Cathlapotle in 1805, the town was saturated with European goods and residents were accustomed to financial interaction with European explorers. ${ }^{93}$

Despite the Chinookan's success in integrating foreign traders into their regional network of exchange, close contact with Europeans exposed Natives along the Columbia River to an assortment of disease that decimated Chinookan populations over the next half-century. While not the first in the region, a series of epidemics in the 1820s and 1830s traveled up the Columbia River and killed an estimated 90 percent of the Chinookan population by $1841 .{ }^{94}$ Presumed to be malaria by contemporary historians, "fever and ague" or "intermittent fever" infected white and Native populations alike. ${ }^{95}$ Fatalities, however, proved severe for Native populations who lacked previous exposure to disease and had little access or interest in modern medicine. ${ }^{96}$

While all Native groups along the Columbia River experienced significant population decline, none suffered more than the populations of the Middle Chinook.

${ }^{91}$ Silverstein, "Chinookans of the Lower Columbia," 535.

92 Daehnke, Cathlapotle ... Catching Time's Secrets, 33-34.

${ }^{93}$ Ibid., 32-33.

${ }^{94}$ Boyd, The Coming of the Spirit of Pestilence, 84.

${ }^{95}$ Daehnke, “A 'Strange Multiplicity’ of Voices," 255.

${ }^{96}$ William Lee Wuerch, "History of the Middle Chinooks to the Reservation Era," (Masters Thesis, University of Oregon, 1979), 93. 
Chinookan villages in the Portland Basin experienced an estimated 98 percent population decline between 1805 and $1841 .{ }^{97}$ Such devastation is attributed to seasonal movement and geography. While most Native peoples of the Portland Basin lived away from the Columbia River for extended periods during the year, the Middle Chinook's sedentary lifestyle meant they were away from their villages only for short forays. This left them in constant contact with the swampy climate of the Columbia River, which increased exposure to disease and resulted in greater rates of infection and fatality. ${ }^{98}$ Amongst the Middle Chinook population centers devastated by disease was Cathlapotle village. When Lewis and Clark visited the village in 1806, they estimated 900 inhabitants to live in the town. ${ }^{99}$ Similar to other villages in the area, historians believe Cathlapotle was abandoned around 1830. Dr. William Fraser Tolmie described the scene of the former village in 1833 :

On its lower bank \& just opposite to Coffin island is the site of an Indian village, which a few years ago contained two or three hundred inhabitants, but at present only its superior verdure distinguished the spot from the surrounding country. Intermittent fever...has committed its fullest ravages and nearly exterminated the villagers, the few survivors deserting a spot where the pestilence seemed most terribly to wreak its vengeance. ${ }^{100}$

Once a thriving village of 900 inhabitants and 14 plankhouses, the decomposing remains of Cathlapotle served only as a reminder of the Pacific Northwest's indigenous past by the mid-1830s.

${ }^{97}$ Boyd, The Coming of the Spirit of Pestilence, 244.

${ }^{98}$ Ibid.

99 "Estimate of Western Indians," The Journals of the Lewis and Clark Expedition, http://lewisandclarkjournals.unl.edu/read/? xmlsrc=18051806.winter.part2\& xslsrc=LCstyles.xsl\#noten3029, (accessed 15 July 2011).

${ }^{100}$ William Tolmie, The Journals of William Fraser Tolmie, Physician and Fur Trader, (Vancouver, Canada.: Mitchell Press, 1963), 183. 
Following the "fever and ague" epidemics of the 1820s and 1830s, Native demographics in the Portland Basin changed dramatically. Inland tribes began to shift towards the banks of the Columbia River and its economically productive land. While originally occupying old Chinookan villages on a seasonal basis in the 1830s, Natives of interior origin like the Cowlitz moved downstream permanently. ${ }^{101}$ The village of Cathlapotle reflected this demographic shift. Historical and archaeological accounts indicate inland tribes from 1830 to the mid-1850s reoccupied the village site and its vicinity. In 1834, Hudson's Bay Company physician John Townsend reported treating a sick Cowlitz girl in a village of 100 inhabitants. ${ }^{102}$ The village is believed to have been in the vicinity of, or perhaps at, the former village of Cathlapotle. ${ }^{103}$ Similarly, in 1854, Indian agent William Tappan guessed there were 140 to 200 Sahaptins "living in the valley of the Cathlapootle River," though not necessarily at the exact site of the former village. ${ }^{104}$

The arrival of white Americans looking to start a new life in the West also changed the Portland Basin's demographic composition. Squatters eager to develop "open land" placed enormous pressure on the few Natives that remained along the Columbia River in the late 1840s and early 1850s, and government officials increasingly looked for political means to displace aboriginal peoples from their land. ${ }^{105}$ The passage of the Donation Land Claim Act of 1850 was evidence of this attempt to solve the

\footnotetext{
${ }^{101}$ Boyd, The Coming of the Spirit of Pestilence, 256.

102 Ibid.

${ }^{103}$ Tom Melanson to John Barnett, 20 February 2004, Inactive files drawers at US Fish and Wildlife Service Office, Ridgefield, WA, accessed 23 November 2009.

${ }^{104}$ Boyd, The Coming of the Spirit of Pestilence, 256.

${ }^{105}$ Daehnke, “A 'Strange Multiplicity' of Voices,” 255.
} 
growing tension between Native American land rights and newly arriving settlers.

Granting Euro-Americans ownership of 320 or 640 -acre land claims after four years of "occupancy," this Act gave official sanction to the illegal activity of squatters and opened up new opportunities for homestead settlement. ${ }^{106}$ Settlers soon journeyed to the Pacific Northwest in droves, and intensified calls for the relocation of "hostile" Native Americans initiated treaty negotiations that sought to extinguish all land claims of Native Americans west of the Cascade Mountains. Under the direction of Oregon Territory's first Superintendent of Indian Affairs, Anson Dart, a series of challenging treaty negotiations were conducted with Chinookan and other Native bands that eventually ceded a majority of the Oregon Territory's western lands yet secured parcels of Native homelands as permanent reservations. ${ }^{107}$ These treaties were never ratified by the US Senate, however, as Secretary of the Interior Alexander Stuart objected to the presence of reservations west of the Cascades. ${ }^{108}$ As tensions continued to mount between Natives and white settlers in 1855, new Superintendent of Indian Affairs Joel Palmer called for the removal of the few remaining Middle Chinookans from the Portland Basin and had them sent them to the Grand Ronde Reservation in the Oregon Coastal Ranges. ${ }^{109}$ The former site of Cathlapotle was officially free for white settlement in the second half of the $19^{\text {th }}$ century, and the time of Chinookan control over the Columbia River had passed.

${ }^{106}$ Wuerch, "History of the Middle Chinooks," 119; Kevin D. Hatfield, "Donation Land Law" in Encyclopedia of United States Indian Policy and Law, ed: Paul Finkelman and Tim Allen Garrison, (Washington DC: CQ Press, 2008) 266-267.

${ }^{107}$ Gray H. Whaley, "Oregon, Illahee, and the Empire Republic: A Case Study of American Colonialism, 1843-1858," Western Historical Quarterly 36, No. 2 (Summer, 2005): 167-168.

108 “Anson Dart, 1797 - 1879," The Oregon Encyclopedia, http://www.oregonencyclopedia.org/entry/view/anson_dart/, (accessed 16 July 2011). ${ }^{109}$ Wuerch, "History of the Middle Chinooks," 137. 


\section{The Carty Generations}

In 1839, a young Irish immigrant named James Carty built a cabin above the mouth of the Lake River. ${ }^{110}$ A cooper for the Hudson's Bay Company, Carty most likely settled at this location due to its fertile, flood plain soil and its close proximity to a Hudson's Bay Company grazing trail that stretched from the Cowlitz Prairie to Fort Vancouver. ${ }^{111}$ While technically a squatter for his first two years of residence in Wapato Portage, Carty legitimized his presence on the land by filing a Donation Land Claim for the property that was recorded as DLC 48 in $1851 .{ }^{112}$ Upon his death in 1873 , James Carty's nephew, James N. Carty, inherited DLC 48. He also purchased portions of DLC 57 , the property that included the former site of Cathlapotle. ${ }^{113}$

For the next century, the site of the former Chinookan village remained uniquely undisturbed. While James N. Carty farmed small portions of his land, his son William and his grandson Jim were principally politicians, leaving the land fallow. To profit from their property, the Carty family continually leased their land to dairy farmers and ranchers in need of large sources of hay for grazing. Owners of surrounding Wapato Portage sites, on the other hand, increasingly developed or sold their properties to industrial stakeholders in the late $19^{\text {th }}$ century and early $20^{\text {th }}$ century. Steamboat landings, sawmills, shingle mills, and wood treatment plants were erected on the banks of

${ }^{110}$ Elizabeth Morrison, Ridgefield National Wildlife Refuge: Historical Perspective and Present Management, (Ridgefield National Wildlife Refuge: Bureau of Sport, Fisheries and Wildlife, 1967) 3.

${ }^{111}$ Alex Bourdeau, "Geologically Complex: The Flood Plain of the Lower Columbia River," Inactive file drawers at the U.S. Fish and Wildlife Service's Region 1 Cultural Resources Office, Sherwood, OR (accessed 21 April 2010), 12.

112 Ibid.

${ }^{113}$ Ibid., 13. 
the area's rivers, and landholdings were logged or filled with dredge spoils taken from the Lake River. ${ }^{114}$ The "Carty Dairy Unit", however, remained unexcavated and mostly undisturbed while under the care of four generations of the Carty family.

In 1965, Jim Carty sold the Carty Dairy Unit to the Department of the Interior's U.S. Fish and Wildlife Service. With tidal marsh zones uplifted by a significant Alaskan earthquake in 1964, critical nesting grounds for the dusky Canada goose and other migratory species were left vulnerable to predators. ${ }^{115}$ As population figures of these species quickly diminished, concerned bird conservationists searched for ways to help the species adapt to the significantly altered landscape. As part of this effort, the Migratory Bird Commission passed the Migratory Bird Conservation Act in 1965. This Act authorized the United States Fish and Wildlife Service to rent or purchase land in the pursuit of establishing waterfowl refuges that would protect and enhance migratory bird populations. With relatively low levels of development, seasonal and permanent wetlands, and agricultural land suitable for feeding waterfowl, the Carty Dairy Unit, together with the Roth Diary Unit, the Ridgeport Dairy Unit, the River 'S' property, and Bachelor Island, was flagged as suitable option for the new Act's purposes. ${ }^{116}$ Purchased by the United States Fish and Wildlife Service in 1965, these five properties, totaling over 5,150 acres, were amalgamated into one and renamed the Ridgefield National Wildlife Refuge. ${ }^{117}$

${ }_{114}^{114}$ Morrison, Historical Perspective and Present Management, 15-16.

${ }^{115}$ Bourdeau, "Geologically Complex, "16.

${ }^{116}$ Ibid.

${ }^{117}$ U.S Fish and Wildlife Service, "Ridgefield National Wildlife Refuge Home Page," http://www.fws.gov/ridgefieldrefuges/ridgefield/, (accessed 12 April 2011). 


\section{The Site as the Ridgefield National Wildlife Refuge}

With the aim of maintaining and enhancing a suitable feeding and resting habitat for migratory birds, the U.S. Fish and Wildlife Service has "intensively managed"118 the natural environment of the Ridgefield National Wildlife Refuge since 1965. To maximize the production of food for wildlife, employees of the U.S Fish and Wildlife Service control the flooding and the draining of the wetlands, in addition to grazing cattle, harvesting hay, removing invasive plant species and actively farming specific portions of the Refuge's agricultural areas. ${ }^{119}$ Beyond test excavations performed in 1976, 1979, and 1984, the U.S. Fish and Wildlife Service conducted no activity that disturbed the remnants of the former Cathlapotle village site. ${ }^{120}$ Instead, the area remained uniquely undisturbed amongst the onslaught of development that occurred in both the Portland Basin and throughout the Pacific Northwest in the late $19^{\text {th }}$ and early $20^{\text {th }}$ century.

As native populations disappeared from their homelands and white settlement encroached, a majority of culturally significant indigenous sites were destroyed over time due to erosion, development, and looting. ${ }^{121}$ Evidence of the way life used to be on the Columbia River slowly disappeared as floods, machinery and people removed the proof of thousands of years of life that came before them, and historians were left only with first-person accounts of encounters with Natives and their villages steeped in colonial perspectives. The former site of Cathlapotle, however, remained largely intact due to the

${ }^{118}$ U.S. Fish and Wildlife Service, "Ridgefield National Wildlife Refuge Summary", http://www.fws.gov/refuges/profiles/index.cfm?id=13551, (accessed 12 April 2011). 119 Ibid.

${ }^{120}$ Bourdeau, "Geologically Complex," 19-21.

${ }^{121}$ Daehnke, Cathlapotle ... Catching Time's Secrets, 4. 
"benign use" of the land by its non-Native owners post-abandonment. ${ }^{122}$ This would prove extremely significant in the early 1990s, when the U.S. Fish and Wildlife Service, in partnership with Portland State University and the Chinook Indian Nation, located and excavated the site of the former town. What they uncovered during this excavation significantly enhanced archaeologists' understanding of the complex systems of Pacific Northwest hunter-gatherers and the residents of Cathlapotle. Beyond historical and anthropological insight, the dig also provided the project's partners a rare opportunity to collaborate in the interpretation and presentation of a history that deviated from the colonial myth that dominated the area's local history.

\section{The Cathlapotle Archaeology Project}

In 1991, Portland State University archaeologist Dr. Kenneth Ames and U.S. Fish and Wildlife Service Region 1 archaeologist Anan Raymond collaborated to locate the site of the former village of Cathlapotle. On an exploratory search near Brush Ridge on the Ridgefield National Wildlife Refuge, the duo discovered a number of surface depressions commonly associated with abandoned structures. ${ }^{123}$ Suspecting these depressions to be remnants of the semi-subterranean wooden floors and cellars typical of Chinookan plankhouses, archaeologists from the U.S. Fish and Wildlife Service and Portland State University's Anthropology Department augured four different areas surrounding the depressions in December of 1991. These probes revealed only minor

${ }^{122}$ Bourdeau, “Geologically Complex,” 14-15.

${ }^{123}$ Ibid., 21. 
amounts of cultural material. ${ }^{124}$ After an intense review of ethnographic and historical data and collaboration with former owner James Carty, a more specific site was chosen for auger tests in 1992. These tests proved more successful, as the summer months made surface material more visible and a site of approximately 240 meters long and 80 meters wide was identified as the former Indian village. ${ }^{125}$

Understanding the unique opportunity this site presented to Pacific Northwest archaeologists and Native American stakeholders, Portland State University and the U.S. Fish and Wildlife Service designed a multi-year, cooperative archaeological research project in 1993 that proposed to study the daily life of Cathlapotle residents prior to and following Euro-American contact. From this study, environmental education programs were to be generated to raise awareness about the area's natural and cultural heritage. Due to the site's location on federal land, U.S. Fish and Wildlife Service and Portland State University archaeologists had an exceptional opportunity to approach the archaeological process in a slow and deliberate manner. They also had an academic interest in, and a legal obligation to, consult tribal bodies with potential connections to the site. ${ }^{126}$ Section 106 of the National Historic Preservation Act and U.S. Fish and Wildlife Service policy mandate the involvement of Native American governments in all Service actions that may affect their cultural or religious interests, including

\footnotetext{
${ }^{124}$ William Cornett, "DRAFT Preliminary Investigations at Cathlapotle, 45CL1, Ridgefield National Wildlife Refuge, Washington," Inactive files of Gary Johnson, Chinook, WA, accessed 8 June 2010, 10.

125 Ibid., 13-14.

${ }^{126}$ Anan Raymond to Mark Mercier, 20 April 1993, Inactive file drawers at U.S. Fish and Wildlife Service's Region 1 Cultural Resources Office, Sherwood, Oregon, accessed 21 April 2010.
} 
archaeological sites. ${ }^{127}$ Adhering to these mandates, Anan Raymond contacted representatives of the Chinook Indian Nation, the Cowlitz Tribe, and the Confederated Tribes of the Grand Ronde in the summer of 1993 (and later the Yakama in 1995) to discuss the potential of the project and to request involvement of each tribal body in the process. ${ }^{128}$ While the Cowlitz and the Confederated Tribes of the Grand Ronde chose not to get involved in 1993, the Chinook Indian Nation requested an active voice and a partnership role in the project. ${ }^{129}$ What resulted from this request was a consultation model that guided a new partnership between the U.S. Fish and Wildlife Service, Portland State University, and the Chinook Indian Nation in the Cathlapotle Archaeology Program (CAP).

\section{The Partners}

\section{Portland State University}

Portland State University is an urban institution located twenty miles south of Ridgefield National Wildlife Refuge in Portland, Oregon. With a student body of just under 30,000 students, the University offers 226 degree programs and partners with over 1,000 community organizations. ${ }^{130}$ Within the College of Liberal Arts and Sciences, the Department of Anthropology provides students the opportunity to gain a level of

\footnotetext{
${ }^{127}$ US Fish and Wildlife Service, "614 FW 5, Authorization to Use," http://www.fws.gov/policy/614fw5.html, (accessed 4 March 2011).

${ }^{128}$ Bruce Wiseman to Mary Thompson, "Draft Memorandum of Agreement for Cathlapotle Archaeological Program," 3 April 3 1995, inactive file drawers, U.S. Fish and Wildlife Service's Region 1 Cultural Resources Office, Sherwood, Oregon, accessed 21 April 2010.

${ }^{129}$ Daehnke, “A ‘Strange Multiplicity’ of Voices," 256.

${ }^{130}$ Portland State University, "Profile: Snapshot of Portland State," http://www.pdx.edu/profile/Snapshot-of-Portland-State, (accessed 21 March 2011).
} 
competency in general anthropology through the acquisition of a Bachelor of Arts, a Bachelor of Science, or a Master of Arts. ${ }^{131}$ The specialization of this Department's faculty encompasses a wide range of anthropological topics, including archaeology, biological anthropology and sociocultural anthropology.

With areas of concentration that include cultural and social archaeology of North America and archeological methods and theory, Dr. Kenneth Ames taught courses, supervised field schools and internships, and advised archaeological research projects at Portland State University in the late 1980s and early 1990s. ${ }^{132}$ As the supervisor of a long-term research project focused on the archaeology of the Wapato Valley, Dr. Ames supervised students in the excavation of a single plankhouse at the Meier site (35CO5) from 1987 to $1991 .{ }^{133}$ Just a few miles from the former site of Cathlapotle, the Meier excavation yielded a wide variety of artifacts and data relating to the structure and the function of Chinookan plankhouses. Hoping to expand upon the findings of this site, Dr. Ames collaborated with U.S. Fish and Wildlife Service's Regional Archaeologist, Anan Raymond, to identify the possible location of Cathlapotle for further excavation. With the discovery of plankhouse depressions in December 1991 and cultural material in 1992, Portland State University's Wapato Valley Archaeology Project was extended to incorporate the Cathlapotle site. As principal investigator for the University at Cathlapotle, Dr. Ames supervised six field schools from 1992 to 1996. Beyond providing

\footnotetext{
${ }^{131}$ Portland State University, "Anthropology at PSU: Programs," http://www.anthropology.pdx.edu/programs/programs.html, (accessed 21 March 2011). ${ }^{132}$ Portland State University, "Anthropology at PSU: Archaeology," http://www.anthropology.pdx.edu/archaeology.html, (accessed 21 March 2011). ${ }_{133}$ “The Virtual Meier Site," http://web.pdx.edu/ b5cs/virtualmeier/virtualmeier.html, (accessed 21 March 2011).
} 
archaeologists further evidence of the complexities of Chinookan culture and daily life, these field schools provided Portland State University students the opportunity to gain remarkable field experience and better understanding of archaeological processes. For Dr. Ames, the findings at the Cathlapotle site also had the potential to expand upon his study of complex hunter-gathers of the Pacific Northwest Coast.

\section{U.S. Fish and Wildlife Service}

Since the establishment of the Ridgefield Wildlife Refuge in 1965, the United States Fish and Wildlife Service has been responsible for the management of the area's natural and cultural resources. With the mission of working with various groups to conserve, protect and enhance the habitats of fish, wildlife, and plants, this government agency is charged with maintaining a healthy and natural environment that allows the American public to enjoy the outdoors and the nation's shared heritage. ${ }^{134}$ Beyond “intensive management" of over 96 million acres of National Wildlife Refuge land, the U.S. Fish and Wildlife Service has a responsibility to manage the area's cultural resources. Stewardship is one of the Service's core principles that guide them in the conservation of natural resources for future generations. ${ }^{135}$ Additionally, cultural resource laws like the National Historic Preservation Act (NHPA) requires all federallyowned sites with historic or cultural value to be actively managed by the applicable federal agency. Section 110 of this Act states historic properties "under the jurisdiction

\footnotetext{
${ }^{134}$ U.S. Fish and Wildlife Service, "Agency Overview: Conserving the Nature of America," http://www.fws.gov/fwsataglance.html, (accessed 4 March 2011).

135 Ibid.
} 
or control of the agency are to be managed and maintained in a way that considers the preservation of their historic, archeological, architectural, and cultural values."

The U.S. Fish and Wildlife Service, therefore, had a legal obligation to protect and manage the former site of Cathlapotle if it rested within Ridgefield National Wildlife Refuge. While the exact location of the former village remained in dispute until 1993 , the significance of finding the site was understood well by Refuge archaeologists in 1991 . An archaeological investigation into the former site of Cathlapotle, therefore, was an important element of the Ridgefield National Wildlife Refuge's cultural stewardship program in the late 1980 s and early 1990 s. ${ }^{137}$ Directly aligning with the objectives of PSU's aforementioned Wapato Valley Archaeology Project, the U.S. Fish and Wildlife Service's regional archaeologist, Anan Raymond, joined forces with Dr. Ken Ames to search for the former site of Cathlapotle. Following the affirmation of the site's location in 1993, legal mandates then required the U.S. Fish and Wildlife Service to protect and manage the archaeological resource.

\section{The Chinook Indian Nation}

The modern day Chinook Indian Nation represents five Chinookan-speaking bands of the Lower Columbia River including the Lower Chinook, the Clatsop, the Willipa, the Wakiakum, and the Kathlamet. Headquartered in Chinook, Washington, this tribal body has over 2,000 enrolled members and hosts a wide variety of social and

\footnotetext{
${ }^{136}$ National Park Service, "Federal Agency Historic Preservation Program", accessed May 4, 2010, http://www.nps.gov/history/hps/fapa_110.htm, (accessed 4 March 2011).

${ }^{137}$ Daehnke, "A 'Strange Multiplicity' of Voices," 253.
} 
cultural gatherings. ${ }^{138}$ While the site of Cathlapotle has no singular tribal representative due to the havoc wreaked upon the area by disease, the cultural similarities between the different bands of the Chinook Indian Nation and the people of Cathlapotle made it so many of the Chinook Indian Nation felt strongly connected to the site's ancestors. ${ }^{139}$ As conveyed by Gary Johnson, Chairman of the Chinook Indian Nation's Cultural Committee:

We feel responsibility, and we are tied by blood to the tribes further on up the river. And we feel it is very much our responsibility to oversee our ancestors' territories... We see that as an area that is really important for us to protect and to be sure that things are done properly there so that other people don't step into our territory. ${ }^{140}$

This sense of responsibility led the Chinook Indian Nation to accept the U.S. Fish and Wildlife Service and Portland State University's offer to participate in the Cathlapotle Archaeology Project in 1993.

Beyond the cultural significance of the site, the Chinook Indian Nation was also driven to participate in the Cathlapotle Archaeology Project to further legitimize its pursuit for federal recognition. In August of 1851, the Chinook signed the Tansy Point Treaty establishing a reservation west of the Cascade Mountain ranges. As previously articulated, the Anson Dart Treaties (including the Tansy Point Treaty) were never ratified by Congress and new negotiations were held with Washington Governor Isaac Stevens in February of 1855. These negotiations proposed a new reservation for the Chinook, the Upper and Lower Chehalis, the Quinault, the Satsop, and the Cowlitz that

\footnotetext{
${ }^{138}$ Daehnke, Cathlapotle ... Catching Time's Secrets, 39.

${ }^{139}$ Daehnke, “A 'Strange Multiplicity' of Voices," 254-257.

${ }^{140}$ Gary Johnson, interview conducted by Jon Daehnke, 5 September 2006, digital voice recording, on file with Jon Daehnke, as quoted in Daehnke, "A 'Strange Multiplicity' of Voices", 32.
} 
extended from Cape Flattery to Grays Harbor, Washington. ${ }^{141}$ Opposed to living in the territory of their historic enemies, the Chinook refused to sign the Chehalis River Treaty, and later, the Treaty of Olympia. ${ }^{142}$ As a result, the Chinook remained "unrecognized" as a one of the few non-treaty Indian tribes in southwestern Washington during the mid to late $19^{\text {th }}$ century.

Despite their lack of official tribal recognition, the Chinook continued to operate as a tribal unit throughout the late $19^{\text {th }}$ and early $20^{\text {th }}$ centuries. While aggressive white settlement wedged tribal members into isolated pockets within their homeland, the Chinook Indian Tribe maintained their communal lifestyle and adapted their ceremonial rituals to adhere to their changing way of life. This is reflected in Bureau of Indian Affairs Agent Charles Roblin's observations of the Chinook during his compilation of Special Enrollment rolls from 1916 to 1919:

In Pacific, Wahkiakum and Gray's Harbor Counties, Washington, there are a number of small Indian settlements, comprising the remnants of the tribes originally inhabiting the country around the harbors and inlets of the Pacific Coast and Columbia River. These have almost entirely lost their character as Indian settlements; and yet, so far as it has been possible, the Indians can be said to have kept up their 'tribal relations' and communal life. They can hardly be said to have 'severed tribal relations' as the fact is that the white civilization and communities have simply surrounded them and overwhelmed them, thus making tribal conditions impossible. ${ }^{143}$

${ }^{141}$ Daehnke, "A 'Strange Multiplicity' of Voices," 260.

${ }^{142}$ John H. Brown and Robert H. Ruby, The Chinook Indians: Traders of the Lower Columbia River, (Norman: University of Oklahoma Press, 1976), 236.

${ }^{143}$ Charles Roblin as quoted in Stephen Dow Beckham, Chinook Indian Tribe: Petition for Federal Acknowledgement, (Lake Oswego: USA Research, 1987), 231-232. 
Understanding the Chinook to be active in their attempts at maintaining their tribal identity, the Bureau of Indian Affairs continued to provide services to the Chinook Tribe throughout the late $19^{\text {th }}$ and early $20^{\text {th }}$ century. ${ }^{144}$

The three branches of the United States government also recognized the Chinook Tribe as a tribal entity until the second half of the $20^{\text {th }}$ century. As argued by Stephen Dow Beckham, passing time and court case decisions gradually extended the benefits, rights, privileges, and immunities that accompanied the Treaty of Olympia to the Chinook Indian Tribe. ${ }^{145}$ An executive order issued by President Ulysses S. Grant in 1873, for example, created the Quinault reservation for all fish-eating tribes of western Washington. As later clarified in the 1931 Supreme Court case Halbert vs. United States, this executive order allowed members of the Chinook Tribe to acquire allotments on the Quinault reservation between 1932 and 1935 without abandoning their tribal affiliation. ${ }^{146}$ Additionally, the Act of August 12, 1912 appropriated the Chinook \$20,000 for lands ceded to the United States government in the unratified Tansy Point Treaty. ${ }^{147}$ While this sum proved to be minor compensation for lands the Chinook had lost, the Act more significantly stated the "treaties or agreements [previously signed by the Chinook] should be considered and treated by Congress as having the force and effect of a ratified

\footnotetext{
${ }^{144}$ United States Department of the Interior, Office of Federal Acknowledgement, "Summary Under the Criteria and Evidence for Final Determination For Federal Acknowledgement of the Chinook Indian Tribe/Chinook Indian Nation," 3 January 2001, www.bia.gov/idc/groups/xofa/documents/text/idc-001483.pdf (accessed 21 December 2010), 10.

${ }^{145}$ Beckham, Chinook Indian Tribe, 12.

${ }^{146}$ Ibid., 85-86.

${ }^{147}$ Alice B. Kehoe, North American Indians, (Englewood Cliffs, N.J.: Prentice-Hall, 1981), 416.
} 
treaty."148 The United States Congress also acknowledged the Chinook in the Act of February 12,1925 , in which the Chinook Tribe was provided the right to bring all claims against the United States government, both legal and equitable, to court. ${ }^{149}$ Finally, pursuant to the Indian Claims Commission Act of 1946, a judicial panel further recognized the Chinook Tribe in 1971 by awarding members further compensation for the 762,000 acres of territory lost to the federal government in the mid-nineteenth century. $^{150}$

Despite never having been officially recognized by the federal government, the Chinook Tribe was ironically one of the many tribes, bands, groups and communities of Indians located west of the Cascade Mountains to have their Federal trust relationship terminated by Congress in $1954 .^{151}$ Losing the rights and services that had been provided to the Tribe in previous years, the Chinook were now left to maintain their tribal culture with few resources. Around the same time, the Chinook Tribe divided into two factions: the Chinook Indian Nation, representing those who had historically resided along the north bank of the Columbia River, and the Chinook Indian Tribe, representing the families of Bay Center and South Bend, Washington. While the Chinook Indian Tribe increasingly focused on the maintenance of tribal culture, the preservation of tribal history, and the development of economic programs, the Chinook Indian Nation pursued

\footnotetext{
${ }^{148}$ United States Department of the Interior, Office of Federal Acknowledgement, "Summary Under the Criteria," 10.

149 Ibid., 11.

${ }^{150}$ Kehoe, North American Indians, 416.

${ }^{151}$ United States Department of the Interior, Office of Federal Acknowledgement, "Summary Under the Criteria," 5.
} 
land claim matters. ${ }^{152}$ Upon announcement of the Federal Acknowledgement Program in June of 1977, however, the two factions amalgamated once again for federal recognition purposes. ${ }^{153}$ As a legally unified entity, the Chinook Indian Nation filed a petition for federal acknowledgement in 1981.

In an assessment process heavily weighted upon simplified notions of tribal identity and the demonstration of tribal continuity through paper trails, the Chinook Indian Nation struggled to establish themselves as a valid tribal entity throughout the 1980s and early 1990s. ${ }^{154}$ Enmeshed in their struggle for federal acknowledgement and lacking financial resources and personnel to oversee their cultural resource activities, the Chinook Indian Nation appeared on paper to be an outside candidate for participation in the Cathlapotle Archaeology Project. When presented with the opportunity to participate in the excavation and educational programs at Cathlapotle, however, the Chinook Indian Nation showed great enthusiasm for the project in 1991 and 1993. Project participant Jon Daehnke argues that, beyond the cultural significance of the site, the Chinook Indian Nation's enthusiasm for the project closely aligned with their fight for federal recognition, as "Cathlapotle served as an important place for cultural memory and legitimization of the legacy of Chinookan peoples along the Columbia River."155 Furthermore, the formation of a partnership with the U.S. Fish and Wildlife Service would further represent the Chinook Indian Nation's consistent government-to-

${ }^{152}$ Beckham, Chinook Indian Tribe, 286, 288.

${ }^{153}$ Kehoe, North American Indians: A Comprehensive Account, 416.

${ }^{154}$ Daehnke, "A 'Strange Multiplicity' of Voices,” 261-262.

155 Ibid., 254. 
government relationship with the different sectors of the United States government, despite being officially "unrecognized."

\section{$\underline{\text { Results of the Project }}$}

Within five years of the discovery of plankhouse depressions on the Ridgefield National Wildlife Refuge, the Cathlapotle Archaeology Project (CAP) had conducted six field schools that unearthed over 75,000 artifacts and the foundations of eleven plankhouses. ${ }^{156}$ Dating as far back as 600 years, these artifacts, animal bones, waste products and radiocarbon dates provided significant archaeological insight into the daily life of Cathlapotle residents and their use of the surrounding habitat. ${ }^{157}$ With research focused around the gathering of archaeological evidence on social organization, the use of technology, environmental manipulation, and practices of food production, it was revealed that the inhabitants of Cathlapotle maintained a large town with monumental architecture, enormous wealth, a highly evolved artistic style, and a well-established aristocracy. ${ }^{158}$ The largest plankhouse foundation was measured to be 200 feet long by 45 feet wide, and at least four of the plankhouses were found to be divided into compartments as described in the Journals of Lewis and Clark. As articulated by U.S.

Fish and Wildlife Service archaeologist Anan Raymond, the work at Cathlapotle

\footnotetext{
${ }^{156}$ Virginia Parks, Discover Cathlapotle!: a teacher's workshop guide for the Cathlapotle Environmental and Heritage Education Kit (Portland, OR: U.S. Fish and Wildlife Service, 1995), 11.

${ }^{157}$ Merlin Douglass, "In Search of Cathlapotle," Winter 2001, inactive file drawers at the U.S. Fish and Wildlife Service's Region 1 Cultural Resources Office, Sherwood, Oregon, accessed 21 April 2010.

${ }^{158}$ Ibid.
} 
provided a rare example of "a time when the Columbia River was full of Chinook Indians living in great affluence." 159

Based on the results of the archaeological dig, the Cathlapotle Archaeological Project produced multiple academic, educational and interpretive opportunities that conveyed the site's history and significance to the wider Pacific Northwest community. A number of participating Portland State University students published Masters theses and $\mathrm{PhD}$ dissertations based on their work at the site during the field schools, and Dr. Kenneth Ames integrated his findings from the Project into an analysis of Pacific Northwest complex hunter-gatherers in the publication of Peoples of the Northwest Coast: Their Archaeology and Prehistory (2000). Additionally, a preliminary report on the archaeological investigations at the site was published in 1999. The findings of the archaeological dig also provided a basis of comparison for the discoveries at the Meier archeological site a few years prior.

Outside of the academic community, a number of educational programs were developed based on the findings of the archaeological project. In collaboration with the Chinook Indian Nation and Portland State University, the U.S. Fish and Wildlife Department developed the Discover Cathlapotle! Environmental and Heritage Education Kit, which sought to promote understanding of the past and present Chinook culture, foster stewardship for the conservation of cultural and natural resources, and provide knowledge about the archaeological process to students ranging from third to sixth grade. ${ }^{160}$ Comprised of replica artifacts, samples of raw cultural and natural materials,

${ }^{159}$ Ibid.

${ }^{160}$ Parks, Discover Cathlapotle!, 16. 
multimedia references and a teacher's guide with background information and lesson plans, this kit was developed to assist the populations of the Portland and Vancouver metropolitan area and the rural community of Ridgefield in gaining a sense of responsibility for their natural and cultural resources. ${ }^{161}$ Portland State University Masters student Jon Daehnke also created an educational booklet, Cathlapotle...catching time's secrets, which conveyed the site's history and archaeological findings. With illustrations by Chinook Indian Nation artist Charles Funk, the U.S. Fish and Wildlife Service's Region 1 Cultural Resources Team published the informational booklet in 2002. Finally, the Chinook Indian Nation, Portland State University, and the U.S. Fish and Wildlife Service collaborated to conduct annual "Cathlapotle Open Houses" during Washington State's Archaeology Week. These open houses presented CAP's archaeological findings and provided the general public an opportunity to learn more about past and present Chinookan culture. ${ }^{162}$ The open houses also provided an ideal forum for the Chinook Indian Nation to share the groups public outreach mission and to exhibit their exceptional woodworking, basket weaving and tool manufacturing skills. ${ }^{163}$

Most significantly, however, the Cathlapotle Archaeology Project developed a unique and successful partnership that unveiled numerous opportunities for nuanced historical interpretation and the eventual construction of a plankhouse at Ridgefield

${ }^{161}$ Ibid.; U.S. Fish and Wildlife Service, "Cathlapotle Cultural Resources at Ridgefield National Wildlife Refuge," September 2000, inactive file drawers at the U.S. Fish and Wildlife Service's Region 1 Cultural Resources Office, Sherwood, Oregon, accessed 21 April 2010.

${ }^{162}$ Anan Raymond, Alex Bourdeau and Virginia Parks to Tim Tarabochia, 23 August 1995, inactive files drawers of Gary Johnson, Chinook, Washington, accessed 8 June 2010.

${ }^{163}$ Virginia Parks to Tony Johnson and Gary Johnson, "Notes for Tony and Gary," n.d., inactive file drawers of Gary Johnson, Chinook, Washington, accessed 8 June 2010. 
National Wildlife Refuge. In 1997, the Advisory Council on Historic Preservation recognized the U.S. Fish and Wildlife Service for its "creative or exemplary approach to the Section 106 process. ${ }^{\not 164}$ Furthermore, the U.S. Fish and Wildlife Service received the first Chairman's Award for Federal Achievement in Historic Preservation, presented in 2002. As articulated by the Advisory Council on Historic Preservation's Chairman John Nau, III:

Archaeology may seem remote from the core mission of the Fish and Wildlife Service, but in fact all Federal agencies are required to consider historic resources in their activities. Cathlapotle is an extraordinary example of the vision appropriate to the resource and history it preserves and honors. ${ }^{165}$

While not viewed to be a Section 106 project by the U.S. Fish and Wildlife Service archaeologists invested in the project, ${ }^{166}$ the Advisory Council on Historic Preservation felt the tri-partnership was an exceptional example of collaboration with culturally and historically invested Native groups in a time when many agencies and organizations struggled to navigate the new, post-NAGPRA system of cultural resource management. The Cathlapotle Archaeology Project's research and outreach objectives, and the constant collaboration between Portland State University, the Chinook Indian Nation and the U.S. Fish and Wildlife Service provided a sound model for other organizations to follow as they embarked on projects in a new era of cultural resource mandates.

\footnotetext{
${ }^{164}$ Virginia Parks to Tony Johnson and Gary Johnson, "SAA Annual Meeting - Seattle 98, Paper on Cathlapotle," 29 August 1997, inactive file drawers of Gary Johnson, Chinook, Washington, accessed 8 June 2010.

${ }^{165}$ Advisory Council on Historic Preservation, "First Chairman's Awards for Federal Achievement in Historic Preservation Presented to GSA and U.S. Fish and Wildlife Service", http://www.achp.gov/news-gsa-fws-awards.html, accessed 11 March 2011. ${ }^{166}$ Virginia Parks to Tony and Gary Johnson, "SAA Annual Meeting."
} 
Beyond institutional recognition of the success of the Cathlapotle Archaeology Project, personal reflections of the involved partners conveyed the true achievement of this unique collaboration. Having endured decades of historical and cultural misrepresentation that resulted from little or no consultation with the Tribe, the Chinook Indian Nation was increasingly wary of collaborative projects that promised equal outcomes for the tribal body in the early 1990s. ${ }^{167}$ While the Cathlapotle Archaeology Project had the opportunity to become another example of this misrepresentation, constant engagement with the Chinook Indian Nation by Portland State University and the U.S. Fish and Wildlife Service created a trusting relationship based on respect and enthusiasm for what each partner contributed to the project. As articulated in a letter from Tim Tarabochia, Chairman of the Chinook Indian Nation, to Anan Raymond in July of 1994:

I truly appreciate your sincere efforts and manner in which you have approached the Chinook tribe... we have not always been approached and kept informed on cultural resource projects by other public and private parties. I commend you for your sincere efforts to obtain the involvement and input of the Chinook Tribe and its members at the Cathlapotle site. ${ }^{168}$

Appreciation of the partnership proved to be mutual, as archaeologists from the U.S. Fish and Wildlife Service and Portland State University constantly conveyed their gratitude for the Chinook Indian Nation's participation and contributions to the archaeological and

${ }^{167}$ Chinook Indian Nation Culture Committee, interview by author, 8 June 2010, Chinook, WA, digital recording.

${ }^{168}$ Tim Tarabochia to Anan Raymond, "Your letter and enclosures of June 24, 1994, Cathlapotle Village Site/Ridgefield National Wildlife Refuge, etc," 27 July 1994, inactive file drawers at the U.S. Fish and Wildlife Service's Region 1 Cultural Resources Office, Sherwood, Oregon, accessed 21 April 2010. 
educational process. As summarized by Portland State University Masters student Jon Daehnke in his publication Cathlapotle: Catching Time's Secrets:

Cathlapotle does not represent a static past. It represents a connection to people in the present, and it is through a partnership between the Chinook and archaeologists that we have been able to learn so much about this important site. ${ }^{169}$

It is this respect for the contributions of each partner that made the Archaeology Project a success. More importantly, it laid the foundation for future collaboration that would result in the construction of a replica Plankhouse on the Ridgefield National Wildlife Refuge in the first decade of the $21^{\text {st }}$ century.

${ }^{169}$ Daehnke, Cathlapotle ... Catching Time’s Secrets, 39. 


\section{CHAPTER II}

\section{PLANKHOUSE DESIGN AND CONSTRUCTION}

Despite the enormous successes of the partnership that resulted from the archaeological dig at the former site of Cathlapotle, the stakeholders of CAP believed their work to be incomplete even after the site was refilled and the physical findings were analyzed. As explained by U.S. Fish and Wildlife Service archaeologist Anan Raymond:

As we were doing the excavations, Dr. Ames and I discussed the frustration that we had this huge archaeological site that was very interesting and full of data, but there was not much to show for it on the surface. You know, you take people out there, and it is basically a pile of dirt overgrown with jungle, and so we sort of fantasized, 'Wouldn't it be great if we had a replica of one of these plankhouses to show and share with other people about what a fantastic site and what grand, amazing houses these people lived in., ${ }^{170}$

Believing this fantasy to be "mostly a wild idea," the U.S. Fish and Wildlife Service and Portland State University focused their attention on the educational resources being produced from the archaeological findings. ${ }^{171}$ The Chinook Indian Nation, in the meantime, focused their attention on securing the archaeological site and making sure the artifacts removed from the ground had a safe and permanent home with experts versed in the culturally sensitive display of tribal artifacts. ${ }^{172}$ Despite unanimous support for the construction of a full-scale plankhouse among the CAP partners, the feasibility of funding such a project appeared impossible at the end of the $20^{\text {th }}$ century. This "wild idea", however, soon turned into a reality, as the approaching Lewis and Clark

${ }^{170}$ Anan Raymond, U.S. Fish and Wildlife Service Region 1 Archaeologist, interview by author, 27 May 2010, Sherwood, Oregon, digital recording.

${ }^{171}$ Ibid.

${ }^{172}$ Gary Johnson to Bruce Wiseman, 11 June 1995, inactive file drawer at the U.S. Fish and Wildlife Service's Region 1 Cultural Resources Office, Sherwood, Oregon, accessed 21 April 2010. 
Bicentennial commemorations provided the financial capability and the cultural impetus necessary to implement such a large-scale project.

\section{The Beginnings of the Cathlapotle Plankhouse Reconstruction Project}

\section{The Lewis and Clark Bicentennial Commemoration}

Beginning in the early 1990s, Lewis and Clark enthusiasts, academics, and representatives of historical institutions and federal agencies initiated planning for the highly anticipated 200-year anniversary of the Lewis and Clark Expedition. Formed in 1993, the National Lewis and Clark Bicentennial Council began developing a system of organization and collaboration that would assist all interested individuals, community groups and state, federal and tribal governments in "promoting programs, cultural sensitivity and harmony, and sustaining stewardship of natural and historic resources along the route of the Expedition" from 2004 to $2006 .{ }^{173}$ To achieve this goal, the Bicentennial Council established Memorandums of Understanding with a variety of federal agencies that established systems of cooperation in the planning and implementation of bicentennial activities. ${ }^{174}$ They also met quarterly with the United States Senate and the United States House of Representatives Lewis and Clark Bicentennial Caucus to provide resources for the upcoming commemoration. ${ }^{175}$ The Bicentennial Council served as a major fundraiser and fiscal agent for the national

${ }^{173}$ National Lewis \& Clark Bicentennial Council, "About Us," http://web.archive.org/web/200102050140/http://lewisandclark200.org/aboutus.html, (accessed 4 April 2011).

${ }^{174}$ Ibid.

175 "Lewis \& Clark Expedition Caucus - Mission Statement", n.d., http://classicweb.archive.org/web/20010411065315/www.lewisandclark200.org/caucusmission.html. 
coordination of bicentennial events, and together with the Department of the Interior, they identified and published all federal, state and philanthropic assistance opportunities for those hoping to undertaken a Bicentennial project. ${ }^{176}$

With the objective of encouraging historical accuracy and multi-cultural perspectives in all Bicentennial programs and materials, the National Lewis and Clark Bicentennial Council (NLCBC) established the Circle of Tribal Advisors (COTA) to assist them in promoting and encouraging tribal participation in the Bicentennial commemoration. ${ }^{177}$ Understanding the controversial role the Lewis and Clark Expedition played in the colonial devastation that occurred throughout the $19^{\text {th }}$ and $20^{\text {th }}$ centuries, the Bicentennial Council searched for ways to avoid the protests that plagued the Columbus Day anniversary celebrations in $1992 .{ }^{178}$ The post-NAGPRA historical environment also increasingly demanded collaboration with Native groups in the telling of a wellbalanced history of the Expedition. The Council, therefore, heavily integrated tribal representatives into the planning and implementation process of Bicentennial projects and events. ${ }^{179}$ Such integration encouraged an extraordinary exchange of information and perspectives that illuminated the complex history associated with the Lewis and Clark

${ }^{176}$ Kindra Ramble and Laura Volk, "Lewis and Clark Bicentennial Sourcebook: Federal, State, and Philanthropic Assistance for State and Community Projects," n.d., http://web.archive.org/web/20010226185022/http://lewisandclark200.org/, (accessed 31 March 2011).

${ }^{177}$ Lewis and Clark Bicentennial Council, "Goals Statement," Lewis and Clark Bicentennial Council, http://web.archive.org/web/20010624104333/http://www.lewisandclark200.org/goals.htm 1, (accessed 31 March 2011).

${ }^{178}$ For further reading on the controversial Columbus Day celebrations of 1992, refer to Karen Coody Cooper's Spirited Encounters (109-119).

${ }^{179}$ Ed: Roberta Conner, Edward Hall III, and Sammye Meadows, Enough Good People: Reflections of Tribal Involvement and Inter-Cultural Collaboration 2003-2006, (Grand Junction, CO: Colorado Printing Company), 9. 
Expedition and challenged the colonial myths of heroism and discovery embedded in America's contemporary imagination. As articulated by the editors of Enough Good People, the significant participation of Natives in the planning of Bicentennial events "respected everyone's ability to understand that the expedition... was not just a great, extended camping adventure but a truly pivotal episode in the conquest of Native America." 180

Significant funding was also extended to Native tribes to attract their involvement in the Bicentennial commemorations, as COTA and NLCBC members quickly realized participation in the Lewis and Clark Bicentennial commemorations was not a priority for a majority of Native groups. While an accurate representation of the history surrounding the Expedition was important to a significant number of Native groups, they were more focused on finding resources for the revitalization of their languages and cultures, the protection of their historic and cultural resources, and the provision of essential services like elderly care, education, and health care. ${ }^{181}$ To accommodate Native need with the Council's desire for tribal involvement, large grants like the National Park Service's Challenge Cost Share program were provided to federal government agencies for collaborative Bicentennial projects. COTA's Tribal Involvement Grants also offered funding for cultural preservation projects to Native groups participating in the Bicentennial commemoration. ${ }^{182}$ As articulated by Oregonian columnist and editor David Sarasohn, the Lewis and Clark Bicentennial offered tribes an unprecedented

\footnotetext{
${ }^{180}$ Conner, Hall III, and Meadows, Enough Good People, 72.

${ }^{181}$ Ibid., $72-73$.

${ }^{182}$ David Sarasohn, Waiting for Lewis and Clark: The Bicentennial and the Changing West (Portland: Oregon Historical Society Press, 2005), 5.; Ed: Conner, Hall, and Meadows, Enough Good People, 88-89.
} 
chance to "turn legends into leverage," as Native groups were enticed to participate through the provision of funding opportunities that strengthened tribal communities and produced outcomes that would far outlast the Expedition's commemoration. ${ }^{183}$ This is evident in the Chinook Indian Nation's decision to participate in the Cathlapotle Plankhouse Reconstruction Project. As best articulated by tribal member and Project Manager, Greg Robinson, participating in a project rooted in the Bicentennial commemoration "was an oil and water situation from the start. Eventually, funding possibilities that had long term benefit to the Tribe were a major force that moved us forward." $" 184$

\section{The Original Vision of the Cathlapotle Plankhouse}

With the celebration of the Lewis and Clark Expedition fast approaching, the vision of building a life-size plankhouse on the Ridgefield National Wildlife Refuge transformed from a fantasy to a reality in the early 2000s. Familiar with Anan Raymond's and Dr. Kenneth Ames' vision for the construction of a plankhouse that complimented the Cathlapotle archaeological site, Susan Saul, a former Ridgefield National Wildlife Refuge employee, presented the idea to the Lewis and Clark Bicentennial Committee of Vancouver / Clark County. Following further discussions with the U.S. Fish and Wildlife Service staff, Portland State University archaeologists, Chinook Indian Nation tribal members and interested community partners, the Lewis and Clark Bicentennial Commission of Vancouver / Clark County identified the construction

${ }^{183}$ Ibid.

${ }^{184}$ Greg Robinson to author, 24 May 2011. 
of a Chinookan plankhouse to be one of their Bicentennial "Legacy Projects" in $2002 .{ }^{185}$ In addition to attracting the attention of community supporters, this designation gave those invested in the new Cathlapotle Reconstruction Plankhouse Project increased chances for funding on the local, state and national level.

To begin the Cathlapotle Plankhouse Project, interested parties including the U.S. Fish and Wildlife Service, the Chinook Indian Nation, the Lewis and Clark Bicentennial Committee of Vancouver / Clark County, the Clark County Historic Society, the Fort Vancouver Regional Library District and the Friends of the Ridgefield National Wildlife Refuge developed a model for cooperation that would guide them in the fundraising, design, construction, and interpretation of the Cathlapotle Plankhouse. While the U.S. Fish and Wildlife Service took responsibility for technical administration and fundraising, all partners agreed to assist in the planning and implementation of projects, special events and educational and interpretive programs associated with the Plankhouse. ${ }^{186}$ With the involvement of such a diverse group of Southwest Washington historical organizations, the U.S. Fish and Wildlife Service hoped to present a balanced perspective of Cathlapotle's history while effectively promoting public messages that would ensure the protection of the area's natural and cultural resources. ${ }^{187}$

\footnotetext{
185 The Cathlapotle Plankhouse, "Cathlapotle Plankhouse Timeline", http://www.plankhouse.org/Plankhouse \%20Project\%20Timeline \%20and\%20History/Pla nkhouse\%20Timeline.htm, (accessed 21 January 2010).

186 "Memorandum of Understanding between U.S. Fish and Wildlife Service, Ridgefield National Wildlife Refuge and the Friends of Ridgefield Refuge, Clark County Historical Society of Clark County, Fort Vancouver Regional Library District, Lewis \& Clark Bicentennial Committee - Vancouver/Clark County," 13 January 2003, inactive file drawer at U.S. Fish and Wildlife Service Office, Ridgefield, Washington, accessed 23 November 2009.

${ }^{187}$ Ibid.
} 
Responsible for the funding, construction and administration of contracts for the Cathlapotle Plankhouse Reconstruction Project, the U.S. Fish and Wildlife Service divided the Project into three different phases, each with specific objectives, deadlines and measurable outcomes. Phase I of the Plankhouse Project included the acquisition of a preliminary plankhouse design, an architectural plan, working drawings, and a review of these plans by the U.S. Fish and Wildlife Service, the Chinook Indian Nation's Culture Committee, the archaeological community and the local community. ${ }^{188}$ Phase II involved all financial and logistical elements of the construction process, while Phase III included the production of public programs, curriculum materials, interpretive resources and the creation of plankhouse "accessories" like tools, traditional woven mats, and other common artifacts. ${ }^{189}$ Together, these three stages were to produce a full-scale and culturally accurate plankhouse that would serve as a living classroom for the public and a ceremonial site for the Chinook Indian Nation. ${ }^{190}$

Hoping to expand upon the success of the Cathlapotle Archaeology Project, the U.S. Fish and Wildlife Service's Region 1 Cultural Resources Team (Cultural Resources Team) envisioned a significant role for the Chinook Indian Nation in the new Plankhouse Project. With the increased likelihood of a full-scale replica materializing in 2001, U.S. Fish and Wildlife Service employees Anan Raymond and Virginia Parks met with the Chinook Indian Nation Culture Committee to discuss the project and the role the Tribe

\footnotetext{
${ }^{188}$ Friends of the Ridgefield National Wildlife Refuge, "Hugh \& Jane Ferguson Foundation - Cathlapotle Plankhouse Reconstruction Project," n.d., inactive file drawer at U.S. Fish and Wildlife Service's Region 1 Cultural Resources Office, Sherwood, Oregon, accessed 21 April 2011.

189 Ibid.

190 Ibid.
} 
might like to play. ${ }^{191}$ With this feedback, the Cultural Resource Team and Refuge employees developed a project strategy that heavily incorporated the tribal body throughout each phase of the Project. As articulated in a letter to the Chinook Indian Nation from the Manager of Ridgefield National Wildlife Refuge in April of 2002, the Cultural Resource Team and the Refuge recognized the Tribe as their most important partner in the development of a project "that is appropriate, accurate, and beneficial to the Tribe." ${ }^{192}$

To make the Chinook Indian Nation's involvement in the Cathlapotle Plankhouse Reconstruction Project significant and meaningful, the U.S. Fish and Wildlife Service hired Chinook Indian Nation member Greg Robinson as the Plankhouse construction manager. Additionally, tribal member Tony Johnson and respected carver Adam MacIssac were commissioned to embellish internal posts with Chinookan designs. Anan Raymond believed the employment of tribal members to be important, as it provided the Chinook Indian Nation proper compensation for their cultural expertise while generating a deeper sense of ownership in the Plankhouse. ${ }^{193}$ The U.S. Fish and Wildlife Service also envisioned a hands-on role for tribal members interested in the preparation of materials, the construction of the Plankhouse, and the creation of accessories that would authentically furnish the structure's interior. ${ }^{194}$

${ }^{191}$ Tom Melanson to Chinook Indian Nation Tribal Council, 24 April 2002, inactive file drawers at U.S. Fish and Wildlife's Region 1 Cultural Resources Office, Sherwood, Oregon, accessed 21 April 2010.

${ }^{192}$ Ibid.

${ }^{193}$ Raymond, interview by author.

${ }^{194}$ Art Peterson to Everyone!, 8 November 2002, inactive file drawers at the U.S. Fish and Wildlife Service's Region 1 Cultural Resources Office, Sherwood, OR, accessed 21 April 2010. 
The Cultural Resource Team also imagined a large role for community members in the development of the Plankhouse and its accoutrements. As articulated in one of the first grant applications written for the project, "public outreach during construction will be designed to encourage participation from around the region." 195 Public art workshops instructed by Chinook Indian Nation members would teach interested participants the art of splitting planks, carving roof support posts, weaving baskets and rush mats, and making tools, stone mauls, and cordage. The Cultural Resource Team also hoped to recruit volunteers from the general public to assist in the construction process through volunteer workdays. ${ }^{196}$ Such involvement, Project managers believed, would connect the community to the Plankhouse and inspire further stewardship of the Refuge's natural and cultural resources.

\section{Phase I - The Conceptual Design of the Cathlapotle Plankhouse}

To begin the first phase of the Cathlapotle Plankhouse Reconstruction Project, parties invested in the development of a full-scale Chinookan plankhouse acquired funding for the production of conceptual and construction drawings. The City of Vancouver awarded the Plankhouse Project \$5,000 through its Transient Resident Tax Grant Program, and the U.S. Fish and Wildlife Service secured \$16,000 through the Agency's Challenge Cost Share Program. Together with a $\$ 7,000$ grant from the Hugh \& Jane Ferguson Foundation and a \$1,200 contribution from the Friends of the Wildlife Refuge, Project directors were able to commission architect Art Peterson of Cedar Tree

\footnotetext{
${ }^{195}$ Friends of the Ridgefield National Wildlife Refuge, "Hugh \& Jane Ferguson Foundation."

196، Plankhouse Project Topic of Meeting: Replica Will Cost around \$300,000, (Vancouver) Columbian, 26 November 2002, C3.
} 
Architects to begin designing the plankhouse in March of 2002. ${ }^{197}$ With previous experience in the design of Pacific Northwest longhouses and smokehouses, Art Peterson was a respected tribal architect with significant understanding of Native American culture and the different functions of plankhouses.

As Peterson developed conceptual plans in the summer of 2002, the U.S. Fish and Wildlife Service focused its attention on finding grant funding for Phase II of the Project. To fund the components of the Plankhouse's foundation and flooring, the U.S. Fish and Wildlife Service secured National Park Service funding totaling $\$ 75,000$. The Bureau of Land Management, the National Forest Service, the Department of Natural Resources, and private individuals also donated over $\$ 61,000$ of trees to construct the Plankhouse's frame, walls and roof, and grant applications for the Meyer Memorial Trust, the Murdoch Charitable Trust and the Cheney Foundation were submitted to fund miscellaneous construction costs. With increasing amounts of funding secured and community anticipation mounting, the Plankhouse partners hosted a kick-off event at the Refuge in September of 2002. It was at this event that the conceptual drawings were revealed and the community got their first look at what would soon stand at the site. ${ }^{198}$ A hearth lighting ceremony was also held during the Refuge's highly popular Bluegrass and Birdfest celebrations in October. Finally, a public meeting was held in late November to explain the project in detail, update the community on fundraising efforts, and to recruit

197 Tom Melanson to Chinook Indian Nation Tribal Council, 24 April 2002.

198 The Cathlapotle Plankhouse, "Cathlapotle Plankhouse Timeline." 
volunteers for the highly anticipated craft workshops and construction working days that would commence in early $2003 .{ }^{199}$

\section{Challenges to Design Authenticity}

Despite significant collaboration between the U.S. Fish and Wildlife Service Cultural Resources Team, the Friends of Ridgefield, the Lewis and Clark Bicentennial Committee of Vancouver / Clark County, the Chinook Indian Nation, the community, and the project architect, tensions emerged towards the end of Phase I. These tensions were the direct result of interpretive inconsistencies in building codes and the safety measures required by the various levels of the U.S. Fish and Wildlife Service's bureaucracy. In its initial meeting with the Chinook Indian Nation's Culture Committee in September of 2001, the Cultural Resources Team presented the Project objective to be the construction of an authentic and culturally accurate building that would reflect what Lewis and Clark would have seen in 1805 and 1806. While enthusiastic about the potential of the project, the Tribe expressed concerns at this meeting regarding the access and safety requirements that accompany the construction of buildings on federal land. ${ }^{200}$ Incorrectly believing the Plankhouse would not be subject to mainstream code restrictions, the local Cultural Resources Team and Ridgefield National Wildlife Refuge Manager, Tom Melanson, assured the Chinook Indian Nation that the Plankhouse would be authentic. ${ }^{201}$ As conveyed by Tony Johnson, a member of the Chinook Indian

\footnotetext{
${ }^{199}$ Mhari Doyle, "Plank House Starts Warmly," (Vancouver) Columbian, 14 October 14, 2002, C1.

${ }^{200}$ Chinook Indian Nation Culture Committee, interview by author.

${ }^{201}$ Raymond, interview by author.
} 
Nation's Culture Committee, the Tribe was "led to believe that the [U.S.] Fish and Wildlife Service would have a level of freedom in building the Plankhouse that would allow us...to one hundred percent replicate a traditional longhouse., ${ }^{202}$ Archaeologist Anan Raymond supports this statement, admitting the local office of the U.S. Fish and Wildlife Service "developed expectations on the part of the tribe about what [Cathlapotle] was going to be like without checking what all of the rules were."203

The Cultural Resources Team's vision for the construction of an authentic, traditional Plankhouse was also conveyed to the project architect, Art Peterson, at the beginning of the design process. Understanding the purpose of the Project to be focused on authenticity and the recovery of traditional methods of construction, Peterson collaborated with the Chinook Indian Nation's Culture Committee, the Ridgefield National Wildlife Refuge staff, the U.S. Fish and Wildlife's Cultural Resources Team, and archaeologist Dr. Kenneth Ames to design a building that reflected as many traditional interior and exterior elements as possible. ${ }^{204}$ The experienced architect, therefore, designed the Plankhouse using the code requirements of a "New Cultural Property." This classification, Peterson believed, provided the U.S. Fish and Wildlife Service the authority to free the Plankhouse from the strictest access and safety requirements for cultural and historical reasons. ${ }^{205}$ With the Service's provision of a design brief that prioritized authenticity, Peterson assumed there would be no issue in

${ }^{202}$ Chinook Indian Nation Culture Committee, interview by author.

${ }^{203}$ Raymond, interview by author.

${ }^{204}$ Cedar Tree Architects, "Plankhouse Code Review and Summary," 5 October 2003, inactive file drawers at the U.S. Fish and Wildlife Service's Region 1 Cultural Resources Office, Sherwood, Oregon, accessed 21 April 2010.

${ }^{205}$ Ibid. 
gaining the waivers necessary to reduce code restrictions that impeded on the structure's traditional appearance.

While the staff of the Ridgefield National Wildlife Refuge, the U.S. Fish and Wildlife Service's Cultural Resources Team, and the Cathlapotle Plankhouse Design Committee supported Art Peterson's petition for flexibility in the interpretation of building codes, different levels of U.S. Fish and Wildlife Service bureaucracy proved less willing to consider alternatives for standard access and safety measures. Approached in the final stages of the design process, the U.S. Fish and Wildlife Service's Division of Engineering reviewed Art Peterson's drawings in June of 2003 and pinpointed a number of potential hazards and non-compliance issues. Among these issues was the need for an additional hinged exit door, a photoluminescent exit sign, and a fire protection engineering review to determine whether fires would be able to be burned within the structure. $^{206}$ The Regional Safety Office also reviewed the plans and identified a number of concerns regarding compliance with National Fire Protection Association requirements. Art Peterson's design, according to this office, did not adequately address the fire safety hazards associated with hosting an open fire and air quality issues related to uncontained combustion and visitor health. Additionally, improper signage, door hardware, fire department access and water supply, and emergency lighting were not

${ }^{206}$ Alan Williams to Tom Melanson and Rebecca Young, "Plankhouse SOP and Design Comments," 3 June 2003, inactive file drawers at the U.S. Fish and Wildlife Service's Region 1 Cultural Resource Office, Sherwood, Oregon, accessed 21 April 2010; Thomas Mackenzie to Gregory Hranac, "Cathlapotle Plankhouse: Project Number 2030221," 7 August 2003, accessed 30 July 2011. 
provided as required. ${ }^{207}$ Such difference in code interpretation greatly threatened the authentic quality of the proposed Plankhouse, as it required the installation of features that would visually contaminate the structure's traditional presentation. Fire also plays a vital role in Chinook Indian Nation ceremonies, providing warmth, light, and life to the Tribe and the venue. Without fires, the structure would be ineffective as a ceremonial structure for the Chinook Indian Nation.

In an effort to resolve the issues identified by the United States Fish and Wildlife Service's Engineering Division and Regional Safety Office, members of the Plankhouse design team expeditiously met with representatives from the these departments at Fort Stevens Long House near Astoria, Oregon. ${ }^{208}$ Here, invested parties in the Plankhouse Project discussed safety issues with representatives from the Regional Engineering Office. Taking note of the way in which the Fort Stevens Long House approached code issues of a similar nature, parties of this meeting concluded that further research was necessary to uncover potential alternatives to safety measures that could be made to maintain the structure's authentic feel. Meeting attendees also agreed that an independent fire safety plan review would be performed and Art Peterson would produce an additional plan review that justified his application of code requirements in his original design. ${ }^{209}$

207 "Briefing Paper: Cathlapotle Plankhouse EN/Safety Issues," 23 February 2004, inactive file drawers at the U.S. Fish and Wildlife Service Regional Safety Office, Portland, Oregon, accessed 30 June 2011.

${ }^{208}$ Art Peterson to Dana Perez, Al Williams, Marv Henry, and Greg Hranac, 8 August 2003, inactive file drawers at the U.S. Fish and Wildlife Service's Region 1 Cultural Resources Office, Sherwood, Oregon, accessed 21 April 2011.

${ }^{209}$ Ibid. 
In his Plankhouse Code Review and Summary completed on October 5, 2003, architect Art Peterson defended his application of building codes within his original design. According to Peterson, six key code issues were at hand: the use and occupancy classification of the building, the allowed occupant load, the egress requirements and number of mandated exits, the building construction type, the construction of open flame devices, and the holding of special events. ${ }^{210}$ As previously explained, Peterson designed the Cathlapotle Plankhouse to qualify as a "New Cultural Property." Such a designation gave the structure code-allowed flexibility to accept alternative and equivalent safety design features that would not compromise the authentic appearance of the Plankhouse. ${ }^{211}$ Peterson also argued for a "Small Assembly Use Occupancy" that would limit the Plankhouse to a capacity of 49 people or less. This limit, Peterson conveyed, would eliminate the requirement for illuminated exit signs and one instead of two emergency exit door would be required. ${ }^{212}$ Cedar Tree Architects also identified code exceptions that allowed open flame devices to be used for ceremonial purposes and special events without a U.S. Fish and Wildlife Service representative present. ${ }^{213}$ With necessary precautions integrated into the Plankhouse's Standard Operating Procedures, Art Peterson argued, his original design successfully balanced the demands of $21^{\text {st }}$ century safety standards with the Plankhouse Project's objective for cultural authenticity. ${ }^{214}$

${ }^{210}$ Cedar Tree Architects, "Plankhouse Code Review and Summary."

${ }^{211}$ Ibid.

${ }^{212}$ Ibid.

${ }^{213}$ Ibid.

${ }^{214}$ Ibid. 
Upon receipt of Art Peterson's code review, the U.S. Fish and Wildlife Service's Regional Safety Office drafted a rebuttal Safety and Fire Protection Review that proposed significant changes to Peterson's original design concept. ${ }^{215}$ As articulated in the October draft of this review, the Department of the Interior policy requires all Agency buildings to abide by the minimum standard of the National Fire Protection Association's Life Safety Code 101. The U.S. Fish and Wildlife Service, therefore, was required to meet the minimum requirements of this Safety Code and exceptions would not be made for the sake of cultural authenticity. As stated by the author of the draft:

Although there is a great desire among members of the Steering Committee, there are no known mandates or regulations to design this building to be authentic...There are, however, mandates to meet fire and safety regulations. There are many recent cases (some are in the news right now) where inappropriate decisions regarding safety/fire protection have resulted in charges of criminal liability. Even more important, we would not want to see harm occur to others... While the desire of the Steering Committee to maintain authenticity is commendable, there is a need for some concessions. ${ }^{216}$

These concessions included a different occupancy classification, the prohibition of open flames, the addition of another exit door, the installation of exit lighting, and the prohibition of nighttime activities. ${ }^{217}$ With construction of the Plankhouse needing to commence with changing weather conditions and the completion of specific grant timelines, the U.S. Fish and Wildlife Service's Regional Engineering Office

215 "DRAFT - Cathlapotle Plankhouse Project, Safety/Fire Protection Review," 8 October 2003, inactive file drawer at the U.S. Fish and Wildlife Service's Region 1 Cultural Resources Office, Sherwood, Oregon, accessed 21 April 2010.

${ }^{216}$ Ibid.

${ }^{217}$ Ibid. 
recommended "careful consideration of the work that is completed on the Plankhouse" while these issues were being resolved. ${ }^{218}$

\section{Phase II - The Erection of the Cathlapotle Plankhouse}

Despite reaching no solution to the code issues that plagued Phase I of the Cathlapotle Plankhouse Reconstruction Project, construction commenced on 1 November 2003. Project partners held a post raising ceremony at the future site of the Cathlapotle Plankhouse to mark the beginning of Phase II. As part of these celebrations, Chinook Indian Nation members Sam Robinson and Gary Johnson and Portland State University's Dr. Kenneth Ames described life inside Chinookan plankhouses from a cultural and anthropological perspective. Key local officials also spoke, including Clark County Commissioner Betty Sue Morris, Lewis and Clark Bicentennial Committee of Vancouver / Clark County Executive Director Arlene Johnson, and Ridgefield Mayor Tim Thompson. ${ }^{219}$ Most importantly, U.S. Fish and Wildlife Service Regional Director David Allen gave a speech, in which he promoted the successful partnerships that had "turned the vision of 'building a future for the past' into a reality."220 Discussion of strong partnerships and successful collaboration proved to be a reflection of times past, however, as tensions between $21^{\text {st }}$ century safety standards and the production of a culturally authentic plankhouse increasingly threatened the once strong partnership of the U.S. Fish and Wildlife Service and the Chinook Indian Nation.

218 Ibid.

${ }^{219}$ Dean Baker, "Plank house's first posts to be set in place," (Vancouver) Columbian, 30 October 2003, C1.

220 “Talking Points for Regional Director Dave Allen for the Cathlapotle Plankhouse Project Post Raising Ceremony," 1 November 2003, inactive file drawer at the U.S. Fish and Wildlife Service's Region 1 Cultural Resources Office, Sherwood, Oregon, accessed 21 April 2010. 
As weekly $\log$ preparation workshops commenced at the end of 2003, a newly formed Steering Committee comprised of representatives from the Ridgefield National Wildlife Refuge, the Cultural Resources Team, the Chinook Indian Nation, Lewis and Clark Bicentennial Committee of Vancouver / Clark County, and the public met on a weekly basis to devise solutions to the code issues identified by the U.S. Fish and Wildlife Service's Regional Engineering Office. Responsible for unintentionally misleading the Chinook Indian Nation in regards to code requirements, the Cultural Resources Team and the employees of the Ridgefield National Wildlife Refuge extensively researched the application of safety and access codes in other federal buildings throughout the nation. As articulated by Chinook Indian Nation Culture Committee member Tony Johnson:

They did look at, I am sure, every nuance of their regulation. They also really looked at a lot of pre-existing facilities to say, 'Hey! At this particular location, maybe all the way back on the east coast, there is an open fireplace.' They really did work to accommodate this... Nobody heard that it had be $100 \%$ compliant with code and just rolled over. ${ }^{221}$

In his Plankhouse Code Review and Summary, Art Peterson also examined existing historic replicas and analyzed how they addressed safety and accessibility standards. In his analysis, Peterson noted the Clatsop Plankhouse at Ft. Stevens State Park had only one accessible doorway, no electricity, no running water, no fire extinguishers, and no fire control equipment, while the Siletz Tribal Longhouse had a single traditional entry, no electricity, no running water, no fire equipment, an open fire and no devices for smoke removal. His original design for the Cathlapotle Plankhouse, therefore, was far superior to both existing structures in terms of accessibility, egress, and availability of fire

${ }^{221}$ Chinook Indian Nation Culture Committee, interview by author, 22-23. 
suppression equipment. He also examined the replica of Fort Clatsop at the Fort Clatsop Lewis and Clark National Memorial. With a strict Fire Plan that closely reflected the fire safety precautions proposed in Peterson's Standard Operating Procedures, Fort Clatsop managed daily open fires and the use of candles in their interpretive programs. With the National Park Service's concerns for public safety mitigated by this Fire Plan, Peterson argued the Fort set a precedent for the flexible interpretation of code by a federal government agency for the sake of authenticity in the design of historical reconstructions. ${ }^{222}$

Despite the discovery of existing historical constructions that used alternative measures to fulfill safety requirements, the U.S. Fish and Wildlife Service's Regional Engineering Office stood strong in their requirement for the Plankhouse to meet the minimum code standards. As more and more options were investigated and ruled out, frustration mounted amongst the Steering Committee. This frustration is evident in Pat Campbell's email to his fellow Committee members:

We are beyond the time when this project can go forward without compromise from EVERYONE involved. Please leave your egos and agendas at home. A unilateral "decision" that does not meet every party's legitimate concerns is FAILURE. Withdrawal of any party from the project is FAILURE. Not meeting the parameters given to donors and community is FAILURE. If no accommodation to these concerns can be reached, we will never even approach the vision so carefully crafted from the outset by Refuge, Tribe and Community. We may not complete it at all. ${ }^{223}$

To begin this process of compromise, partners agreed to restate their objectives and priorities for the Project in writing on December 2, 2003. What resulted from this

${ }^{222}$ Cedar Tree Architects, "Plankhouse Code Review and Summary."

${ }^{223}$ Pat Campbell to Steering Committee Members, "We HAVE to make this work!," 9 December 2003, inactive file drawer at the U.S. Fish and Wildlife Service's Region 1 Cultural Resources Office, Sherwood, Oregon, accessed 21 April 2010. 
exercise was a powerful conversation that brought cultural issues to the forefront of discussions on building codes and safety requirements. As articulated by then Culture Committee Chairman Gary Johnson, the Tribe was dedicated to Art Peterson's original design concept, as it stayed "true to [their] ancestors' sensibilities" and allowed members of the general public to understand just how ingenuous and wealthy their ancestors were. ${ }^{24}$ Believing Peterson's Code Review to have established a concise, legal path for the completion of an authentic plankhouse, Johnson asserted the Regional Engineering Office's continued "attempts to modify the plankhouse [were] seen as criticisms of [the Chinook Indian Nation's] ancestors' technology and culture."225 At a later meeting with Plankhouse partners, the mounting cultural frustrations of the Chinook Indian Nation were further expressed by elder Anna May Strong. As recalled by Tony Johnson, who was present at this meeting:

She said at one point in a meeting with those folks that basically implied that Chinook people love each other, care about each other, and if you cared about your people, you would facilitate their entrance and exit from the longhouse through its traditional door in the same way that our people would. That is, if I cannot go through that door, someone is going to pick me up and carry me through the door. This is a really strong statement on her part, I thought, because she basically said, "I kind of challenge the cultural beliefs of the folks involved. You have to facilitate every little issue because nobody is looking out for each other." I remember that very very clearly from the conversations we were having around code compliance. ${ }^{226}$

${ }^{224}$ Gary Johnson, "Chinook Indian Nation / Cathlapotle Plankhouse Project Statement of Support and Position," 29 December 2003, inactive file drawer at the U.S Fish and Wildlife Service's Region 1 Cultural Resource Office, Sherwood, Oregon, accessed 21 April 2010.

${ }^{225}$ Gary Johnson, "Statement of Support and Position."

${ }^{226}$ Chinook Indian Nation Cultural Committee, interview with author. 
For the Chinook Indian Nation, deviations from the project's original plan did not represent a reasonable compromise that would maintain the spirit of the project. ${ }^{227}$ Instead, changes to the design would represent yet another broken promise in the Chinook Indian Nation's long history with the federal government. As expressed by architect Art Peterson in early 2004, design compromises by the Chinook Nation would make the Plankhouse "yet another white man building."228

With the fate of the project resting on the Steering Committee's ability to balance modern code requirements with the demand for cultural authenticity, project partners considered approaching the U.S. Fish and Wildlife Service's Regional Director for involvement in the decision-making process. Within the U.S. Fish and Wildlife Service, it was the authority of the Regional Director alone to override the findings of the U.S. Fish and Wildlife Regional Engineering Office. ${ }^{229}$ While some on the Steering Committee believed an appeal to the Director "was a stretch at best, ${ }^{, 230}$ architect Art Peterson strongly supported this action, as he felt the Regional Engineering Office's "stubborn display of cultural ignorance, insensitivity and overt disrespect for the heritage of the Plankhouse and the Chinook People served to precipitate divisions among project participants, squander volunteer and consultant time, money and staff resources, create

227 "Statement of Position by the Chinook Indian Nation: A Perspective on the Developing Challenges Facing the Cathlapotle Plankhouse Project," no author or date disclosed, provided by Gary Johnson at the Chinook Cultural Committee meeting, June 8, 2010.

${ }^{228}$ Letter form Art Peterson to David Allen, "Re: the Cathlapotle Plankhouse," February 18, 2004, inactive file drawer at the U.S. Fish and Wildlife Service's Region 1 Cultural Resources Office, Sherwood, Oregon, accessed 21 April 2010. ${ }^{229}$ Ibid.

230 "An Evaluation of Challenges Faces the Cathlapotle Plankhouse Project," n.d., inactive personal files of Gary Johnson, Chinook, Washington, accessed 8 June 2010. 
delays in (the) construction schedule and raise questions about their interest or ability to even provide plan and construction approval to create a traditional, authentic and culturally useful Plankhouse."231 With legal and moral obligations to project financers, volunteers and the community to build an authentic Chinookan Plankhouse, Peterson personally requested a meeting with the Regional Director in mid-February $2004 .^{232}$

The Regional Director granted the Steering Committee a meeting on 1 April 2004. In preparation for this meeting, the Regional Engineering Office also conducted research on different plankhouses and longhouses throughout the nation. Specifically, the Regional Engineering Office searched for precedent upon which to issue waivers to specific code requirements that infringed on the structure's authenticity. After visiting several National Park Service sites and consulting with legal counsel, Regional Director David Allen determined that neither he, nor anyone else in the U.S. Fish and Wildlife Service, had the authority to waive the building code requirements. ${ }^{233}$ This meant changes to Art Peterson's original design were inevitable, much to the dismay of Steering Committee members. To help the Project move forward within a framework of compromise, the Regional Director established the Project Management Team (PMT). This team included members with various interests in the construction of the Plankhouse, including three Chinook Indian Nation members (including Project Manager, Greg Robinson), the Ridgefield National Wildlife Refuge Manager, U.S. Fish and Wildlife

${ }^{231}$ Art Peterson to David Allen, "The Cathlapotle Plankhouse." ${ }^{232}$ Ibid.

${ }^{233}$ Paul Rauch to Sam Whittington, "Help!," 25 February 2011, inactive file drawer at the U.S. Fish and Wildlife Service Regional Office, Portland, Oregon, accessed 30 June 2011; "Cathlapotle Plankhouse - Regional Director's Talking Points, Meeting with Steering Committee," 1 April 2004, inactive file drawer at the U.S. Fish and Wildlife Service's Regional Office, Portland, Oregon, accessed 30 July 2011. 
Service Cultural Resources Team member Anan Raymond, and two representatives from the U.S. Fish and Wildlife Service Regional Engineering Office. ${ }^{234}$ Each team member had designated roles and responsibilities in the continuation of the project, and a tentative schedule of benchmarks was established. ${ }^{235}$ A conflict resolution mechanism was also incorporated to resolve any issues that had a stakeholder reaching an impasse. ${ }^{236}$

Although a Project Management Plan was drafted throughout the summer of 2004, the Project Management Team first met on 15 April 2004. Despite high hopes for the most recent collaborative system, miscommunication at this meeting over the decision-making process related to occupancy limitations initiated the withdrawal of architect Art Peterson and Steering Committee members Pat Campbell and Truman Sturdevant. ${ }^{237}$ In his memorandum to the Friends of the Ridgefield National Wildlife Refuge on14 May 2004, Peterson stated:

The project that we envisioned...has changed to the point that it is an entirely different project. While I enthusiastically embraced the project that we envisioned two years ago, I would not have agreed to become involved in the project as it is described today. The project has also suffered suspensions, delays, the resignation of key participants, and uncertainties that have made it impossible to maintain any sense of progress or continuity for many months. ${ }^{238}$

${ }^{234}$ U.S Fish and Wildlife Service Division of Engineering R-1, "Draft Project Management Plan," 9 September 2004, inactive file drawer at the U.S. Fish and Wildlife Service's Region 1 Cultural Resources Office, Sherwood, Oregon, accessed 21 April 2010.

235 Ibid.

236 Ibid.

237 "Steering Committee Minutes," 6 May 2004, inactive archive at the U.S. Fish and Wildlife Service Regional Office, Portland, Oregon, accessed 30 July 2011.

${ }^{238}$ Art Peterson to James Maul, "Re: Owner-Architect Agreement for the Cathlapotle Plankhouse Reconstruction Project," 14 May 2004, inactive personal files of Gary Johnson, Chinook, Washington, accessed 8 June 2010. 
Similarly, the Chinook Indian Nation Tribal Council passed a motion to withdraw from the Plankhouse Project, as they felt a unilateral decision had been made by U.S. Fish and Wildlife Service regarding this issue. Expressing their disappointment in the U.S. Fish and Wildlife Service's domination of the partnership, Culture Committee Chairman Gary Johnson wrote:

We, like the recently resigned Steering Committee members, cannot recover what has been invested over many years into this project. As is our experience with nearly two centuries of experience with the United States Government promises made have been broken, and the Chinook people are left with very little of substance. ${ }^{239}$

While the Regional Director clarified the miscommunication shortly after these statements, Art Peterson stood by his resignation from the project. ${ }^{240}$ In the meantime, negative press coverage threatened future funding opportunities and lowered volunteer morale within the Project, while the Chinook Indian Nation proceeded cautiously with feelings of betrayal and isolation from the decision-making process. As explained by construction manager, Greg Robinson, this period of time consisted of "a volatile mixture of circumstances that pose[d] a direct threat to completing [the] project."241 While all parties chose to continue in the design and construction process, they did so on extremely unsteady ground.

In order to stop a yearlong stalemate between the Chinook Indian Nation and the U.S. Fish and Wildlife Service, the partners of the Cathlapotle Plankhouse

${ }^{239}$ Gary Johnson to David Allen, 8 May 2004, inactive personal files of Gary Johnson, Chinook, Washington, accessed 8 June 2010.

240 Ibid.

${ }^{241}$ Greg Robinson to Steering Committee Members, "Update," 3 April 2004, inactive file drawer at the U.S. Fish and Wildlife Service Regional Office, Portland, Oregon, accessed 30 July 2011. 
Reconstruction Project modified their objectives and rewrote their mission statement for the structure. Realizing they were now dealing with an entirely new project that had shifted away from the cultural concepts initially agreed upon in 2002, the Chinook Indian Nation reluctantly accepted the notion of a modern plankhouse with a high occupancy limit and all of the safety requirements that accompanied it. ${ }^{242}$ As expressed at a Steering Committee Meeting in July of 2004, the Tribe felt they were in a "no win scenario," as a low occupancy would not accommodate all of its members and a high occupancy compromised the structure's authentic design. With no ideal path to travel, the Chinook Indian Nation made compromises that allowed the design and construction of the Plankhouse to significantly progress over the next six months. Additional contractors were hired to assist Greg Robinson in the erection of the structure, and an Interior Committee was formed to develop plans for the decoration and interpretation of the Plankhouse's internal features. Despite the Tribe's active assistance in this process, Greg Robinson forecasted minimal presence of the Tribe when the modified Plankhouse was completed. ${ }^{243}$ With the installation of modern safety features and no decision made regarding the Tribe's ability to light fires within the Plankhouse, the Chinook Indian Nation seriously questioned the structure's ability host important spiritual ceremonies. After a series of air quality tests that produced contradictory results, fires are only burned within the Plankhouse during private Chinook Indian Nation ceremonies. Before each of

${ }^{242}$ G. Robinson to author, 24 May 2011; “Cathlapotle Plankhouse Project, Steering Committee Minutes," 20 July 2004, inactive file drawer at the U.S. Fish and Wildlife Service Regional Office, Portland, Oregon, accessed 30 June 2011.

243 "Cathlapotle Plankhouse Project, Steering Committee Minutes," 20 July 2004, inactive file drawer at the U.S. Fish and Wildlife Service Regional Office, Portland, Oregon, accessed 30 July 2011. 
these ceremonies, the Tribal Chairman is required to sign a liability waiver releasing the U.S. Fish and Wildlife Service from all liability, claims, deaths and damages. ${ }^{244}$ No fires are burned at public events.

\section{The Cowlitz Indian Tribe}

In addition to the cultural tensions that surrounded the discussion of code compliance and safety regulations in early 2004, the Cathlapotle Plankhouse Reconstruction Project also faced significant financial challenges that were the result of unresolved issues with the Cowlitz Indian Tribe. In June of 2002, the Cowlitz Indian Tribe contacted the U.S. Fish and Wildlife Service to discuss the proposed Plankhouse Project. Having declined participation in the Cathlapotle Archaeology Project in 1993, the newly recognized Cowlitz Tribe now had the capacity and the interest to challenge the cultural affiliation of the Cathlapotle site in 2002. Believing the site to have been a Cowlitz village, Tribe officials entered into a two-year debate over the historic validity of the U.S. Fish and Wildlife Service's assertions that Cathlapotle was a Chinookan village. The Cowlitz also suggested it was inappropriate for the U.S. Fish and Wildlife Service to collaborate with the unrecognized Chinook Indian Nation in a project where the Cowlitz Tribe was a stakeholder. These claims "created a difficult and often emotional struggle for control of the cultural resources of Cathlapotle." ${ }^{245}$ While the details of this struggle are beyond the scope of this examination, it is important to note that in-depth analysis of

\footnotetext{
244 "Memorandum of Understanding between the United States Fish and Wildlife Service and the Chinook Indian Nation," 14 March 2005, inactive file drawer at the U.S. Fish and Wildlife Service's Ridgefield National Wildlife Refuge Office, Ridgefield, Washington, accessed 23 November 2009.

${ }^{245}$ Jon D. Daehnke, “A 'Strange Multiplicity’ of Voices,” 259.
} 
archaeological, historical, ethnographic, and linguistic evidence on the part of the U.S.

Fish and Wildlife Service Cultural Resources Team resulted in the agency defending the Chinookan heritage of the Cathlapotle site. ${ }^{246}$ This stance had a great effect on the Plankhouse Project's ability to progress in construction. It would also put the U.S. Fish and Wildlife's Cultural Resource Team in the middle of a dispute between an unrecognized but highly respected tribal partner and an unfamiliar tribe with legal rights to consultation.

Unhappy with the way in which the U.S. Fish and Wildlife Service conducted consultation regarding the Cathlapotle Plankhouse Reconstruction Project, the Cowlitz Indian Tribe contacted the Ridgefield National Wildlife Refuge Manager in January of 2004 to express their concern regarding the Service's improper engagement in a government-to-government relationship with a recognized tribe. ${ }^{247}$ Correspondence between the two parties in the following month brought little progress or compromise, leading the Cowlitz Indian Tribe to seek "outside help" in the matter. Washington State Historical Society Director David Nicandri and U.S. Fish and Wildlife Service Tribal Liaison Scott Aiken responded to this request by stepping in to mediate the dispute in February $2004 .{ }^{248}$ In the meantime, $\$ 220,000$ of the Washington State Department of Transportation grant funding ear-marked for the reconstruction of the Cathlapotle

\footnotetext{
246 Tom Melanson to John Barnett, 20 February 2004, inactive file drawer at the U.S. Fish and Wildlife Service's Ridgefield National Wildlife Refuge Office, Ridgefield, Washington, accessed 23 November 2009.

${ }^{247}$ John Barnett and Mike Iyall to Tom Melanson, 5 January 2004, inactive file drawer at the U.S. Fish and Wildlife Service's Region 1 Cultural Resources Office, Sherwood, Oregon, accessed 21 April 2010; Tom Melanson to David Nicandri, 14 January 2004, inactive file drawer at the U.S. Fish and Wildlife Service's Ridgefield National Wildlife Refuge Office, Ridgefield, Washington, accessed 23 November 2009.

${ }^{248}$ Daehnke, "A 'Strange Multiplicity' of Voices," 267.
} 
Plankhouse was frozen pending further investigation into the Cowlitz's claims. ${ }^{249}$ Without the Department of Transportation funding, the Plankhouse Steering Committee was forced to lay off Greg Robinson and contracted carvers Tony Johnson and Adam MacIssac due to insufficient funds. ${ }^{250}$ Until a resolution with the Cowlitz was reached and the Department of Transportation funding was released (or matching funds for another grant could be acquired), construction of the Plankhouse was at an indefinite standstill.

In a series of meetings that took place from February to April of 2004, issues surrounding the Cowlitz's claims over Cathlapotle and the U.S. Fish and Wildlife Service's methods of consultation with the Cowlitz Tribe and the Chinook Indian Nation were discussed in-depth. What resulted from this mediation were two Memorandums of Understanding that developed a consultation model for future cooperation in the Cathlapotle Plankhouse Project. The U.S. Fish and Wildlife's Memorandum of Understanding with the Cowlitz recognized the Tribe's right to participate in the development and review of all educational, interpretive, and cultural materials relevant to the their presence at Cathlapotle between 1830 and $1850 .^{251}$ The agreement also stated the term "Chinook" would not be used to describe the residents of Cathlapotle, as the Cowlitz Tribe felt this term implied a direct link of Cathlapotle's ancestors to the

249 "Cathlapotle Plankhouse Project Steering Committee Minutes," 22 January 2004, inactive file drawer at the U.S. Fish and Wildlife Service's Region 1 Cultural Resources Office, Sherwood, Oregon, accessed 21 April 2010.

${ }^{250}$ Ibid.

251 "Memorandum of Understanding between the U.S. Fish and Wildlife Service and the Cowlitz Tribe of Indians," 16 June 2004, inactive file drawer at the U.S. Fish and Wildlife Service's Ridgefield National Wildlife Refuge Office, Ridgefield, Washington, accessed 23 November 2009. 
modern-day Chinook Indian Nation without addressing the historical complexities of identity within the region. ${ }^{252}$ The U.S. Fish and Wildlife Service, in return, maintained their principal relationship with the Chinook Indian Nation in the Plankhouse design and construction process. ${ }^{253}$ As asserted in the U.S. Fish and Wildlife's Memorandum of Understanding with the Chinook Indian Nation, the tribe was the "principal organization that exclusively embodie[d] and perpetuate[d] the traditional and modern culture of the Chinookans of the greater lower Columbia River, including the Cathlapotle Chinookans who historically lived on what is now the Refuge." ${ }^{254}$ With the two Memorandums of Understandings agreed upon and signed, David Nicandri released the Department of Transportation funding in June 2004. ${ }^{255}$ Although construction had already recommenced with the receipt of additional grant funding in late March, the Department of Transportation funds gave the Plankhouse Project the financial stability needed to assure its completion.

\section{The Result}

On 26 March 2005, members of the Chinook Indian Nation entered the completed Plankhouse for the first time to cleanse the building in preparation for its opening to the public. ${ }^{256}$ After three years, $\$ 575,000$, and approximately 3,500 volunteer hours, the fantasy of a full-scale plankhouse standing on the Ridgefield National Wildlife Refuge

252 Daehnke, “A 'Strange Multiplicity' of Voices,” 268.

253 "Memorandum of Understanding with Cowlitz."

254 "Memorandum of Understanding with Chinook Indian Nation."

${ }^{255}$ Daehnke, “A 'Strange Multiplicity' of Voices,” 268.

${ }^{256}$ Gary Johnson, "Plankhouse Opening," 29 March 2005, inactive personal files of Gary Johnson, Chinook, Washington, accessed 8 June 2010. 
had become a reality for the U.S. Fish and Wildlife Service, the Chinook Indian Nation and the Lewis and Clark Bicentennial Committee of Vancouver / Clark County. ${ }^{257}$ Standing 78 feet long, 37 feet wide and 20 feet tall, the "one of a kind" cedar Plankhouse reflected years of academic research and cross-cultural collaboration in every intricate detail of the building. ${ }^{258}$ Hand-split cedar logs and roof planes textured with traditional adzes emphasized the beauty and character of traditional Chinookan structures, and internal adornment of the Plankhouse posts and traditional doorway showcased a history of exquisite artistic expression. ${ }^{259}$ Also present in the building were features that represented safety requirements of the $21^{\text {st }}$ century, including a wheelchair ramp, emergency exit lighting, emergency doorways, and a mechanized smoke ventilation system that would later be removed. ${ }^{260}$

After three years of cultural struggle that resulted in the construction of a building with traditional and modern features, many in the community wondered whether the Cathlapotle Plankhouse would satisfy both the cultural needs of the Chinook Indian Nation and the educational needs of the U.S. Fish and Wildlife Service. While only time would answer this question fully, the sentiments expressed at the Plankhouse opening on 29 March 2005 indicated the historical reconstruction would, indeed, fulfill the objectives

257 Toby McClary, “Chinookans Bring Traditional Plankhouse to Life," Smoke Signals, Chinook Tribe's Traditional Plankhouse Dedication Pullout, (April 15, 2005): 1.

258 “Cathlapotle Plankhouse: Ridgefield National Wildlife Refuge, WA," n.d., inactive personal files of Gary Johnson, Chinook, Washington, accessed 8 June 2010; Foster Church, "Just like old times," Oregonian, 18 March 2005, C1.

${ }^{259}$ Foster Church, "Chinook elders lead way into the Plankhouse," Oregonian, 30 March 2005, D4.

${ }^{260}$ Emily Sohn, "Board Rooms: Near Portland, Oregon, Archaeologists and Indians Have Built an Authentic Chinookan Plankhouse like those Lewis and Clark Saw," Smithsonian (July, 2005): 33. 
of the two project partners. As 150 volunteers and community members filed into the Plankhouse to the sound of Native drummers and singers, the public and project partners alike had the first opportunity to experience the grandeur and cultural richness of what once was the Cathlapotle village. ${ }^{261}$ As expressed by Chinook Indian Nation Tribal Council member Sam Robinson, “I didn't think the plankhouse would have the spiritual feel we originally hoped it would...but when we opened it up and blessed it, there was great pride in it." ${ }^{262}$ This pride could be sensed in Gary Johnson's speech to the Plankhouse visitors when he asked the crowd to look around at the cedar that comprised the entire building. According to Johnson, that cedar was "the keeper of all knowledge" and an important source of cultural renewal for the Chinook Indian Nation. ${ }^{263}$

261 "Cathlapotle Plankhouse Door Opening Program," 29 March 2005, inactive personal files of Gary Johnson, Chinook, Washington, accessed 8 June 2010.

${ }^{262}$ Sam Robinson as quoted in Sohn, "Board Rooms," 33.

${ }^{263}$ Gary Johnson, "Plankhouse Opening," n.d., inactive personal files of Gary Johnson, Chinook, Washington, accessed 8 June 2010. 


\section{CHAPTER III}

\section{CATHLAPOTLE IS: INTERPRETIVE IMPLICATIONS OF A HERITAGE SITE}

While the Cathlapotle Plankhouse Reconstruction Project partners shared a common goal of building a full-scale Chinookan plankhouse on the Ridgefield National Wildlife Refuge, each organization had different motivations that guided the decisionmaking process. Anthropologist James Clifford argues "negotiated reciprocities are increasingly the norm" in post-NAGPRA collaborations with indigenous populations, bringing groups with diverse agendas together to work towards common objectives in an equitable and respectful manner. ${ }^{264}$ While these varying agendas often generate more thorough and comprehensive outcomes, they also require a degree of compromise that inevitably challenges each participant's expectations of the project. The intended uses of the Cathlapotle Plankhouse required each project partner to make concessions that altered their originally envisioned outcome. As a result, it is important to examine what roles have been placed on the Plankhouse since the Reconstruction Project's inception in 2002. After all of the hard work, conflict, and compromise that marked the construction process, does the Plankhouse function as the educational center that the U.S. Fish and Wildlife Service envisioned? And does the site adhere to the cultural and spiritual expectations of the Chinook Indian Nation?

${ }^{264}$ Clifford, "Looking Several Way," 6. 


\section{The Cathlapotle Plankhouse as an Outdoor Educational Center}

As it operates today, the Cathlapotle Plankhouse is first and foremost an outdoor educational center on a wildlife refuge that teaches visitors about the opulent cultural and natural history of the Ridgefield National Wildlife Refuge. ${ }^{265}$ Using carefully constructed interpretive programs that emphasize the rich materiality of the reconstructed plankhouse and the contextual significance of the surrounding site, the U.S. Fish and Wildlife Service, in partnership with the Friends of the Ridgefield National Wildlife Refuge and the Chinook Indian Nation, aspires to provide visitors a glimpse of what life would have been like on the Refuge a few hundred years ago. To avoid the static qualities commonly associated with museum exhibits, partners of the Reconstruction Project designed the Plankhouse to be "a living place" that allowed visitors to interact with physical representations of the past in an environment that contextualizes those representations.

According to anthropologist Laura Peers, "historic reconstructions are distinctive forms of communication and experience because of their rich materiality., ${ }^{, 266}$ In her study of historic reconstructions in North America, Peers observed that visitors responded strongly to the physical stimuli prevalent in historic reconstructions. Opportunities to touch, taste, smell, hear and view different aspects of historic sites act as a catalyst for visitor contemplation that often leads to questions and conversations about less

265 "Standard Operating Procedures - Draft," 17 January 2006, inactive file drawers at the U.S. Fish and Wildlife Service's Region 1 Cultural Resources Office, Sherwood, Oregon, accessed 21 April 2010.

266 Peers, Playing Ourselves, 90. 
ephemeral issues like social history and cross-cultural relations. ${ }^{267}$ Smell is especially important, anthropologist Judith Ostrowitz argues, as it provides visitors with an "experience of place" that is not normally acquired through other sensory experiences. ${ }^{268}$

At the Cathlapotle Plankhouse, the wide array of physical stimuli available to visitors upon entrance elicit strong responses and generate educational opportunities that do not typically arise in traditional museum settings. For example, the chilly temperature of the Plankhouse in the winter led two visitors on two separate visits to ask how the residents of Cathlapotle stayed warm. This question led to a discussion of the Chinookan hunter-gatherer lifestyle and the way in which they used their surroundings to endure harsh conditions. Another visitor handled a Chinookan canoe paddle and took note of its oddly-shaped head. Upon asking the docent for an explanation for the paddle's u-shaped head, a complex story emerged involving the significance of canoes in Chinookan daily life, the significance of wapato to Chinookan trade, and the changing biodiversity of the Columbia River that has made the formerly abundant plant a rarity in the area. Similar educational opportunities exist within all of the sensory elements of the Plankhouse, including its strong smell of timber, the texture of its planks, and the towering beauty of its post carvings. In this sense, the Cathlapotle Plankhouse is a powerful and unique educational tool due to its rich materiality and the stories that lie beneath it.

The site that the Cathlapotle Plankhouse resides on also acts as unique educator of the Refuge's visiting public. Nestled on the shores of Duck Lake, the large timber

\footnotetext{
${ }^{267}$ Ibid, 90, 92 .

${ }^{268}$ Judith Ostrowitz, "Concourse and Periphery: Planning the National Museum of the American Indian," in The National Museum of the American Indian: Critical Conversations, ed: Amy Lonetree and Amanda Cobb, (Lincoln, NE: University of Nebraska Press, 2008), 95.
} 
structure dominates a largely peaceful landscape filled with wildlife and natural vegetation. Guided by a trail that leads them from the Refuge parking lot to the Plankhouse's traditional entrance, visitors are encouraged to leave the present behind them and enter into a "historically-evocative setting" that is meant to emulate the site's appearance during the $18^{\text {th }}$ century. ${ }^{269}$ Despite constant reminders of modernity that manifest themselves in the form of Union Pacific train line that runs parallel to the Plankhouse site, the attempt to provide visitors with the opportunity to go back in time is significant to their educational experience, as it places what they are about to learn about plankhouses, Chinookan culture, and the natural environment into historical context. Anthropologist Patrick Julig argues that historical artifacts and experiences are all too frequently displayed in a sterile manner that reveals little about the actual object. Placing that same artifact in its natural surroundings, however, "relates it immediately to a myriad of facts organized into a functionally meaningful whole." ${ }^{270}$ For example, it is far easier to understand the need for a u-shaped canoe paddle head when you have seen the muddy shores of Duck Lake and can envision the former residents of Cathlapotle planting that paddle into the riverbed as they navigate its shallow waters. Because so many material aspects of Chinookan daily life reflect the surrounding environment, the site of the Plankhouse is an important educational mechanism that provides visitors with important

${ }^{269}$ Lewis and Clark Bicentennial Committee of Vancouver / Clark County, "National Park Service, Lewis and Clark National Historic Trail 2003 Challenge Cost Share Program Application," 13 January 2003, inactive file drawers at the U.S. Fish and Wildlife Service's Region 1 Cultural Resources Office, Sherwood, Oregon, accessed 21 April 2010.

${ }^{270}$ Patrick Julig, Archaeological Theme Parks, Public Archaeology, and Living Museums: Prospects for the Upper Great Lakes Region, (Sudbury, Ontario: Laurentian University Press, 2008), 111. 
background knowledge that helps them understand the Plankhouse and its artifacts in a comprehensive and meaningful way.

To supplement the Cathlapotle Plankhouse's instructive physical qualities, staff from the U.S. Fish and Wildlife Service and the Friends of the Ridgefield Wildlife Refuge, in conjunction with the Chinook Indian Nation, carefully conceived interpretive and public outreach programs that provide visitors with educational opportunities that depict the natural and cultural history of the Refuge. With a goal of enhancing the Refuge experience for traditional wildlife-oriented audiences while also attracting a new heritage-oriented audience, Refuge staff began developing interpretive and public outreach programs well before Plankhouse construction commenced. ${ }^{271}$ Because they depended on volunteer staff and assistance to produce cordage and traditional construction tools for the Plankhouse, Refuge staff developed an interactive program that allowed interested members of the community to learn traditional Chinookan construction methods and crafts. Led by members of the Tribe, hands-on craft workshops and skill sessions provided the community unprecedented access to traditional knowledge and skills that do not typically occur within a traditional museum setting.

Apart from the short-term educational opportunities that supplemented the construction process, Ridgefield National Wildlife Refuge staff also developed long-term public programs and resources that became permanent components of Plankhouse management. ${ }^{272}$ Project partners, educators, U.S. Fish and Wildlife Service staff, and interested community members collaboratively developed an Interpretive and

${ }^{271}$ Lewis and Clark Bicentennial Committee of Vancouver / Clark County, "National Park Service Challenge Cost Share Application.”

${ }^{272}$ Ibid. 
Educational Program Plan and an accompanying implementation manual for the site in $2003 .{ }^{273}$ This plan identified key themes relevant to the Ridgefield National Wildlife Refuge and proposed ways to interpret these themes for student groups and the general public. ${ }^{274}$ Educational programs met both the Washington State and Oregon Essential Academic Learning Requirements, and docents were trained to deliver information on a wide variety of topics, including the site's indigenous history, the practice of archaeology, and the local area's natural environment. Funding from the National Fish and Wildlife Foundation was also secured to contract Native artisans to replicate Chinookan artifacts like beaver tooth knifes, adzes, and digging sticks for a traveling educational kit that would be available to school-aged classrooms while the Plankhouse was being constructed. ${ }^{275}$ Refuge staff hoped to provide "quality experiences for the visiting public, volunteers, and students that were historically, culturally, and visually appropriate" through these early educational and interpretive efforts. ${ }^{276}$

Many of the interpretive and educational opportunities envisioned in the original interpretive program have been implemented and expanded upon in the years following the Plankhouse's opening. Under an interpretive program titled "Lifeways, Landscapes and Wildlife," Friends of the Ridgefield Wildlife Refuge and U.S. Fish and Wildlife Service staff manage four different interpretive series comprised of workshops,

\footnotetext{
273 Ibid.

274 Ibid.

${ }^{275}$ Lewis and Clark Bicentennial Committee of Vancouver / Clark County, "National Wildlife Refuge Friends Group Grant Application Form," 15 April 2004, inactive file drawers at the U.S. Fish and Wildlife Service's Ridgefield National Wildlife Refuge Office, Ridgefield, Washington, accessed 23 November 2009.

${ }^{276}$ Lewis and Clark Bicentennial Committee of Vancouver / Clark County, "National Park Service Challenge Cost Share Application."
} 
demonstrations, lectures, hands-on student experiences, and cultural events. These interpretive series are meant to facilitate understanding of local cultural and historical impacts of the Plankhouse from April to October of each year. ${ }^{277}$ The Artist in Residence Series, for example, features demonstrations of four separate Chinookan artists throughout the months of April, May, and June. For three days a week and one weekend each, these artists demonstrate cultural artistic specialties like weaving, food preparation, carving, and painting. ${ }^{278}$ The Second Sunday Series provides presentations on Chinookan culture, the Refuge's natural history and various aspects of archaeology to Plankhouse attendees, and separate traditional skills workshops offer the public the opportunity to gain hands-on experience in Chinookan craft making like cattail mat weaving. Finally, the Seasonal Gathering Series produces quarterly cultural gatherings that celebrate the changing of the seasons. The salmon bake held during the annual Ridgefield "Birdfest and Bluegrass Festival" in October, for example, celebrates the transition into fall and the upcoming salmon runs.

The Cathlapotle Plankhouse also offers educational programs specifically catered to school groups. With the aim of instructing Oregon and Washington school-aged children about the thriving culture and wildlife that existed on the Lower Columbia River basin prior to Euro-American settlement, Pacific Northwest school groups are led through the Plankhouse by volunteer docents throughout the week. These groups have direct access to the Artist in Residence program, and an Educator's Field Trip Guide offers

${ }^{277}$ Friends of the Ridgefield National Wildlife Refuge, "Cathlapotle Plankhouse Project Lifeways Landscapes and Wildlife Interpretive Program," http://www.ridgefieldfriends.org/plankhouse-lifeways.php, accessed 8 May 2011. ${ }^{278}$ Ibid. 
teachers supplemental activities that discuss the making of cordage, the layout and construction of a plankhouse, and the Chinookan trade language known as Chinook Jargon or Chinuk Wawa. ${ }^{279}$ In the 2008-2009 season, over 3,000 school-aged children visited the Plankhouse. ${ }^{280}$

\section{Interpretive Implications}

The qualities that make the Cathlapotle Plankhouse an effective outdoor educational center have an impact on the structure's interpretive abilities. That the Plankhouse was designed in part as an educational facility places demands on the structure's historical authenticity. The U.S. Fish and Wildlife Service prioritized accommodating large groups of people during the design and construction process. Anticipating school groups on a regular basis, the U.S. Fish and Wildlife Service required the Plankhouse to have a high capacity limit and an area for large groups to sit for educational instruction. Large capacity requirements mandated an increased number of safety and disability access features, including exit signs, exit doors, railings and egress lighting. To preserve the building's authenticity, Art Peterson originally designed the Plankhouse to accommodate fewer than forty-nine souls, a limit that required only one exit door, no illuminated exit signs, and no egress lighting. After many heated discussions that focused on the inherent conflict between modern practicality and cultural

${ }^{279}$ Friends of the Ridgefield National Wildlife Refuge, Cathlapotle Plankhouse Project, "An Educators Guide to Ridgefield National Wildlife Refuge, 5 Revision, January 2007," http://www.ridgefieldfriends.org/downloads/Educators $\% 20$ Guide $\% 20$ to $\% 20$ the $\% 20$ Refu ge.pdf, accessed 15 April 2011.

${ }^{280}$ Friends of the Ridgefield National Wildlife Refuge, "Lifeways Landscapes and Wildlife Interpretive Program." 
authenticity, project partners decided the capacity of the Plankhouse would be increased and modern features would be added to the Plankhouse design. Bleacher seating was also installed along one side of the Plankhouse to accommodate the seating requirements for large schools groups and the crowds attending cultural events.

While these design features assisted in making the Plankhouse a functional educational facility, they also shifted the interpretive objective of the structure. Once envisioned to be an authentic reconstruction that would take visitors back in time, the Cathlapotle Plankhouse gradually transformed into a modern replica that elicits the past and incorporates the present out of practical necessity. A wheelchair access ramp, an illuminated exit sign, bleacher seating, and fire doors are likely not noticed by many visitors, but for some they are a significant detraction that inhibits their ability to reanimate the past. For Chinook Indian Nation members especially, sitting on bleachers during a private ceremony can significantly detract from the spiritual connection they hope to make with the site and their ancestors. It is important to take into consideration, however, that the alterations to the historic authenticity of the Plankhouse allows more visitors and school children the opportunity to learn about the cultural and natural history of the Refuge and the history of Native Americans in the Pacific Northwest. This raises an issue commonly faced by public historians working with indigenous groups to develop interpretive exhibitions and programs: To what degree should the historical authenticity of indigenous representation be sacrificed for wider outreach to mainstream audiences? And more importantly, who decides this? While public historians have increasingly grappled with this question in the past two decades, there remains no clear answer. 


\section{The Cathlapotle Plankhouse as a Cultural Anchor}

For over a century, the Chinook Indian Nation's unrecognized status with the federal government has complicated the Tribe's efforts to preserve and cultivate its identity. Denied access to government funds that provide assistance for daily operations, health, welfare and cultural resource management, the Chinook Indian Nation has spent its limited financial resources on administrative necessities. A modest tribal headquarters in Willapa Bay, Washington, acts as the main business center for the Tribe and is staffed by a part-time administrative assistant. Although vibrant and filled with cultural elements like canoe-shaped beams, this worn, traditional-styled home is far too small to serve as a gathering place for the Tribe or a storage area for culturally significant materials. The Tribe also rents out a room at the Sea Resources Hatchery in Chinook, Washington to host monthly meetings of the Culture Committee. While these administrative functions are necessary for the survival of the Chinook Indian Nation, they leave few resources available for cultural resource preservation and management efforts. Most activities of this nature are, instead, performed by volunteers or outside parties. It also leaves the Chinook Indian Nation without a building of their own to facilitate the individual and group activities necessary to develop and express community values and identity. $^{281}$

The Chinook Indian Nation's status as an unrecognized tribe also leaves the Tribe without a reservation to act as a nucleus for community involvement and cultural unity. While many Native Americans have extremely negative experiences on reservations, Dr.

${ }^{281}$ Krinsky, Contemporary Native American Architecture, 33. 
Frank Porter III argues that reserved territorial bases can be an important element in tribal survival. ${ }^{282}$ In his examination of the legal history of the "landless tribes" of Washington, the Director of the Chelsea House Foundation for American Indian Studies argues scattered 'dispora' groups struggle to maintain their tribal identities without reservations. ${ }^{283}$ While the term "tribal identity" is applied in a legal context within Porter's examination, the importance of reservations in maintaining tribal identity can also be identified within a cultural context. First and foremost, reservations concentrate members of a similar culture within a small proximity. This allows members to be exposed to traditional culture on a daily basis through informal interaction and relationships with other tribal members. Reservations also provide convenient and central gathering places for the celebration and strengthening of that particular culture. With members spread throughout Pacific, Clark, and other Washington and Oregon counties, the Chinook Indian Nation lacks the proximity that facilitates cultural unity and solidifies tribal identity. Furthermore, tribal meetings are oftentimes several hours distant from many members, making attendance at cultural gatherings difficult. While concentrations of Chinook Indian Nation members exist in the towns of Willapa, Chinook and Vancouver, Washington, members outside these population clusters do not have frequent and informal interactions that teach, affirm, and develop their cultural identity.

${ }^{282}$ George Pierre Castile and Robert L. Bee, State and Reservation: New Perspectives on Federal Indian Policy (University of Arizona Press, 1992), 4.

${ }^{283}$ Frank W. Porter III, "Without Reservation: Federal Indian Policy and the Landless Tribes of Washington." In State and Reservation: New Perspectives on Federal Indian Policy, ed. George Pierre Castile and Robert L. Bee, (Tucson, AR: The University of Arizona Press, 1992), 111. 
The Cathlapotle Plankhouse Reconstruction Project, however, provided the Chinook Indian Nation with an unprecedented opportunity to design and build a traditional structure that would embody tribal values and host communal gatherings. Although Cathlapotle offers no solution to the demographic challenges facing the modern-day Tribe, the Plankhouse serves an important role in fulfilling the cultural needs of the unrecognized Chinook Indian Nation. By connecting the Tribe with their cultural ancestors, providing them with opportunities for cultural repatriation, and acting as the Tribe's communal gathering place, the Plankhouse functions as a cultural anchor that affirms, develops, and celebrates the Chinook Indian Nation's modern identity. While this structure cannot substitute for the privileges that come with federal recognition, it grants the Chinook Indian Nation a greater chance for cultural survival as they continue in their battle for political recognition.

From the onset of the Cathlapotle Plankhouse Reconstruction Project, a major priority of the Chinook Indian Nation was to honor the site's tribal ancestors. Having gained a strong connection to Cathlapotle during the Archaeology Project of the 1990s, the Chinook Indian Nation viewed the Plankhouse Project to be an opportunity to venerate the people that had once lived in the village and made it so prosperous. ${ }^{284}$ Culture Committee chairman Tony Johnson recalled, "one of things we were concerned with from the beginning was the ancestors there...We very much wanted that village and the people in it that lived there to be held up and given the honor and respect that they deserve. ${ }^{285}$ A full-scale traditional plankhouse using time-honored construction methods

${ }^{284}$ Chinook Indian Nation Culture Committee, interview by author. 285 Ibid. 
would showcase the ancestors' ingenuity and challenge the colonial stereotypes that viewed Native Americans as primitive and uncivilized beings prior to European contact. ${ }^{286}$ With assurances from project partners that a traditionally designed plankhouse would be built, the Chinook Indian Nation agreed to provide cultural guidance and traditional knowledge for the project as a way of paying homage to their ancestors.

The Chinook Indian Nation had an agenda deeply rooted in expressing cultural values and upending a colonizing historical narrative. As a result, recommended alterations to the structure's original design elicited strong negative reactions from members of the Chinook Indian Nation. Anthropologist Laura Peers states "issues of technical authenticity go hand in hand with respect for the ancestors who produced such objects using little or no European technology." ${ }^{287}$ The comments of Gary Johnson in the Tribe's Statement of Support and Position for the Plankhouse in December 2003 reflect this relationship between authenticity and respect for one's ancestors:

The cultural and spiritual aspects of this traditional Plankhouse are considered a paramount importance to the Chinook Indian Nation and its members. We do not have an interest in building a 'replica,' but instead hope to have a house with all of the soul and spiritual aspects of any house that previously existed at Cathlapotle...Continued attempts to modify the plankhouse are seen as criticisms of our ancestors' technology and culture. ${ }^{288}$

Mutual compromise in the design of the Plankhouse may have circumvented the code compliance and safety issues that delayed construction for over a year, but such a compromise challenged the Chinook Indian Nation's impetus and primary objective of

${ }^{286}$ G. Johnson, "Statement of Support and Position."

${ }^{287}$ Peers, Playing Ourselves, 104.

${ }^{288}$ G. Johnson, "Statement of Support and Position." 
the project. Because historic reconstructions like the Plankhouse are "extraordinarily material entities that communicate with visitors through sensory simulation," the details of a structure's physical recreation are vitally important in the depiction of the past ${ }^{289}$ Modern safety amenities caused members of the Chinook Indian Nation to question whether the Plankhouse could reanimate their past properly. Moreover, while these elements proved to be only minor components in a largely traditional plankhouse, their presence represented centuries of white imposition forced on Native American tribes.

The U.S. Fish and Wildlife Service's Regional Office remained firm in their requirements for code compliance, forcing the Chinook Indian Nation to reexamine their role in the project. The Tribe desperately wanted to the see the Plankhouse completed for educational and ceremonial purposes, but many felt the spirit of the project would be destroyed with the addition of modern safety features. When negotiations reached a stalemate, the Chinook Indian Nation's Tribal Council was forced to decide whether to withdraw or to continue the project with a redefined objective. ${ }^{290}$ With so many of its limited resources already invested in the site and so much hope for cultural revival resting on the Project, the Chinook Indian Nation tentatively agreed to continue. Anan Raymond remembers that Tribal Council member Sam Robinson explained the Chinook Indian Nation's decision to him in these terms:

We have a vision of what we want. We are not going to get there with this project, but we are taking a big step to that vision we want. And progress occurs in baby steps..." I think that was ultimately the sentiment that the Tribe embraced. They said, "Damnit, we are not getting what was initially sold and our expectations were dashed and disappointed. However, we

${ }^{289}$ Peers, Playing Ourselves, 89.

${ }^{290}$ Gary Johnson to David Allen, 8 May 2004. 
are still getting something that is really cool and valuable and still meaningful. It will be meaningful and we can make it meaningful. ${ }^{291}$

By redefining the project's goal as the construction of a " $21^{\text {st }}$ century traditional plankhouse," 292 or a "hybrid," 293 the Chinook Indian Nation could agree to the addition of modern safety features in return for a waiver that provided the Chinook Indian Nation extraordinary use of the Plankhouse for cultural purposes. ${ }^{294}$ While uneasy with this compromise, members of the Chinook Indian Nation believed they were doing the best they could to honor their ancestors in altered circumstances. According to architectural historian Carol Herselle Krinsky, compromise is increasingly common in the construction of Native American architecture, as demands for practicality and regulations increasingly pressure architects to "paraphrase" traditional structures instead of replicating them. ${ }^{295}$

Despite modern alterations, the Cathlapotle Plankhouse appears to provide the modern-day Tribe with the linkage to the site's ancestors that they had originally envisioned. As best expressed by a member of the Chinook Indian Nation Culture Committee, the Cathlapotle Plankhouse has "a feeling of timelessness. We talk about ancestors, but when you are at the Plankhouse, you feel totally connected with them. And their life is part of yours." ${ }^{296}$ According to another member of the Chinook Indian Nation Culture Committee, "when I go to the Plankhouse at Cathlapotle, I look at the

\footnotetext{
${ }^{291}$ Raymond, interview by author.

292 Ibid.

${ }^{293}$ Greg Robinson to author, 24 May 2011.

${ }^{294}$ Raymond, interview by author; Chinook Indian Nation Culture Committee Interview, interview by author.

${ }^{295}$ Krinsky, Contemporary Native American Architecture, 81.

${ }^{296}$ Chinook Indian Nation Culture Committee, interview by author.
} 
timbers and I can see my past. I can see what was once glorious. What was once stupendously [tragic]."297

Drawing a connection to Cathlapotle's ancestors is extremely important for the present-day Chinook Indian Nation, as historic reconstructions increasingly constitute significant sites of cultural memory and identity for Native peoples. ${ }^{298}$ Not only does the Plankhouse provide current members of the Chinook Indian Nation with a deeper understanding of their cultural roots, but it also acts as a permanent physical reminder of what life used to be that will be visible for future generations. As explained by a young Chinook Indian Nation Culture Committee member:

I had no idea growing up that we lived in - or my ancestors - lived in houses. And it was not until after I saw the Plankhouse for the first time - and then when I went and saw it and heard the stories of how it came to be and how families would come and one would own the Plankhouse, and then everybody would be welcome for other family members to come in and stay during the different seasons and stuff like that. I was able to use my modern way of thinking and put it in perspective. It was like owning an apartment complex. ${ }^{299}$

By contextualizing his ancestors' way of life in modern terms, this young member understood the importance of his past. This comprehension translated into an obvious sense of pride in the young man's ancestors and his Chinookan identity. As the threat of cultural assimilation challenges each generation more, this sense of pride will be a vital key to the survival of the Chinook Indian Nation's tribal identity. The permanence of Cathlapotle, therefore, is important in affirming, developing and celebrating the modernday identity of the Chinook Indian Nation.

297 Ibid.

${ }^{298}$ Peers, Playing Ourselves, 104.

${ }^{299}$ Chinook Indian Nation Culture Committee, interview by author. 
Beyond honoring the ancestors of the Cathlapotle site, the Plankhouse has also played (and continues to play) a major role in what James Clifford refers to as "cultural retrieval." 300 Over the many years that have separated the Chinook Indian Nation from their ancestors at Cathlapotle, traditional skills associated with the construction of a plankhouse and its accompanying "accessories" have been lost or limited to few members within the Tribe. This loss of knowledge can be catastrophic for unrecognized tribes who often have little beyond their past to solidify their identity. Throughout the Cathlapotle Plankhouse Reconstruction Project, however, members of the Chinook Indian Nation had the opportunity to regain traditional skills using a number of time-honored construction processes. Workshops exposed members of the Chinook Indian Nation to previously unknown traditional skills and methods of construction. Members also reconstructed traditional tools like adzes and hand chisels and learned how to use these tools in the present context of reconstructing the Plankhouse. Such opportunities for "cultural retrieval" provided a cultural anchor for the Chinook Indian Nation, as they repatriated traditional knowledge and resurrected traditional technology that was previously inaccessible to tribal members. ${ }^{301}$

Although construction concluded in 2006, the process of cultural retrieval at the Cathlapotle Plankhouse continues for members of the Chinook Indian Nation today. Tribal experts and artists have weekly opportunities to learn, experiment with and convey traditional skills and knowledge to the general public through the integration of "Native interpreters" into the site's artist-in-residence and Second Sunday Series interpretive

\footnotetext{
${ }^{300}$ Clifford, "Looking Several Ways," 8.

${ }^{301}$ Peers, Playing Ourselves, 83; Nelson Graburn and Naomi Leite-Goldberg, review of "Looking Several Ways" by James Clifford, 24.
} 
programs. The process of "making" while simultaneously instructing others is also about teaching oneself and strengthening aspects of Native identity. ${ }^{302}$ In her examination of the role and effect of Native interpreters at historical reconstructions throughout North America, Laura Peers noted that the performance and demonstration of unknown or forgotten traditional skills unveiled new conduits for Native performers to access cultural traditions and strengthen individual and tribal identity. ${ }^{303}$ By continuing to develop and participate in interpretive programs at the Cathlapotle Plankhouse, participating Chinook Indian Nation members prolong and enhance their opportunities for cultural retrieval.

Finally, the Cathlapotle Plankhouse serves as a site for spiritual ceremonies that affirm, develop and celebrate the identity of the Chinook Indian Nation and its members. Each January, members of the Chinook Indian Nation gather at the Plankhouse for their annual Winter Gathering. In a ceremony open only to Chinook Indian Nation members and those they invite, attendees sing, dance, drum, and tell traditional stories within the filled-to-capacity Plankhouse. These annual ceremonies play a vital role in the cultural renewal of the Chinook Indian Nation, as they remind members of their ceremonial heritage and bring forth the customs and the values of the past to the present. ${ }^{304}$ According to Gary Johnson:

That is really an exciting part about the Plankhouse - the Winter Gathering and things that go on there - is that children and grandchildren are experiencing these things as they grow up that many of us (did not have)...And it is easier to understand that when you go to the Plankhouse and have those moments with the singing and the dancing, the drumming, and the fires. ${ }^{305}$

\footnotetext{
302 Peers, Playing Ourselves, 83.

${ }^{303}$ Peers, Playing Ourselves, 83.

${ }^{304}$ G. Johnson, "Plankhouse Opening."

${ }^{305}$ Chinook Indian Nation Culture Committee, interview by author.
} 
While tribal ceremonies of this sort can be (and have been) hosted in venues other than the Plankhouse, the materiality of the structure provides the Tribe a tangible link to their past and imparts a sense of realism, pride, spirituality, understanding, and healing that is not otherwise captured when performed in modern-day buildings. Architectural historian Carol Herselle Krinsky argues the materials, the colors, the external form, and the interior spaces of "Amerindian" architecture embody tribal values and traditions in a manner that promotes communal pride and enhances psychological well-being. ${ }^{306}$ For the Chinook Indian Nation, the Cathlapotle Plankhouse acts as a rare and special place for the Tribe to come together, celebrate their heritage and bring back traditions. Such celebration, combined with opportunities for cultural retrieval and the building's linkage to the site's ancestors, make the Cathlapotle Plankhouse a cultural beacon for the modern-day Chinook Indian Nation.

\section{Interpretive Implications}

Like its function as an educational center, the qualities that make the Cathlapotle Plankhouse a source of identity and pride for members of the Chinook Indian Nation also have implications for the reconstruction's interpretive capabilities. Understanding the Plankhouse would act as both an educational center and as a site for Chinook Indian Nation ceremonies, project partners designed the structure to inform visitors through traditional physical features and interpretive elements that would not impede on the ceremonial aspects of the Plankhouse. Considerations regarding its ceremonial uses led project partners away from the physical aids traditionally used in museums like

\footnotetext{
${ }^{306}$ Krinsky, Contemporary Native American Architecture, 33.
} 
interpretive panels, artifact cases and other informational apparatuses typically found in museums. Alternative informative displays at the Plankhouse include the oral presentation of historical information, physical interaction with artifacts, verbal interaction with docents, and hands-on learning experiences with the different interpretive series held at the facility throughout the year. These alternative forms of interpretation help to maintain the historically authentic and ceremonial feel of the Plankhouse, as Chinook Indian Nation can celebrate their culture in an environment free of obtrusive informational tools.

While alternative modes of interpretation significantly preserve the historical authenticity of the Plankhouse, project partners take large interpretative risks by not providing written forms of information throughout the structure. As Laura Peers points out, the materiality of historic reconstructions is a valuable tool in beginning conversations that can lead to the discussion of meaningful and complex historical issues like cross-cultural relations. ${ }^{307}$ The same materiality, however, can also enchant visitors, preventing them from looking beyond the surface of these places to find the deeper meanings embedded in this materiality. ${ }^{308}$ Anthropologist Daan van Dartel's identifies a similar interpretive risk in her discussion of the layers of meaning embedded in historical objects. According to van Dartel, objects without appropriate historical interpretation -the context in which the object was made, and the object's developmental value in daily life -- are merely "curiosities" of the past. ${ }^{309}$

\footnotetext{
${ }^{307}$ Peers, Playing Ourselves, 101-102.

308 Ibid., 99

${ }^{309}$ Daan van Dartel, “There's a Story Behind Everything: Moving Towards the Intangible at the Tropenmuseum," in Sharing Cultures 2009: International Conference
} 
At Cathlapotle, docents and volunteers are responsible for providing the historical interpretation that can "release" an object's embedded meaning. While many of the docents at the Plankhouse are highly knowledgeable and well trained, the responsibility to make the Plankhouse and its accessories more than just historical replicas of the past rests on their shoulders. If a docent at Cathlapotle is new, outnumbered by visitors, or absent during an attendee's time in the Plankhouse, there is a great risk that interpretive themes will not be communicated to or understood by visitors through objects alone. Had a docent not been present to answer the aforementioned visitor's question about the oddly shaped canoe paddle, the economic, political and social importance of that canoe paddle in Chinookan culture would not have been revealed to the group. Or had I been on the other side of the room looking at the post carvings while this question was asked, I might not have heard the docent's explanation of the paddle's significance. Without interpretative intervention of some form, viewers are left to form their own assumptions about the paddle, which may reflect colonial misunderstandings and foreclose complex engagement with the object. ${ }^{310}$ Interpretive forms common to museums could easily address these risks, but the Plankhouse must also maintain ceremonial legitimacy. For a group that has historically been represented through objects of curiosity by museums and educational institutions, the presence of traditional museum displays like interpretive panels and artifact cases would detract from the spiritual power and cultural significance of the Plankhouse.

on Intangible Heritage, ed: Sergio Lira, et al. (Portugal: Green Lines Institute for Sustainable Development, 2009), 344.

${ }^{310}$ Trofanenko, "Displayed Objects, Indigenous Identities, and Public Pedagogy," 312. 


\section{The Cathlapotle Plankhouse as a Political Arena}

In addition to functioning as an educational center and a source of cultural identity, the Cathlapotle Plankhouse also serves as a political arena. Laura Peers contends historic reconstructions can be and often are used to unravel "power-laden cultural nostalgic fantasies about colonial relations" that distort the portrayal of people and relationships in history. ${ }^{311}$ The pure physicality of historically reconstructed buildings and their accessories, she argues, can be used to explore and teach about political dynamics and cross-cultural issues by stressing the commonalities between visitors' lives and those of Native people in the past. ${ }^{312}$ Mary Louise Pratt describes these sites of contestation to be "contact zones" where dissimilar cultures meet, clash and grapple with each other. ${ }^{313}$ As it exists today, the Cathlapotle Plankhouse functions as one of these contact zones, as historical misinterpretations, cultural misconceptions and existing power structures are strategically challenged through the physical structure and its interpretation.

First and foremost, the Cathlapotle Plankhouse is a political arena where colonial nostalgia and historical misinterpretations are constantly examined and disputed. In a region where local history enthusiastically celebrates the expedition of Lewis and Clark and the adventures of the Oregon Trail, the Cathlapotle Plankhouse is a unique historical site where colonial myths of Native American primitivism and extinction are confronted. The existence of the structure alone challenges the common misconception that Native

${ }^{311}$ Peers, Playing Ourselves, 101.

312 Ibid.

313 Pratt, Imperial Eyes: Travel Writing and Transculturation, (London: Routledge, 1992), 4, as quoted in Peers, Playing Ourselves, xx. 
Americans were primitive beings with simple technologies prior to European contact. As visitors enter through the Plankhouse's traditional oval doorway, they are engulfed by the impressively large structure whose ceiling and large art forms tower above them. Every detail of the timber building showcases exemplary craftsmanship and artistic skill, and the heavy aroma of cedar constantly reminds visitors that such a building was handmade using material found only in the natural environment. Even without instructive interpretation, the plankhouse informs visitors of the immense manpower and ingenuity required to assemble such a building through visual and sensory cues. Such instruction through physical representation and material detail challenges the misconception that Native Americans were unsophisticated in their use of technology.

The Cathlapotle Plankhouse also challenges the colonial misconception of Native American primitiveness by providing visitors with a historical referential space to learn about Chinookan society and its complex social and political structure. Stereotypes of the larger Native American population that commonly identified them as uncivilized due to their nomadic, hunter-gather lifestyle, their supposed lack of material wealth, and their communal social structure, are confronted at the Cathlapotle Plankhouse through the interpretation of its physical features. The existence of the Plankhouse refutes the common myth that all Native Americans lived in tepees, and the internal features of the structure depict a culture of economic prosperity, social hierarchy, the ownership of property, and the existence of elaborate material culture, qualities typically associated with "civilized" non-Native societies. ${ }^{314}$ Such re-education through material culture subtly challenges visitors' misunderstandings about Northwest Native American history.

${ }^{314}$ K. Ames, Peoples of the Northwest Coast, 13. 
The Cathlapotle Plankhouse is in Laura Peer's terms, an "arena in which Native peoples challenge majority society...challenge their stories and myths, challenge their histories, challenge structures of power." 315

The Plankhouse also acts as a political arena where colonial myths about the extinction of Native Americans are contested. Cultural anthropologist Patricia Pierce Erikson argues that stereotypes inherent in historic representations of "Indianness" have consistently overwritten the existence and persistence of modern-day Native American communities. $^{316}$ With limited exposure to such communities, historians, anthropologists, ethnographers, and majority America relegate Native culture to the past. In the rare instances that Native culture is brought to the forefront of the mainstream public's attention, it is often accompanied by demands for "authenticity" defined by white society and rooted in colonial romanticism. ${ }^{317}$ In such instances, Native Americans are faced with a dilemma: do they minimize their modern existence by "playing Indian" to the expectations of majority society or do they represent themselves as they are in the modern day and face accusations of being inauthentic and, therefore, culturally extinct. ${ }^{318}$ In the case of the Cathlapotle Plankhouse, the Chinook Indian Nation uses the reconstruction and a unique version of cultural performance to assert their modern-day existence and politically challenge the concept that Native Americans cannot evolve or adapt without losing their claims to indigeneity.

315 Peers, Playing Ourselves, xxi.

${ }^{316}$ Erikson, “Decolonizing the 'Nation's Attic,' 46.

${ }^{317}$ Raibmon, Authentic Indians, 3.

318 Ibid., 7-9. 
While the traditional qualities of the reconstructed plankhouse exhibit the Chinook Indian Nation's maintenance and practice of cultural knowledge to mainstream society, the Tribe does not participate in cultural performances that reproduce colonial stereotypes of Native American culture. Instead of conducting ceremonies or participating in interpretive programs that are based around singing, dancing, traditional regalia, and role-playing, the Chinook Indian Nation conducts lectures and facilitates traditional skills workshops as representatives of the $21^{\text {st }}$ century Chinook Indian Nation. While some members adorn traditional Chinookan hats or button blankets as they instruct public audiences, a majority of them sport contemporary clothing and discuss the evolution of the Tribe, its art, and its cultural preservation. By participating in this kind of "cultural performance" at the Cathlapotle Plankhouse, the Tribe memorializes its past while asserting its existence as a modern-day entity to visitors. This is a powerful political act for groups who have long been marginalized and made to disappear, anthropologist James Clifford argues, as it challenges mainstream society's misconceptions of Native America's cultural extinction. ${ }^{319}$

The Cathlapotle Plankhouse also serves as political arena where existing power structures are challenged. Most significantly, the Plankhouse has and continues to function as a key political apparatus in the Chinook Indian Nation's fight for federal recognition. Although officially recognized by the Clinton Administration on 3 January 2001, the Bush Administration rescinded the Chinook Indian Nation's status in 2002 on the basis that they had not adequately met three of the seven mandatory criteria for federal acknowledgement, including the requirement that the Tribe be identified as an

${ }^{319}$ Clifford, "Looking Several Ways," 8. 
American Indian entity on a "substantially continuous basis since 1900."320 Arguing that federal policies are responsible for the Chinook Indian Nation's “lack of tribal continuity," the Tribe considered withdrawing from the Plankhouse Project in protest of the United States government. ${ }^{321}$ After deliberation, however, the Tribe remained partnered with the U.S. Fish and Wildlife Service and the Lewis and Clark Bicentennial Committee of Vancouver/Clark County. Beyond the Project's cultural benefits for the Tribe and its historical benefits for the wider community, the construction of the Cathlapotle Plankhouse showed potential as a powerful political tool in the Tribe's challenge of the federal government's structure of power.

Despite being named in several treaties and participating in numerous projects with a range of federal agencies throughout the $20^{\text {th }}$ century, the Bureau of Indian Affairs denied the Chinook Indian Nation recognition several times between 1980 and 2002. In continuing their partnership with U.S. Fish and Wildlife Service, the Chinook Indian Nation maintained a valuable relationship that served as a prime example of the U.S. government's continuous relationship with a tribe it claimed not to exist. Gary Johnson highlighted the political irony associated with the Chinook Indian Nation's relationship with the U.S. Fish and Wildlife Service and the Tribe's most recent denial of recognition:

320 According to the Bureau of Indian Affairs, the Chinook Indian Nation did not satisfy criteria (a), (b), or (c), which read as follows:

a. The petitioner has been identified as an American Indian entity on a substantially continuous basis since 1900 .

b. A predominant portion of the petitioning group comprises a distinct community and has existed as a community from historical times until the present.

c. The petitioner has maintained political influence or authority over its members as an autonomous entity from historical times until the present.

${ }^{321}$ Mhari Doyle, "Plank house starts warmly," (Vancouver) Columbian, 14 October 2002, C1, C5. 
We have agreements on the Plankhouse and I do not believe the federal government can deny who we are when they continue to work with us. And I think that is just a hugely important part about getting this done and working with them. ${ }^{322}$

By continuing their government-to-government relationship with the U.S. Fish and Wildlife Service throughout the Cathlapotle Plankhouse Reconstruction Project, the Chinook Indian Nation hoped to challenge the existing power structure that denied tribal recognition. Chinook Indian nation member, Cliff Snider, best articulated this motivation at the hearth lighting ceremony that launched the Plankhouse Project in October, 2002:

The whole world will recognize the Chinook Indian tribe... Now we just want the (U.S.) Bureau of Indian Affairs to follow suit...The plank house means that we're a sovereign tribe that still exists...We want this to bring awareness back to Washington D.C. We do exist, and we have since the beginning of time. ${ }^{323}$

Media attention surrounding the Cathlapotle Plankhouse Reconstruction Project and the Lewis and Clark Bicentennial also served as an important political apparatus for publicizing the Chinook Indian Nation's struggles in the recognition process. While much of the press focused on the building process and its progression, the issue of Chinook recognition was peppered throughout newspaper articles on the Plankhouse. Shortly following the withdrawal of Chinook Indian Nation recognition, for example, newspaper articles covering the Project's kick-off and the ceremonial hearth lighting discussed the retraction of Chinook recognition and its implications for the Tribe's ability to participate in the reconstruction. ${ }^{324}$ Closer to the Plankhouse's conclusion, press coverage integrated discussion of the Chinook Indian Nation's political status into

${ }^{322}$ Chinook Indian Nation Culture Committee, interview by author.

${ }^{323}$ Doyle, "Plank house starts warmly."

${ }^{324}$ Dean Baker, "Plankhouse Project Kicks Off Saturday," (Vancouver) Columbian, 3 September 2002, C1; Foster Church, "Ridgefield Rebirth Ahead for Native American Culture," Oregonian, 6 September 2002, D3. 
articles focused on construction methods, funding sources and progress reports. Finally, with the completion of the Plankhouse and the approach of Lewis and Clark Bicentennial celebrations, media coverage examined the significance of the Cathlapotle Plankhouse in calling attention to the Chinook Indian Nation's political struggles. Whether recognition was deliberately emphasized or fortuitously embraced by the local media, the coverage surrounding the Cathlapotle Plankhouse Reconstruction Project proved to be politically significant for the Tribe, as they used it to publicly challenge and condemn the existing governmental power structure that refused to recognize them.

More significantly, media attention of the Cathlapotle Plankhouse Reconstruction Project resulted in the publication of advocacy articles in Vancouver's largest newspaper, the Columbian. In his March 2004 article titled "Payback time on the Columbia; Chinook helped Lewis and Clark survive 200 years ago, now hope bicentennial will lead to official recognition," Dean Baker detailed the Chinook Indian Nation's plans to use the Lewis and Clark Bicentennial as "a springboard to lobby for legal recognition." The columnist quoted a number of tribal representatives in the effort to paint a sympathetic picture of hardworking, culturally invested and imperiled tribal members whose future rested in the hands of the federal government. Describing the Chinook Indian Nation's current financial situation to be "little more than a social club scrambling for funds," Baker effectively promoted and publicized the Chinook's fight for recognition. ${ }^{325}$ Not even a month later, Columbian editor Tom Koenninger supplemented Baker's article with an editorial titled "Recognition of Chinook Long Overdue." Koenninger referred to the

${ }^{325}$ Dean Baker, "Payback time on the Columbia; Chinook helped Lewis and Clark survive 200 years ago, now hope bicentennial will lead to official recognition," (Vancouver) Columbian, 22 March 2004, A1. 
federal government's denial of Chinook recognition as "an injustice to a tribe of American Indians that borders on shameful neglect.." ${ }^{326}$ These articles appealed to the general public to support the Chinook Indian Nation in their fight to attain recognition.

By calling attention to the Chinook Indian Nation's fight for recognition, local media coverage of the Plankhouse brought about opportunities for the Chinook Indian Nation and other local tribes to heighten awareness of additional political issues connected to recognition, including poverty, land claims, access to federal funding, and cultural preservation. The Chinook Indian Nation's use of a heritage project to supplement a political battle is a common strategy, according to James Clifford, who argues:

Heritage is not a substitute for land claims, struggles over subsistence rights, development, education, and health projects, defense of sacred sites, and repatriation of human remains or stolen artifacts, but it is closely connected to all of these struggles. ${ }^{327}$

Moreover, the Chinook Indian Nation and other tribes used the attention drawn by the Plankhouse and the Lewis and Clark Bicentennial to highlight the struggles experienced by unrecognized tribes regionally. In an email to regional tribal leaders, for example, Duwamish tribal member Thomas Speer argued the completion of the Cathlapotle Plankhouse to be politically essential for the advancement of all non-recognized tribes throughout the Pacific Northwest:

Snohomish? Chinook? Duwamish? We're all 'in the same boat,' and we're all fighting for the same necessities: a traditional place of gathering that is our own

${ }^{326}$ Tom Koenninger, "Opinion - Recognition of Chinook long overdue," (Vancouver) Columbian, 14 April 2004, C7.

${ }^{327}$ Clifford, "Looking Several Ways," 8. 
cultural survival, language survival, sovereignty, a healthy and economically thriving community. ${ }^{328}$

To facilitate the completion of such a culturally pivotal structure, Speer urges the unrecognized tribes in his email to join together in fighting for the Plankhouse's cultural authenticity, as "together, [they] are far stronger and wise than when [they] are apart.",329

Plankhouse construction manager and Chinook Indian Nation member Greg

Robinson supplemented Speer's depiction of the struggles of non-recognized tribes by placing the Chinook Indian Nation's hardships within the context of the Lewis and Clark Bicentennial celebrations:

Hundreds and millions of dollars will be spent during the commemoration. Cities, Counties and States will benefit greatly. Citizens will get the Hollywood production they know and love. And when the dust settles, what will the Chinooks have gained? We will still be a landless tribe, within our country. We will still struggle to keep the lights on in our one-room office. We will still have never been legally compensated for millions of acres of our land. We will still suffer from diabetes, racism, cultural exploitation and intrusion by 'recognized' and make-believe tribes. ${ }^{330}$

For Greg Robinson, the Chinook Indian Nation, and other non-recognized tribes of the Pacific Northwest, the publicity surrounding the Cathlapotle Plankhouse Reconstruction Project and the Lewis and Clark Bicentennial presented an unprecedented opportunity to publicly challenge the federal power structure that guided the recognition process. The Cathlapotle Plankhouse was and continues to be, therefore, a political arena where

328 Thomas Speer to Gary Johnson, et al., "Together, we are stronger and wiser," 20 February 2004, inactive personal files of Gary Johnson, Chinook, Washington, accessed 8 June 2010.

329 Ibid.

${ }^{330}$ Greg A Robinson, "Chinook Life 5," Chinook Life 2, no. 1 (n.d.), http://www.chinooknation.org/Default.aspx?tabid=38, accessed 11 November 2009. 
historical misinterpretations, cultural misconceptions and existing power structures can be challenged and addressed.

\section{Interpretive Implications}

Karen Coody Cooper criticizes museums for having fed the general public a "steady diet of cultural pabulum" regarding Native Americans that maintained America's master colonial narrative throughout the $20^{\text {th }}$ century. ${ }^{331}$ Complex histories have been and continue to be represented in museums as simple, linear narratives that reflect what Sonya Atalay describes as an epistemological framework "steeped in Western ways of knowing, naming, ordering, analyzing, and understanding the world." ${ }^{332}$ As articulated previously, a paradigmatic shift in the representation of indigenous groups has occurred in the past two decades that gives rise to an interpretive paradox that puts how museums and their publics are accustomed to thinking in conflict with the desires of Native Americans to change that manner of thinking. ${ }^{333}$ Curators increasingly recognize the need to present a dynamic history of Native Americans, but they must also take into consideration the museum's role as a business and an educator of the general public. With attendance numbers acting as one of the few quantitative measurements of a museum's success, curators must balance the need for interpretive change with museum visitors' "genres of expectancy" that demand familiar exhibition formatting and

${ }^{331}$ Cooper, Spirited Encounters, xiii-xiv.

${ }^{332}$ M. Ames, "Curatorial Prerogative?," 83; Sonya Atalay, "No Sense of the Struggle: Creating a Context for Survivance at the National Museum of the American Indian," in The National Museum of the American Indian: Critical Conversations, ed: Amy Lonetree and Amanda J. Cobb, (Lincoln, NE: University of Nebraska Press, 2008), 267. 333 Penney, "Poetics of Museum Representation," 55. 
narratives. ${ }^{334}$ According to Comanche curator Paul Chaat Smith, the average museum visitor does not expect to have their most deeply held beliefs challenged during their visits. ${ }^{335}$ Nor do they expect to encounter historical interpretation that diverges from the interpretive panels, the living history, and the artifact cases that museum audiences have grown accustomed to over the past century. While the contestation of the existing social order can be educational and welcomed by some museum visitors, it can also warrant confusion, anger, and misunderstanding that threatens a museum's perceived historical authority. As evident in the poor reception of the National Museum of the American Indian's inaugural exhibitions, significant ramifications accompany the challenging of the traditional museological paradigm. ${ }^{336}$

In acting as a political arena that challenges the traditional museological paradigm, the Cathlapotle Plankhouse takes interpretive risks that affect the way visitors perceive the site. By challenging the notions of Native American savagery and extinction, the Chinook Indian Nation confronts two of mainstream society's most prominent historical myths that justify the nation's colonization of indigenous Americans. While cultural anthropologist Patricia Pierce Erikson argues much of the

${ }^{334}$ Gwyneira Issac, "What Are Our Expectations Telling Us?: Encounters with the National Museum of the American Indian," in The National Museum of the American Indian: Critical Conversations, ed: Amy Lonetree and Amanda J. Cobb, (Lincoln, NE: University of Nebraska Press, 2008), 245.

${ }^{335}$ Paul Chaat Smith, "Critical Reflections on the Our Peoples Exhibit: A Curator's Perspective," in The National Museum of the American Indian: Critical Conversations, ed: Amy Lonetree and Amanda J. Cobb, (Lincoln, NE: University of Nebraska Press, 2008), 136.

${ }^{336}$ Amy Lonetree and Amanda Cobb's anthology, The National Museum of the American Indian: Critical Conversation (2008) provides a well-rounded discussion of the way in which the first exhibits at the National Museum of the American Indian were received by a broad spectrum of user groups. 
public is open to contestation of this kind, visitors previously comforted by these myths may become confused by the historical and ideological contest occurring within the Plankhouse walls. Without appropriate mediation of visitors' ideological battle, this confusion often manifests itself in accusations of a lack of authenticity or historical scholarship. For example, I visited the Plankhouse with a friend who had little knowledge of Native American history in the Pacific Northwest. After meeting one of the artist-in-residences and self-touring the structure, we had a conversation in which my friend expressed slight dissatisfaction in the idea that the Chinookan artist-in-residence was not dressed in more traditional clothing. Probing deeper into this dissatisfaction, I discovered my friend viewed the artist, and subsequently his artwork, as lacking in authenticity because he did not reflect her understanding of what Native Americans were/are. While she acknowledged that Native Americans had the right and the ability to change like members of all other cultures, she admitted that something "just did not sit right ${ }^{\prime 337}$ in relation to the authenticity of the artist's work. My friend's ideological struggle with the notion of modern-day Native Americans is an example of the confusion that can result from the Plankhouse's contestation of historical myths and misrepresentations. While it is necessary for the Cathlapotle Plankhouse to engage visitors in this revisionist discussion, there are repercussions that can lead visitors to leave the site confused, unsettled and unmotivated to return.

Because the funding for the design, construction, and interpretation of the Cathlapotle Plankhouse derived from funds allocated for the Lewis and Clark Bicentennial celebrations, many visitors expect the site to detail the history of the famous

${ }^{337}$ Author's personal experience. 
Expedition. For these visitors, the discussion of negative impacts the Expedition had on the future of Native Americans in the Pacific Northwest challenges the nostalgic colonial narrative associated with adventure, discovery and settlement. While many "Lewis and Clark buffs" find the Native element of the Lewis and Clark story to be insightful and interesting, others may find it threatening, as it challenges the very foundation of their identity as Americans. While a dynamic and well-rounded representation of Cathlapotle's history is essential in reframing the historical narrative of the Pacific Northwest, it also risks irritating visitors in a manner that reflects poorly on the historical site.

\section{Cathlapotle Is...}

As it exists today, the Cathlapotle Plankhouse functions as a diverse facility that meets the needs of a wide variety of user groups. As an educational center for visitors to the Ridgefield National Wildlife Refuge, the Plankhouse operates as a unique interpretive tool that uses alternative, multi-sensory forms of instruction to articulate the natural and cultural heritage of the site. As a cultural anchor for the Chinook Indian Nation, the Plankhouse honors the site's ancestors and provides the Tribe a communal gathering place that affirms, develops and celebrates their modern identity. Finally, the building serves as a political arena that challenges historical misinterpretations and existing power structures through its presence on the landscape and the interpretation that occurs within it. To fulfill these various multicultural needs, project partners were required to make compromises in the design, construction and interpretation process that modified the original vision of the Plankhouse. Despite the tensions that accompanied these "negotiated reciprocities," the cross-cultural collaboration between the U.S. Fish and 
Wildlife Service the Chinook Indian nation produced a unique and meaningful heritage building on the Ridgefield National Wildlife Refuge. 


\section{CONCLUSION}

A shift in the paradigm of Native American representation in the late 1980s and early 1990s has created an environment that promotes and, at times, legally mandates public historians and museum professionals to consult with the indigenous groups they seek to represent. ${ }^{338}$ Nearly two decades after the passage of the National Museum of the American Indian Act of 1989 (NMAIA) and the Native American Grave Protection and Repatriation Act of 1990 (NAGPRA), encouraging examples of cross-cultural collaboration have produced well-rounded, culturally comprehensive products that confront historic misrepresentations of Native Americans and provide an active voice to modern tribal entities. At the same time, less encouraging examples of this collaborative process have also emerged, as public historians and museum professionals attempt to navigate the newly charted waters of cross-cultural consultation with little experience and immature institutional policy to guide them. As museum professionals learn and grow from these successes and challenges, a shift in the balance of power between Native Americans and the institutions that represent them becomes more prominent. While tribal identities are far from having equal authority in deciding when, how and where they are presented to mainstream America, the growing association of cross-cultural collaboration with "good history" has given Native Americans increased power to act as custodians of their own culture. ${ }^{339}$

${ }^{338}$ Sullivan, Abraham and Griffin, Cultural Change in Museums, 233-234, 238; Maurer, "From Europe to American," 15, 26-28; Nason, "'Our' Indians," 40-45.

${ }^{339}$ M. Ames, "Curatorial Prerogative?," 85; Kreps, Liberating Culture, 3. 
In the case of the Cathlapotle Plankhouse Reconstruction Project, the shift in the power dynamic associated with indigenous representation in the last two decades becomes evident in a number of instances. First and foremost, the plethora of funding available for specifically Native projects during the Lewis and Clark Bicentennial commemoration suggests the Bicentennial Committee had identified a growing association of tribal involvement with successful and well-rounded history projects. In an environment that was increasingly challenging the invisibility and misrepresentation of Native American history and culture, organizers could not afford to champion a unidimensional colonial narrative that disregarded the catastrophic effects experienced by indigenous Americans. As such, large amounts of funding were offered to Native projects and projects with Native partners, including the Cathlapotle Plankhouse. The Chinook Indian Nation's participation in the Reconstruction Project was, therefore, crucial to its feasibility. This fact increased the Tribe's power to negotiate the terms of the partnership and the role they played in the Project. Such power became evident in the partners' dispute over access and safety codes in 2003.

While both the Chinook Indian Nation and the U.S. Fish and Wildlife Service were genuine in their desire for an equal partnership in the Cathlapotle Plankhouse Reconstruction Project, circumstances beyond the control of invested individuals disrupted the balance of power in a manner that challenged the stability of the partnership. As the bureaucratic nature of the U.S. Fish and Wildlife Service restricted the Agency's flexibility in the application of access and safety codes, control over the outcome of the Plankhouse Project shifted to the U.S. Fish and Wildlife Service and its Engineering Department. In an attempt to equalize the relationship once again, the 
Chinook Indian Nation asserted their ability to control the outcome by threatening to withdraw from the Project. As revealed in a letter from Gary Johnson to Regional Director David Allen, the Chinook Indian Nation understood the significance of their participation in the Project:

On May 8, 2004 the council passed a motion to withdraw participation from the Cathlapotle Plankhouse project unless the original intent of the P[roject] $\mathrm{M}$ [anagement] $\mathrm{T}[\mathrm{eam}]$ is upheld and the unilateral decision to make occupancy over forty-nine is reversed within 30 days. At the expiration of this time period the Chinook Nation will withdraw its support form the Cathlapotle Plankhouse project, announce this action via a press release and will consider contacting the Murdock and Meyer Foundations regarding its decision to withdraw from the project and its reasoning for this action...The Plankhouse has benefited immeasurably from the Chinook Nation's involvement in this project. ${ }^{340}$

Without Tribe support for and participation in the Cathlapotle Plankhouse Reconstruction

Project, the U.S. Fish and Wildlife Service would have been in direct violation of the legal agreements they held made with various funding bodies. Additionally, the Plankhouse would potentially lose the sense of historical authority and cultural authenticity. As tribal member Greg Robinson commented, the Plankhouse without the Chinook Indian Nation was a "sailboat without wind." 341 Understanding all they had to lose with the Chinook Indian Nation's resignation, the U.S. Fish and Wildlife Service's Engineering Department compromised for the first time in the year-long debate over safety codes. While the power of the U.S. Fish and Wildlife Service's bureaucracy required the Chinook Indian Nation to sacrifice many elements of the Plankhouse's

${ }^{340}$ Gary Johnson to David Allen, 8 May 2004, Gary Johnson's personal files, Chinook, WA, accessed 8 June 2010.

${ }^{341}$ G. Robinson to author, 24 May 2011. 
authenticity, the Tribe was granted the power to have fire in the structure for private tribal events; a power that not even the US Fish and Wildlife Service have. ${ }^{342}$

While the shifting balance of power between Native Americans and those that interpret them becomes apparent in the examination of the Cathlapotle Plankhouse Reconstruction Project, so too do the inequities that still remain. While some of the challenges faced by public historians and museum professionals in cross-cultural collaborations are the product of cultural misunderstanding and conflicting agendas, many are the result of confining institutional structures and policies. As argued by archaeologist Jon D. Daehnke, cross-cultural collaborations never occur on equal footing due to the colonial structures they take place in. ${ }^{343}$ While museums and historic sites are working to integrate Native Americans into the exhibition design and collections management process, the way in which these institutions operate and conduct business automatically renders Native Americans inferior in the decision-making process. First and foremost, public historians and museum professionals set the ground rules for collaboration, as they are the ones that determine whose history is important, who gets invited into the consultation process, what content is included and how it is interpreted. ${ }^{344}$ Additionally, demands for participation are usually required to be given in the 'language of the master' and gain legitimacy through institutions rooted in colonialism. ${ }^{345} \mathrm{~A}$ majority of projects, therefore, are unequal from the outset.

\footnotetext{
342 Raymond, interview by author.

${ }^{343}$ Daehnke, “A 'Strange Multiplicity' of Voices,” 270-271.

${ }^{344}$ M. Ames, "Curatorial Prerogative?," 78-79.

${ }^{345}$ Daehnke, “A 'Strange Multiplicity' of Voices,” 270.
} 
Further complicating the matter is the idea that the definition of equality begins from an institutional perspective. ${ }^{346}$ Even with the integration of Native themes, voices, and consultants, collaborative projects continue to be guided and controlled by representatives of colonial-embedded institutions. This is evident in the design of the Cathlapotle Plankhouse, as the U.S. Fish and Wildlife Service's desire for the Plankhouse to serve as an educational facility trumped the Chinook Indian Nation's desire for a traditionally-designed structure. Understanding the significant ramifications an increased occupancy would have on the authentic feel of the building, the U.S. Fish and Wildlife Service demanded regulations that catered to their need to accommodate large groups of people in the Plankhouse.

A lack of change in museum policy and procedure is also a source of inequality that stems from institutional structures embedded in colonialism. As articulated by anthropologist and museum director Michael Ames, museums are "complex social organizations composed of intertwined layers and routines, obligations, schedules, and competing interests that frequently inhibit prompt or consistent responses to new initiatives. ${ }^{״ 347}$ While demands for Native American involvement are prevalent within museums and other representative bodies, mechanisms that make this involvement possible and meaningful have been slower to develop. Quality cross-cultural collaboration requires greater resources and increasingly flexible timelines. ${ }^{348}$ In an industry commonly under-resourced and run by strict production schedules, these two

\footnotetext{
${ }^{346}$ M. Ames, "Curatorial Prerogative?," 76.

${ }^{347}$ Ibid., 85.

${ }^{348}$ Ibid., 81-82.
} 
requirements are not easily achieved. Additionally, policies and procedures need to be closely examined and changed to reflect their objective for consultation.

In the case of the Cathlapotle Plankhouse, the U.S. Fish and Wildlife Service mandated the management of identified cultural resources found on their land. While this mandate reflects the best of intentions for better representation of Native American culture, the policies and procedures of the Agency did not reflect its objective for cultural management and cross-cultural collaboration. For example, the U.S. Fish and Wildlife Service's Engineering Department refused to provide code exceptions to maintain the authenticity of the Plankhouse. For members of the Engineering Division and the Regional Safety Office, Agency policy was clear in its requirements of buildings built on their land. While Cultural Resource Team member Anan Raymond believed exceptions to the building code would be made due to its cultural, historic, and educational nature, building policy did not reflect special treatment for cultural resource management projects mandated by other policy. ${ }^{349}$ The benefits that derived from the Chinook Indian Nation's participation in the Project, therefore, were limited by restrictive and, at times, contradictory guidelines. Such contradiction baffled the Chinook Indian Tribe, construction manager Greg Robinson comments, as "the inability of the [U.S. Fish and Wildlife Service] to work creatively outside their box of regulations was beyond perplexing.",350

Finally, the very nature of established institutions creates an unbalanced power dynamic in their collaborations with Native American tribes. Most often bigger in size,

${ }^{349}$ For further discussion of the subject, please refer to Jon D. Daehnke's forthcoming article in Wicazo Sa Review.

${ }^{350}$ G. Robinson to author, 24 May 2011. 
richer in resources, and more respected as educational authorities, museums and historic agencies are often victims of their own characteristics in cross-cultural collaborations. In the Cathlapotle Plankhouse Reconstruction Project, for example, the U.S. Fish and Wildlife Service's size and capacity gave them considerable power over the small and under-resourced Chinook Indian Nation. While seemingly equal in voice and authority when the Project was confined to the small Cultural Resources Team and the Chinook Indian Nation, the integration of the various levels of U.S. Fish and Wildlife Service bureaucracy dramatically shifted the balance of power in favor of the Agency. As Jon D. Daehnke conveys in a forthcoming article about the Cathlapotle Plankhouse, the Chinook Indian Nation felt like the ground rules and the visions of the Project had been changed mid-project by higher-level bureaucratic authorities with little stake in the Project. In the eyes of the Tribe, the Plankhouse was no longer a collaboration between a confined body of people. ${ }^{351}$ Instead, it was yet another example of the federal government using its substantial power to control and define Native American tribes.

Cultural Resources Team member Anan Raymond reflected on this issue of scale in cross-cultural collaborations during my interview with him in May of 2010. When asked whether he thought conflict in cross-cultural collaborations was inevitable, Raymond responded as such:

I think it is inevitable or more likely when you have a government like the Fish and Wildlife Service and a tribe than it might be with an academic institution like a museum or a university and a tribe. And it is because of scale. The scale of the federal government - and the Fish and Wildlife Service is a tiny agency in the federal government, but even the scale of the Fish and Wildlife Service or just the scale of the Ridgefield National Wildlife Refuge in terms of money, manpower, and the whole pile of authority and laws behind it - dwarfs the capacity and scale

${ }^{351}$ Jon D. Daehnke, forthcoming article in Wicazo Sa Review. 
of almost any tribe in the Northwest. Certainly, it dwarfs the scale and capacity of the Chinook Tribe, an unrecognized tribe. So, although it is discouraging to say that such conflict is inevitable, I think there is something to that because of the vastly different capacity between the two entities who conduct business the way we conduct business in the 21 st century. I mean, ultimately, the tribe is forced to conduct business our way. That is a problem with scale and it is just the way the politics of these two governments are set up... They have nothing to do with philosophy or personalities or mission. ${ }^{352}$

Although the U.S. Fish and Wildlife Service could not control the innate power the Agency gained as a result of their larger size and their elevated capacity, the uneven power dynamic that were the product of these qualities created great obstacles to their partnership with the Chinook Indian Nation.

While public historians and museum professionals continue to grapple with the inequities that still exist in cross-cultural collaboration with Native American tribes, examples like the Cathlapotle Plankhouse provide a useful foundation from which these professionals can learn and grow. As more anthropologists, museologists, and public historians examine case studies and publish reflections on successful and unsuccessful collaborations with Native groups, "critical conversations" will occur and representation strategies will be fleshed out and adopted by institutional authorities. ${ }^{353}$ This has already begun to happen, as editors are assembling books of compiled articles that discuss the different dimensions of Native American representation and cross-cultural collaboration. $^{354}$

\footnotetext{
352 Raymond, interview by author, 22-23.

${ }^{353}$ Lonetree and Cobb, Critical Conversations, xiii.

${ }^{354}$ Examples of anthologies that discuss the different dimensions of cross-cultural collaboration and Native American representation include the Smithsonian Institutes The Changing Presentation of the American Indian (2000) and Amy Lonetree and Amanda Cobb's Critical Conversations (2008).
} 
In the meantime, public historians and museum professionals need to challenge the traditional structure of museum exhibitions and public history projects in creative and imaginative ways. As Cynthia Lamar reflects in her critique of an early exhibit at the National Museum of the American Indian, a majority of the ideas that emerged from collaboration with Native groups that challenged the conventional approaches to museology did not make into the exhibit due to budgetary restrictions, time issues, and the desire of museum professionals to stick with what they knew worked well. In other words, an exhibition with great cultural and historical potential was "constrained by conventionality." ${ }^{355}$ Amanda Cobb expands upon this idea, encouraging museums and other representative institutions to refrain from reverting back to traditional styles. Instead, Cobb argues, museums need to experiment with the symbolism and non-linear forms of meaning in Native American culture while preparing visitors for what they will see and engaging them to view exhibitions differently. ${ }^{356}$ These calls for change in the traditional museum model of Native American representation are summarized best by National Museum of the American Indian Director, W. Richard West, who contends museums must "reanalyze, redirect and in many cases, reformulate entirely the concepts

${ }^{355}$ Cynthia Chavez Lamar, "Collaborative Exhibit Development at the Smithsonian's National Museum of the American Indian," in The National Museum of the American Indian: Critical Conversations, ed: Amy Lonetree and Amanda J. Cobb, (Lincoln, NE: University of Nebraska Press, 2008), 156.

${ }^{356}$ Amanda J. Cobb, "The National Museum of the American Indian as Cultural Sovereignty," in The National Museum of the American Indian: Critical Conversations, ed: Amy Lonetree and Amanda J. Cobb, (Lincoln, NE: University of Nebraska Press, 2008), 350. 
and presentations of the past concerning Indian culture...In a very real sense, the walls of the museum must come down.",357

At the Cathlapotle Plankhouse, project partners challenged the conventional notions of museums and education centers in a manner that allowed the structure to serve a diverse range of purposes for a number of different stakeholders. First and foremost, the physical structure of the Plankhouse creatively balances the U.S. Fish and Wildlife Service's practical needs for educational accommodation with the Chinook Indian Nation's needs for cultural authenticity. From the outside, the structure provides a historically evocative setting that allows visitors to transport themselves "back in time" and contextualize what they are about to learn inside the Plankhouse with its surrounding environment. Inside the Plankhouse, interpretation of the structure relies on its rich materiality and oral instruction to deliver information that would normally be provided by interpretive panels and artifact cases. As argued by Laura Peers, opportunities to touch, taste, smell, hear and view different aspects of historic sites act as a catalyst for visitor contemplation that often leads to questions and conversations about less ephemeral issues like social history and cross-cultural relations. ${ }^{358}$ With a wide variety of physical stimuli to generate multifaceted historical conversations, Plankhouse partners have provided a uniquely interactive and educational atmosphere that largely preserves the structure's authentic feel for both visitors and Chinook Indian Nation ceremonies. While there are interpretive implications that accompany this method of information delivery, partners of the Cathlapotle Plankhouse have challenged conventional notions of museum displays in

${ }^{357}$ Richard West, as cited in Bordewich, Killing the White Man's Indian, 171.

${ }^{358}$ Peers, Playing Ourselves, 90, 92. 
a fashion that has also led to a more nuanced understanding of Chinookan history at the Ridgefield National Wildlife Refuge.

The Cathlapotle Plankhouse also uniquely challenges the conventional notions of museums and education centers by addressing the colonial-based myths of Native American savagery and extinction in a subtle and physically-based manner. The mere existence of the Plankhouse challenges the invisibility of Native American peoples in the Pacific Northwest's colonial narrative. Additionally, the internal features of the structure reject notions of Native American barbarianism by depicting a culture of economic prosperity, social hierarchy, the ownership of property, and the existence of elaborate material culture; qualities typically associated with "civilized" non-Native societies. ${ }^{359}$ The Chinook Indian Nation's participation in instructional activities and cultural events as $21^{\text {st }}$ century tribal members also rejects the colonial misrepresentation of Native American as extinct or incapable of evolution without assimilation. ${ }^{360}$ James Clifford $^{3}$ argues this assertion of modern existence is "a powerful political act for groups who have long been marginalized and made to disappear., ${ }^{361}$ Encouragingly, the Chinook Indian Nation and the U.S. Fish and Wildlife Service have challenged deeply-rooted colonial myths in a subtle yet effective manner, using materiality to contradict stereotypes and historical misconceptions of Native Americans. In an era that increasingly encourages well-rounded and encompassing historical narratives, the Cathlapotle Plankhouse serves

${ }^{359} \mathrm{~K}$. Ames, Peoples of the Northwest Coast, 13.

${ }^{360}$ Raibmon, Authentic Indians, 9.

${ }^{361}$ Clifford, "Looking Several Ways,", 9. 
as a positive example of the ways in which history can be revised within "contact zones" in a tactful and educational fashion. ${ }^{362}$

In a time of increasing and continuously evolving change within the museum paradigm in relation to Native American representation, the Cathlapotle Plankhouse provides public historians and museum professionals another example of the challenges and rewards that result from cross-cultural collaboration. Although unified in their objective to building a full-scale Chinookan plankhouse on the Ridgefield National Wildlife Refuge, the principal partners of the Cathlapotle Plankhouse Reconstruction Project each had different priorities for the Plankhouse that both complimented and complicated each other. Invariably, compromises were made that allowed the Plankhouse to act as an educational center for the U.S. Fish and Wildlife Service and a cultural hub and a political arena for the Chinook Indian Nation. While these "mutual reciprocities" were accompanied by interpretive implications that detracted from the other partner's priorities, they also strengthened the Plankhouse's ability to be a unique and meaningful place for a wide range of user groups. ${ }^{363}$ While the design, construction and interpretation process of this structure was hindered by a number of cultural challenges, it is important to note that the partnership between the U.S. Fish and Wildlife Service and the Chinook Indian Nation created a significant heritage structure that is worthy of emulation. Perhaps the most important lesson public historians and museum professionals can take away from Cathlapotle is that "we are now a mere two decades

${ }^{362}$ Mary Louise Pratt, Imperial Eyes: Travel Writing and Transculturation, as quoted in Peers, Playing Ourselves, xx.

${ }^{363}$ Ibid., 6. 
down the road in a process that is still unfolding and will continue to unfold for years to come."364

${ }^{364}$ Phillips, review of "Looking Several Ways," 25. 


\section{SECONDARY SOURCES CONSULTED}

Ames, Kenneth M., William Cornet, Cameron Smith, Elizabeth Sobel, Stephen Hamilton, John Wolf, and Doria Raetz. Archaeological Investigations at 45CL1 Cathlapotle (1991-1996), Ridgefield National Refuge, Clark County, Washington - A Preliminary Report. US Fish and Wildlife Service, 1999.

Ames, Kenneth M., and Herbert D. G. Maschner. Peoples of the Northwest Coast: Their Archaeology and Prehistory. New York, NY: Thames \& Hudson, 1999.

Ames, Michael M. "Are Changing Representations of First Peoples in Canadian Museums and Galleries Challenging the Curatorial Prerogative?" In The Changing Presentation of the American Indian: Museums and Native Cultures, ed. National Museum of the American Indian, 73 - 88. Washington, D.C.: National Museum of the American Indian, 2000.

Atalay, Sonya. "No Sense of the Struggle: Creating a Context for Survivance at the National Museum of the American Indian." In The National Museum of the American Indian: Critical Conversations, ed. Amy Lonetree and Amanda J. Cobb, 267 - 289. Lincoln, NE: University of Nebraska Press, 2008.

Atkin, Tony and Carol Herselle Krinsky. "Cultural Identity in Modern Native American Architecture: A Case Study." Journal of Architecture 49, no. 4 (May, 1996): 237 245.

Boyd, Robert T. The Coming of the Spirit of Pestilence: Introduced Infectious Diseases and Population Decline Among Northwest Coast Indians, 1774-1874. Seattle, WA: University of Washington Press, 1999.

Beckham, Stephen Dow. Chinook Indian Tribe: Petition for Federal Acknowledgement. Lake Oswego: USA Research, 1987.

Bordewich, Fergus M. Killing the White Man's Indian: Reinventing Native Americans at the End of the Twentieth Century. New York, NY: Doubleday, 1996.

Brady, Miranda. "A Dialogic Response to the Problematized Past." In Contesting Knowledge: Museums and Indigenous Perspectives, ed. Susan Sleeper-Smith, 133 155. Lincoln, NE: University of Nebraska Press, 2009.

Brightman, Robert. "Culture and Culture Theory in Native North America." In New Perspectives on Nä̈ve North America: Cultures, Histories and Representations, ed. Sergei A. Kan and Pauline Turner Strong, 351 - 394. Lincoln, NE: University of Nebraska Press, 2006. 
Carpio, Myla Vicenti. “(Un)disturbing Exhibitions: Indigenous Historical Memory at the National Museum of the American Indian." In The National Museum of the American Indian: Critical Conversations, ed. Amy Lonetree and Amanda J. Cobb, 290 - 304. Lincoln, NE: University of Nebraska Press, 2008.

Castile, George Pierre and Robert L. Bee. State and Reservation: New Perspectives on Federal Indian Policy. Tuscon, AR: The University of Arizona Press, 1992.

Clements, Janice. "The Integration of Traditional Indian Beliefs into the Museum at Warm Springs." In The Changing Presentation of the American Indian: Museums and Native Cultures, ed. National Museum of the American Indian, 67 - 71. Washington, D.C.: National Museum of the American Indian, 2000.

Clifford, James. "Four Northwest Coast Museums: Travel Reflections." In Exhibiting Cultures: The Poetics and Politics of Museum Display, ed. Ivan Karp and Steven D. Lavine, 212 - 254. Washington, D.C.: Smithsonian Institution Press, 1991. . "Looking Several Ways: Anthropology and Native Heritage in Alaska." Current Anthropology 45, no. 1 (February 2004): 5 - 30.

Cobb, Amanda J. "The National Museum of the American Indian as Cultural Sovereignty." In The National Museum of the American Indian: Critical Conversations, ed Amy Lonetree and Amanda J. Cobb, 331 - 352. Lincoln, NE: University of Nebraska Press, 2008.

Conner, Roberta, Edward Hall III, and Sammye Meadows. Enough Good People: Reflections of Tribal Involvement and Inter-Cultural Collaboration 2003-2006. Grand Junction, CO: Colorado Printing Company.

Cooper, Karen Coody. Spirited Encounters: American Indians Protest Museum Policies and Practices. Lanham, MD: AltaMira Press, 2008.

Daehnke, Jon D. “A 'Strange Multiplicity’ of Voices: Heritage Stewardship, Contested Sites, and Colonial Legacies on the Columbia River." Journal of Social Archaeology 7, (2007): $250-275$.

. Cathlapotle ... Catching Time's Secrets. Sherwood OR: U.S. Fish \& Wildlife Service Cultural Resources Team Region 1, 2002.

. "Public Outreach and the "Hows" of Archaeology: Archaeology as a Model for Education.” M.A. thesis, Portland State University, 2002.

Deloria, Philip J. Indians in Unexpected Places. Lawrence, KS: University Press of Kansas, 2004. 
. Playing Indian. New Haven, CT: Yale University Press, 1998.

Erikson, Patricia Pierce. 'Decolonizing the 'Nation's Attic:' The National Museum of the American Indian and the Politics of Knowledge-Making in a National Space.” In The National Museum of the American Indian: Critical Conversations, ed. Amy Lonetree and Amanda J. Cobb, 43 - 83. Lincoln, NE: University of Nebraska Press, 2008.

Fine-Dare, Kathleen S. Grave Injustice: The American Indian Repatriation Movement and NAGPRA. Lincoln, NE: University of Nebraska Press, 2002.

Franchere, Gabriel. Adventures at Astoria, 1810-1814, ed. and trans. Hoyt Franchere. Norman, OK: University of Oklahoma Press, 1967.

Green, Anna and Kathleen Troup, The Houses of History: A Critical Reader in the Twentieth-Century History and Theory. Washington Square, NY: New York University Press, 1999.

Hendry, Joy. Reclaiming Culture: Indigenous People and Self-Representation. New York, NY: Palgrave MacMillan, 2005.

Hill, Richard W., Sr. "The Indian in the Cabinet of Curiosity." In The Changing Presentation of the American Indian: Museums and Native Cultures, ed. National Museum of the American Indian, 103 - 108. Washington, D.C.: National Museum of the American Indian, 2000.

Hoagland, Alison K. "Totem Poles and Plank Houses: Reconstructing Native Culture in Southeast Alaska." Perspectives in Vernacular Architecture 6 (1997): 174-185.

Huhndorf, Shari M. Going Native: Indians in the American Cultural Imagination. Ithaca, NY: Cornell University Press, 2001.

Issac, Gwyneira. "What Are Our Expectations Telling Us?: Encounters with the National Museum of the American Indian." In The National Museum of the American Indian: Critical Conversations, ed: Amy Lonetree and Amanda J. Cobb, 241 - 266. Lincoln, NE: University of Nebraska Press, 2008.

Jansen-Verbeke, Myriam. "Territorial Embedding of Intangible Heritage and Cultural Tourism.” In Sharing Cultures 2009: International Conference on Intangible Heritage, ed: Sergio Lira, Rogerio Amoeda, Cristina Pinheiro, Joao Pinheiro, and Fernando Oliveira, 301 - 306. Barcelos, Portugal: Green Lines Institute for Sustainable Development, 2009. 
Jacknis, Ira. "A New Thing?: The National Museum of the American Indian in Historical and Institutional Context." In The National Museum of the American Indian: Critical Conversations, ed. Amy Lonetree and Amanda J. Cobb, 3 - 42. Lincoln, NE: University of Nebraska Press, 2008.

Jonaitis, Aldona and Janet Catherine Berlo. "'Indian Country' on the National Mall: The Mainstream Press versus the National Museum of the American Indian." In The National Museum of the American Indian: Critical Conversations, ed. Amy Lonetree and Amanda J. Cobb, 208 - 240. Lincoln, NE: University of Nebraska Press, 2008.

Julig, Patrick. Archaeological Theme Parks, Public Archaeology, and Living Museums: Prospects for the Upper Great Lakes Region. Sudbury, Ontario: Laurentian University Press, 2008.

Kehoe, Alice B. North American Indians: A Comprehensive Account. Englewood Cliffs, N.J.: Prentice-Hall, 1981.

King, C. Richard. "Surrounded by Indians: The Exhibition of Comanche and the Predicament of Representing Native American History." The Public Historian 18, no. 4 (Autumn, 1996): 37 - 51.

Kreps, Christina F. Liberating Culture: Cross-Cultural Perspectives on Museums, Curation, and Heritage Preservation. New York, NY: Routledge, 2003.

Krinsky, Carol Herselle. Contemporary Native American Architecture: Cultural Regeneration and Creativity. New York, NY: Oxford University Press, 1996.

Lamar, Cynthia Chavez. "Collaborative Exhibit Development at the Smithsonian's National Museum of the American Indian." In The National Museum of the American Indian: Critical Conversations, ed: Amy Lonetree and Amanda J. Cobb, 144 - 164. Lincoln, NE: University of Nebraska Press, 2008.

Mason, Courtney W., "The Buffalo Nations/Luxton Museum: Tourism, Regional Forces and Problematizing Cultural Representations of Aboriginal Peoples in Banff, Canada." International Journal of Heritage Studies 15, no. 4 (July 2009): 355 - 373.

Maurer, Evan. "Presenting the American Indian: From Europe to America." In The Changing Presentation of the American Indian: Museums and Native Cultures, ed: National Museum of the American Indian, 15 - 28. Washington, D.C.: National Museum of the American Indian, 2000. 
Mitsche, N., F. Vogt, D. Knox, I. Cooper, P. Lombardi, and D. Ciaffi. "Intangibles: Enhancing Access to Cities Cultural Heritage through Interpretation." In Sharing Cultures 2009: International Conference on Intangible Heritage, ed. Sergio Lira, Rogerio Amoeda, Cristina Pinheiro, Joao Pinheiro, and Fernando Oliveira, 319 - 327. Barcelos, Portugal: Green Lines Institute for Sustainable Development, 2009.

Moore, John H. "The Enduring Reservations of Oklahoma." In State and Reservation: New Perspectives on Federal Indian Policy, ed. George Pierre Castile and Robert L. Bee, 92 - 109. Tuscon, AR: The University of Arizona Press, 1992.

Nason, James D. "'Our' Indians: The Unidimensional Indian in the Disembodied Local Past." In The Changing Presentation of the American Indian: Museums and Native Cultures, ed. National Museum of the American Indian, 29 - 46. Washington, D.C.: National Museum of the American Indian, 2000.

Nichols, Roger L. Indians in the United States and Canada: A Comparative History. Lincoln, NE: University of Nebraska Press, 1998.

Ostrowitz, Judith. "Concourse and Periphery: Planning the National Museum of the American Indian." In The National Museum of the American Indian: Critical Conversations, ed. Amy Lonetree and Amanda Cobb, 84 - 127. Lincoln, NE: University of Nebraska Press, 2008.

Park, H.Y. "Re-imagining Two Koreas as One Nation: Heritage Tourism Experiences of Changdeok Palace, South Korea." In Sharing Cultures 2009: International Conference on Intangible Heritage, ed. Sergio Lira, Rogerio Amoeda, Cristina Pinheiro, Joao Pinheiro, and Fernando Oliveira, 329 - 337. Barcelos, Portugal: Green Lines Institute for Sustainable Development, 2009.

Parks, Virginia. Discover Cathlapotle!: A Teacher's Workshop Guide for the Cathlapotle Environmental and Heritage Education Kit. Portland, OR: U.S. Fish and Wildlife Service, 1995.

Parman, Donald L. Indians and the American West in the Twentieth Century. Bloomington, IN: Indiana University Press, 1994.

Peers, Laura. Playing Ourselves: Interpreting Native Histories at Historic Reconstructions. Lanham, MD: Altamira Press, 2007.

Penney, David W. "The Poetics of Museum Representations: Tropes of Recent American Indian Art Exhibitions." In The Changing Presentation of the American Indian: Museums and Native Cultures, ed. National Museum of the American Indian, 47 - 65. Washington, D.C.: National Museum of the American Indian, 2000. 
Porter, Frank W. III, "Without Reservation: Federal Indian Policy and the Landless Tribes of Washington." In State and Reservation: New Perspectives on Federal Indian Policy, ed. George Pierre Castile and Robert L. Bee, 110 - 135. Tuscon, AR: The University of Arizona Press, 1992.

Raibmon, Paige. Authentic Indians: Episodes of Encounter from the Late-NinteenthCentury Northwest Coast. Durham, NC: Duke University Press, 2005.

Ray, Verne Frederick. Lower Chinook Ethnographic Notes. Seattle, WA: University of Washington, 1938.

Ruby, Robert H. Ruby and John H. Brown. The Chinook Indians: Traders of the Lower Columbia River. Norman: University of Oklahoma Press, 1976.

Sarasohn, David. Waiting for Lewis and Clark: The Bicentennial and the Changing West. Portland, OR: Oregon Historical Society Press, 2005.

Silverstein, Michael. "Chinookans of the Lower Columbia River." In Handbook of North American Indians, Volume 7: Northwest Coast, ed. Wayne Suttles and William Sturtevant (Smithsonian Institution, 1990).

Smith, Paul Chaat. "Critical Reflections on the Our Peoples Exhibit: A Curator's Perspective." In The National Museum of the American Indian: Critical Conversations, ed. Amy Lonetree and Amanda J. Cobb, 131 - 143. Lincoln, NE: University of Nebraska Press, 2008.

Sohn, Emily. "Board Rooms: Near Portland, Oregon, Archaeologists and Indians Have Built an Authentic Chinookan Plankhouse like those Lewis and Clark Saw," Smithsonian 36, no. 4 (2005): 30-33.

Stone, Thomas. "Listening to the Voices: Preserving Aboriginal Heritage 'Then' and 'Now,' A Comparison of Two Symposia." In Sharing Cultures 2009: International Conference on Intangible Heritage, ed. Sergio Lira, Rogerio Amoeda, Cristina Pinheiro, Joao Pinheiro, and Fernando Oliveira, 341 - 351. Barcelos, Portugal: Green Lines Institute for Sustainable Development, 2009.

Sullivan, Tim J., Morris Abraham, and Des Griffin. "NAGPRA: Effective Repatriation Programs and Cultural Change in Museums," CURATOR 43 (2000): 231-260.

Tolmie, William Tolmie. The Journals of William Fraser Tolmie, Physician and Fur Trader. Vancouver, Canada.: Mitchell Press, 1963.

Trofanenko, Brenda. "Displayed Objects, Indigenous Identities, and Public Pedagogy." Anthropology and Education Quarterly 37, no. 4 (2006): 309 - 327. 
Warrior, R.A. “A Marginal Voice.” Native Peoples 1, no. 3 (1991).

van Dartel, Daan, “There's a Story Behind Everything: Moving Towards the Intangible at the Tropenmuseum." In Sharing Cultures 2009: International Conference on Intangible Heritage, ed. Sergio Lira, Rogerio Amoeda, Cristina Pinheiro, Joao Pinheiro, and Fernando Oliveira, 341 - 351. Barcelos, Portugal: Green Lines Institute for Sustainable Development, 2009.

Wedll, Joycelyn. "Learn About Our Past to Understand Our Future: The Story of the Mille Lacs Band of Ojibwe." In The Changing Presentation of the American Indian: Museums and Native Cultures, ed. National Museum of the American Indian, 89 - 97. Washington, D.C.: National Museum of the American Indian, 2000.

Wuerch, William Lee. "History of the Middle Chinooks to the Reservation Era." M.A. Thesis, University of Oregon, 1979.

West, W. Richard Jr. "A New Idea of Ourselves: The Changing Presentation of the American Indian." In The Changing Presentation of the American Indian: Museums and Native Cultures, ed. National Museum of the American Indian, 7 - 13. Washington, D.C.: National Museum of the American Indian, 2000.

. "Cultural Rethink." In The Changing Presentation of the American Indian: Museums and Native Cultures, ed. National Museum of the American Indian, 99 102. Washington, D.C.: National Museum of the American Indian, 2000. 
APPENDIX A

PUBLIC HISTORY COMPONENT

\title{
MEMORANDUM
}

\author{
TO: $\quad$ Katie Harrison \\ FROM: $\quad$ Erica Stevenson \\ DATE: $\quad$ December 7, 2009 \\ RE: $\quad$ Proposed Accession Procedure
}

I have attached to this memo a black and white and a color version of a proposed acquisition and accession procedure that could be integrated into the larger Collections Management Policy of the Cathlapotle Plankhouse. The colored text on the one of the versions is meant to be provide insight as to where I pulled text from to comprise the larger procedure. A legend regarding what color represents which museum policy is at the top of this colored version of the procedure.

Based on the initial comments you had pertaining to what you would like to see in an acquisition policy, I used the "Acquisitions" section of the Issaquah Historical Society's Collections Management Policy that you provided me as a base for this custom procedure. I felt that this policy best conveyed a detailed but brief accessioning procedure that also addressed potentially problematic areas in collections like tax status, appraisals, and rejection of attempted donations. From this base procedure, I replaced and/or inserted additional text from other museum policies that I felt better explained the necessary processes or addressed issues not present in the Issaquah Historical Society's policy. I also inserted my own text at points in an attempt to address procedures that you and I have discussed (e.g. the presence of the Cultural Committee and their need to approve accessions into the permanent collection in particular cases), which is reflected in the color-coded version of my proposed policy.

This is my best attempt to understand the collection needs of Cathlapotle, acknowledging that you have a far superior comprehension of what is best for the collection. I, therefore, left section B and section C (Specific Criteria for Acquisitions and Criteria for Purchases) 
blank, as I felt you would have a better grasp on what you would like included in those sections. The Issaquah Historical Society's policy provides a good template for considerations, but I did not want to inject them in this proposal due to my lack of familiarity with your specific intentions for the collection.

While many of my additions or changes in the Issaquah Historical Society's policy were based on my belief that other policies encompassed more or stated something in a better manner, a few insertions I feel require extra explanation. In Section A, Number 7, I inserted the purple text from the Samish Indian Nation because I felt that they would be the best institution to articulate and interpret issues revolving around NAGPRA. I was uncertain if this directly reflected the policy you would like for Cathlapotle, but I felt an addition acknowledging NAGPRA in some form was needed since the collection at the Plankhouse is comprised of American Indian objects.

I also chose to combine the idea of a donor file and a catalogue file. While these are two different things in some of the policies that you provided me, I felt with the current space and funding limitations of the Plankhouse that combining these two files would be a better use of available resources. I wanted you to be aware of this editorial choice on my behalf in the event that you have additional knowledge for why it is important for these two files to be separate. From my experience at the Oregon Historical Society, artifact files operate as both donor and catalogue files in a sufficient manner. I also generated the name "artifact file" for these combined files, as this name, I felt, made the purpose of these files transparent. You will not see a reference to "artifact files" in any of the other policies.

I have also inserted the presence of the Cultural Committee into the proposal due to our previous conversation regarding Sam Robinson's desire to sometimes but not always run by potential educational and permanent collection acquisitions with the Cultural Committee. While I feel that the presence of this Committee in the policy is vital, I was not sure to what extent you and they were wanting to be involved in the approval process of donated artifacts, so please pay close attention to my additions of this Committee in the policy to make sure that their role is represented as you have envisioned it.

Finally, I have provided some example forms that I have created from documents that you have provided me or that I have used in the past with the Oregon Historical Society. These are just recommended forms regarding their format and content. I have provided you electronic copies with them in the disk that accompanies this memo.

Otherwise, I hope that my additions are self-explanatory. If you have any questions, please email me and I will let you know what my thought process was. I would also love to continue helping with this project in the future if you are happy with what I have produced, so keep me in mind if you like what you see! 


\section{LEGEND}

Black text $=$ Issaquah Historical Society's Collections Management Policy

Red text $=$ The Thomas Burke Memorial Washington State Museum Policy

Orange text $=$ Henry Art Gallery Collections Policy

Green text $=$ Renton Historical Society and Museum Collections Policy

Blue text $=$ My own wording

Brown text $=$ The Wing Luke Asian Museum Policy and Procedures Manual

Purple text $=$ Samish Indian Nation Collections Management Policy

\section{ACQUISITIONS}

\section{A. General Criteria for Acquisitions}

Any acquisition made as a result of gift, bequest, purchase or exchange will be in the best interests of the Museum, the public it serves, and the public trust it represents in owning and expanding the collection:

1. The item must be appropriate to the permanent collection in that it relates to the stated goals and mission of the Museum.

2. The item must be of high quality for collection, exhibition, education, or research use.

3. The item must be in good physical condition or economically repairable, unless it is a unique, one-of-a-kind item.

4. The item must not be excessively duplicated in the permanent collection.

5. The item must not be a significant financial burden to retain in terms of extensive restoration, maintenance, or storage needs, unless funds for extraordinary costs are available.

6. The item must not present a hazard to health or well being of museum staff, volunteers or visitors. Hazardous artifacts are defined as those that have become dangerous because of damage, deterioration, or chemical composition that could cause explosion, fire or other conditions of destructive nature. Examples include fabrics suffering chemical reaction or items contaminated with mildew or animal feces.

7. The item was collected legally and is in conformity with tribal, national, state, and local laws and regulations. The Cathlapotle Plankhouse may acquire objects that have been legally confiscated or repatriated and given to the Cathlapotle Plankhouse by appropriate authorities regardless of how the objects were collected originally.

B. Specific Criteria for Acquisitions 


\section{Criteria for Purchases \\ D. Accession Procedure}

All objects offered to the Museum are to be reviewed by the Cultural Committee and the Plankhouse Coordinator. The Cultural Committee and the Plankhouse Coordinator together determine whether or not to accept an object based on the general criteria for acquisitions. All proposed purchases require approval of the Cultural Committee.

\section{Temporary Collection Receipt}

A temporary collection receipt is issued for all objects that are presented for consideration by the Cultural Committee. On this form, the potential donor's name, address, and any information relating to the artifact and its respective provenance should be included. The potential donor should sign the form to show that there is no guarantee that this item will be accessioned or accepted. A sample Temporary Collection Receipt has been attached to this policy. (Attachment A)

If the Cultural Committee accepts the object, the donation is assigned an accession number.

\section{Accession Number}

Upon acceptance, a donation is assigned an accession number. The accession number consists of the year of the accession, the accession number, and the number of the object within that accession. If there are two parts to an object, the largest or most important part of the object is labeled with the letter " $\mathrm{A}$ " at the end of the accession number, and other parts are labeled with b, c, d, etc. Donations comprised of only one object do not require the third number, and objects with a single part do not require the addition of a letter.

\section{EXAMPLE:}

Accession Number: 1991.4.10 A, B

$1991=$ the year the object was received

$.4=$ the $4^{\text {th }}$ accession of the year 1991 ( $4^{\text {th }}$ donor of the year $)$

$.10=$ the $10^{\text {th }}$ object in the $4^{\text {th }}$ accession group of objects (if only one object is accessioned, there is no need to use this third number, e.g. 1991.4)

$\mathrm{A}, \mathrm{B}=$ if the object has more than one part, each part is given a letter

3. Acknowledgment Letter, Deed of Gift, and/or Bill of Sale 
For each new accession, a formal acknowledgement letter is sent by the Plankhouse Director to the donor listing the objects received. Each acknowledgement letter should include the accession number assigned to the gift so that if there are any questions, the original records can be readily consulted. A sample acknowledgement letter has been generated for assistance in this process. (Attachment B)

A Deed of Gift should be included with the acknowledgement letter, along with a self-addressed stamped envelope for the original Deed to be returned in. When a donation is accepted by the Plankhouse, the donor is required to sign a Deed of Gift, which relinquishes the object to the Plankhouse as an outright gift, unrestricted and without limiting conditions. Items cannot be considered fully accessioned without this document. A photocopy should be made of the signed Deed of Gift for the donor and for the artifact file. For objects without a Deed of Gift, the object shall be deemed abandoned and the validated Temporary Collections Receipt will act in its place after five years. A sample Deed of Gift has been generated for assistance in this process (Attachment C).

In the instance an object was purchased for the collection, a Bill of Sale must be obtained for proof of purchase.

\section{Accession Record}

After an item has been issued an accession number, a record of this accession must be produced, detailing (when applicable):

1. Accession number

2. Object name

3. Category and class of donation

4. Acquisition date and source information

5. Original maker / artist and location

6. Measurements

7. Associated activities and / or use of item

8. Related artifacts

9. Material make-up of object

10. Technique of manufacture

11. Condensed description, including inscription and//or markings

12. Provenance

13. Condition of item

Accession records should be entered into an electronic database, as well as printed in paper form to be filed in individual artifact files (see below). An accessioning worksheet has been generated to provide assistance in the creation of an accession record. (Attachment D)

5. Artifact Files 
An artifact file for all properly acknowledged gifts and purchases to the Plankhouse should be created after accessioning. These files should hold copies of all paperwork involving acquisition, including basic object information, correspondence with the donor or seller, and ownership history. Such paperwork would include the Temporary Collection Receipt, the acknowledgement letter, the Deed of Gift, and the accession record. Additional information regarding an object's use, storage requirements, etc. should also be stored in this file.

In the instance an item has been purchased, artifact files should also contain any paperwork and receipts regarding the purchase of the item. This includes copies of the Bill of Sale, receipts, and correspondence with the vendor / artist.

\section{Tax Status of Donor and Museum}

Donors will be asked to contact tax advisors for specific information concerning donations to the Plankhouse. The Cathlapotle Plankhouse will not advise the donor as to the specifics regarding charitable contributions. The responsibility rests solely with the donor.

\section{Appraisals and Authentications}

The Cathlapotle Plankhouse shall not make appraisals of objects to establish taxdeductible value of gifts offered to the Plankhouse or for any other purpose. This could be construed as a conflict of interest.

\section{If Object Is Not Accepted}

When the Cultural Committee does not accept an object, the owner is notified as to the Committee's decision. When the owner retrieves the object, they must sign the Plankhouse's copy of the Temporary Collection Receipt, indicating that the object has been returned.

\section{Objects Acquired for Educational Purposes}

The educational portion of Cathlapotle's collection seeks to acquire archival, archaeological, ethnographic and contemporary objects that can be used to aid in teaching the history of the Ridgefield National Wildlife Refuge.

Expendable objects may be accepted or purchased for educational purposes, with the recommendation of the Cultural Committee, if they are relevant and useful to the purposes and activities of the Cathlapotle Plankhouse's education and public programs. Those objects are acknowledged but not accessioned into the Plankhouse's collections. An agreement setting forth an adequate description of the 
objects involved is prepared for all gifts made to the Plankhouse for educational purposes. 


\section{MEMORANDUM}

TO: $\quad$ Katie Harrison

FROM: $\quad$ Erica Stevenson

DATE: $\quad$ November $4^{\text {th }}, 2009$

RE: $\quad$ Storage of Bone, Antler, Ivory, and Teeth

Bone, antler, ivory and teeth are similar in make-up and appearance, but they do have slight structural and physical differences that can help a collector differentiate the materials. All, however, are stored in similar conditions.

\section{STRUCTURAL AND PHYSICAL DIFFERENCES}

Bone, ivory, and teeth are composed of both mineral and carbon-based materials. The mineral part of bone is made up mostly of calcium, phosphorus, and fluoride. The carbon-based portion is composed of a protein called ossein. This protein is similar to the collagen found in skin.

Ivory is technically the tusk of an elephant, but the category can be broadened to include whale, hippopotamus, boar, or other animal teeth. All of these consist dentin, which grows in a layered structure. The composition of ivory is both organic and inorganic, making it extremely sensitive and reactive.

Bone is similarly sensitive and reactive to environmental factors. Bone has small pores that appear black or dark in appearance, differentiating itself from ivory.

The internal structure of antler is similar to bone, with a large porous area below the surface. The outer surfaces can be distinguished from bone by the fact that the larger sections of antlers generally have raised bumps and protrusions, whereas skeletal bones are smooth except in attachment areas.

Teeth have two major components: the root area, which is similar to bone in composition and appearance, and the upper surface, which consists of compact enamel. The root area is usually a yellowish tan color with a matte surface, and the enamel is shiny and can be white or yellowish white. The enamel layer is generally resistant to decay and breakage. The root section, however, can dry out and split, causing stresses to the enamel layer that may result in further delamination and breakage. 


\section{STORAGE AND HANDLING}

The deterioration of bone, antler, ivory, and teeth is caused by:

- extreme dryness

- excess heat, which leads to destruction of the protein portion and loss of moisture, causing shrinkage and cracking of the surface

- excess moisture, which leads to swelling of the protein portion and promotes mold growth

- combination of excess heat and moisture, which destroys the ossein and can cause warping and cracking when the item dries out

- rodent attack, especially on bones and the dentine of teeth

- acids

- exposure to strong visible and ultraviolet light, which causes bleaching of the natural color of ivory

To prevent the aforementioned deterioration, a consistent temperature and humidity are important for these materials. Generally a relative humidity level of no less than 30 percent in the winter and no more than 55 percent in the summer is best, with fluctuations of not more than 15 percent during each season. The optimum temperature is 68 degrees Fahrenheit with fluctuations of no more than $+/-3$ degrees a day. Avoid storing and exhibiting these objects near radiators, heat pipes, outside windows, or incandescent lights, which can cause excessive drying and temperature fluctuations.

Items with holes, straps, appendages, or other attachments must never be hung or supported by those attachments. A support can be provided at the base of the item, and the handle or strap can be supported in a natural position.

Bone, antler, ivory, and teeth items are generally not susceptible to insects. Maintain good housekeeping and employ regular pest control services to prevent rodents and small animals from getting to the items and gnawing on their surface.

Bone, antler, ivory, and teeth items can become infested with mold, particularly if the relative humidity in the storage or display areas is allowed to exceed 60 percent for long periods of time. Mold infestations can be recognized by a white or greenish fuzzy growth on the surface of items. Good ventilation and air circulation in storage and display areas will help prevent mold. It fit does occur, ask a conservator about how to clean the surfaces safely.

Regarding light, keep materials out of harsh, strong lighting due to the possibility of bleaching. 
When handling these items, you can use bare hands, but keep in mind that body oils can stain the material, especially light colored and matted, porous-textured objects. The use of cotton or latex gloves is suggested when handling objects of this nature.

\section{SOURCES USED:}

- Sherelyn Ogden, Caring for American Indian Objects: A Practical and Cultural Guide, (St. Paul: Minnesota Historical Society Press, 2004).

- Ed: Arthur Shultz, Caring for Your Collections, (New York: Harry N. Abrams, Inc. Publishers, 1992).

- Ed: Rebecca Buck and Jean Allman Gilmore, The New Museum Registration Methods, (Washington DC: American Association of Museums, 1998.) 


\section{MEMORANDUM}

TO: $\quad$ Katie Harrison

FROM: $\quad$ Erica Stevenson

DATE: $\quad$ October 9, 2009

RE: $\quad$ Storage of Animal Pelts

I spoke with Heidi Pierson, the museum technician at Fort Vancouver, regarding the storage of animal pelts. She said the ideal storage environment would be 45 degrees Fahrenheit at 58 percent humidity. She advised me that circulation is essential in maintaining the quality of the pelt, making cloth the best option to wrap the furs in. She made sure to emphasize to not wrap them in plastic.

She also said that if we cannot find an adequate storage environment, she recommended a fur storage facility. She was fairly sure there were some in the area, but a quick initial search on my part produced no information as of yet. I am going to continue to look to see if there are some in the area and what they might charge for the use of their space.

I also did some research in conservation / preservation and collections management books. All of them emphasized the importance of providing consistent temperatures and humidity conditions due to the expanding and contracting nature of skin. In conditions of low humidity, the skin of the pelts can shrink, crack and split, while too high of humidity risks fungal activity (which begins between 60 to 65 percent) and an increased occurrence of pests. Both can loosen the hair follicles and cause balding. Excessive heat, on the other hand, can cause shrinking, cracking, and distortion of the pelt. Moisture and heat together can cause the skin to turn into a gelatin or a glue-like substance. Skins that have been treated with a vegetable or mineral-tanning compound are less resistant to deterioration under improper conditions. Pelts are also sensitive to light.

To avoid these issues, temperatures (under normal conditions) should reach no higher than 70 degrees Fahrenheit and the humidity should always remain always within 30 to 50 percent. Two books recommend, however, that this range of humidity be INCREASED in the Pacific Northwest, as furs have the ability to acclimate to the conditions and the normal recommendations can damage the item. If you do not have the option to control the climate of an entire space within these ranges, the books suggest creating a "microenvironment" in an enclosed space like a cabinet or a box, where conditions can be controlled by humidity-buffering materials. These materials include silica gel, tissue paper, cloth (muslin, towels, sheets), and cardboard buffer. In general, 
avoid attics, basements, ventilation ducts, radiators, heat-producing appliances, cold walls, windowsills, and metal and cement surfaces.

Related to how the furs should be stored, flat mounts (supportive inflexible trays) are suggested. Commonly stored within a box, a drawer, or on a shelf covered in muslin fabric, these trays can be made of acid-free corrugated board or Coroplast (polypropylene and polyethylene corrugated board). Cororplast is commonly used by sign makers and is generally easy to find. If the above options are not available, you can use corrugated cardboard with a barrier of Marvelseal or polyester film in between. Heavy objects, especially, should be stored in boxes, individually laid in narrow drawers or supported on shelves by acid-free boards or trays. DO NOT STACK PELTS DIRECTLY ON TOP OF EACH OTHER. If a pelt has 3-D properties, thick layers of unbuffered, acid-free tissue paper can be used to retain the shape. Metal buckles corrode when in contact with tannic acid used in curing leather, making it necessary for some type of barrier like Mylar to be placed in between them.

To avoid pests, proper temperature and humidity conditions, good housekeeping, consistent maintenance, and avoidance of clutter is suggested. In the case that insects are detected, sticky traps inside of containers can be used to catch and identify the types of pests so pest professionals can be consulted. If rodents are detected, sticky traps and other means of non-poison rodent control are the best solutions. Do not use poison rodent control, as this increases your chance of insects if the rodent dies within the collection area.

\section{SOURCES USED:}

- Sherelyn Ogden, Caring for American Indian Objects: A Practical and Cultural Guide, (St. Paul: Minnesota Historical Society Press, 2004).

- Ed: Arthur Shultz, Caring for Your Collections, (New York: Harry N. Abrams, Inc. Publishers, 1992).

- Ed: Rebecca Buck and Jean Allman Gilmore, The New Museum Registration Methods, (Washington DC: American Association of Museums, 1998.)

- Bachmann's Conservation Concerns: A Guide for Collectors and Curators

- Heidi Pierson

Museum Technician

National Park Service

Ft. Vancouver NHS 


\section{MEMORANDUM}

TO: $\quad$ Katie Harrison

FROM: $\quad$ Erica Stevenson

DATE: $\quad$ November 17th, 2009

RE: $\quad$ Storage of Plant Materials

Plant materials include a wide and varied group of plant parts from many species. General categories include grasses, brushes, barks, woods, gourds, stems, roots, seeds, and leaves. These items generally appear in Native American collections in the form of mats, baskets, bark cloth, strings, cord, and other fasteners.

\section{STRUCTURAL MAKE-UP}

Items made from plant materials are inherently fragile and subject to deterioration processes similar to that of paper. The decomposition of items made from plant materials is often initiated by the fragility of the materials themselves, the construction techniques, normal use, inadequate storage, and mishandling. Whatever the reason for deterioration, such decline in condition leaves the items prone to embrittlement, distortion, and areas of loss. While items may appear to be structural sound on the exterior, serious interior degradation can have occurred, requiring a large degree of caution when handling objects with plant material components.

\section{HANDLING AND STORAGE}

Plant materials are susceptible to damage from both humid and dry environments. Swelling due to humidity can cause stress on many traditional construction techniques. This swelling leads to breaks within woven or tied fiber bundles, allowing the bundles to distort and splay out of position. Warping or fractures can also occur on a microscopic level within the plant materials. Color changes and stains are another concern in highly humid environments. Tide lines can form when the combination of social and acidic byproducts within fibers migrates through the plant materials, depositing in a dark wavy line on the surface. High humidity can cause water-based dyes or surface paints to run or bleed into surrounding areas, and it also lends items vulnerable to fungi growth that can cause discoloration, embrittlement, and structural damage. While not as common, low 
humidity and high temperatures can also damage plant materials. Loss of moisture can advance the embrittlement process, again resulting in distortion, delamination, and fractures. This makes it essential to store objects comprised of plant material in a stable environment.

Plant materials are also especially vulnerable to light. Overexposure affects the components inside of plant fibers and accelerates the process of embrittlement, weakening, and fading. It is essential to monitor light exposure in both storage and display areas. It is recommended that items made of plant materials not be displayed for longer than four months at a time in a heavily-controlled environment, making sure to never subject the object to direct and/or bright light.

When storing items made of plant materials, always place a piece of washed cotton muslin underneath the object to prevent slippage while in storage boxes or on shelving. It stored on open shelves, cover the item with a piece of acid-free tissue paper or washed de-sized muslin fabric to prevent dust and dirt from settling on the items. For threedimensional objects, stuff the object from the inside with crumpled acid-free tissue to prevent collapse and the occurrence of creases. If needed, exterior supports like rings and coils can be constructed out of polyethylene tubing or thermal-bonded polyester batting wrapped in washed cotton knit fabric.

Inset infestation is also a special concern for plant materials. Remnants of food stuck in items, as well as the actual item itself, can attract pests. Insects will feed on plant materials or use them as areas in which to lay egg cases, and rodents will use plant materials as areas for nesting. Routine inspection, regular cleaning, and an active program of integrated pest management are the best means of prevention. If any infestation is noted, isolate the item and contact a conservator. Avoid the use of over-thecounter pesticides, as they can stain the item.

When handling items made of plant materials, make sure to have clean hands or use gloves. When moving such objects, use a board or a box for support to limit stress on the item. Three-dimensional objects can be especially fragile and will need extra support inside and out of the object to prevent breakage. Supports can be coiled around the exterior or interior of a basket, conforming to its shape, supporting either a fragile and heavy top edge or a delicate footing.

\section{SOURCES USED:}

- Sherelyn Ogden, Caring for American Indian Objects: A Practical and Cultural Guide, (St. Paul: Minnesota Historical Society Press, 2004).

- Ed: Arthur Shultz, Caring for Your Collections, (New York: Harry N. Abrams, Inc. Publishers, 1992). 


\section{MEMORANDUM}

TO: $\quad$ Katie Harrison

FROM: $\quad$ Erica Stevenson

DATE: $\quad$ November 23, 2009

RE: $\quad$ Storage of Stone

\section{STRUCTURAL AND PHYSICAL DIFFERENCES}

Stone can be found in ethnographic collections in a wide variety of forms, including mineral specimens, sculpture, jewelry, flaked lithic tools, fossils, and rock art. Some items of this sort are very sturdy, while others are more polished and fragile. In general, however, stone is one of the most stable materials of those found in an American Indian collection.

Geologists divide stone into several broad categories: sedimentary, igneous, and metamorphic. Each category contains several different types of stone. The stone in each category is formed in a certain way, which influences how it performs and the use to which it can be put. Each category has unique characteristics, such as hardness and the way that it fractures or breaks when struck, that determine what kind of items are made from it.

\section{STORAGE AND HANDLING}

For the most part, stone items stored indoors have fewer problems than items made of other materials. Despite its relative stability, however, stone needs to be protected from physical and chemical damage like other objects in a collection. Large stone objects are heavy, and heavy items are difficult to move and can break without proper support. Flaked stone can have thin, sharp, brittle edges that are easily broken. Sculptures are usually made of a softer stone, which is more porous and stains easily. Gemstones and mineral specimens can also be altered or damaged by light and pollutants.

Most stones can be safely stored any temperature below 100 degrees Fahrenheit and at a relative humidity below 60 percent. At higher humidity, molds and lichens can grow on stone, and soluble salts within the stone can be mobilized. Also, metallic mineral seams can corrode and stain stone, and iron pyrite can react and be converted to iron sulfate, which can turn to powder and cause stone to fall apart. 
Salt efflorescence is caused by the movement of soluble salts in stone. It looks like a powdery white film or a hard white crust and can cause spalling, flaking, and the loss of pieces of the stone. Efflorescence occurs when the stone dries out and the salts rise to the surface, being left behind as the water evaporates. The salts then crystallize and generate tremendous force, which can cause pieces of the stone to fall off. Stone items found buried or lying on the surface of the ground may contain these soluble salts.

Salts are usually introduced to stone from rising dampness in the ground. This will not happen indoors but can occur when a stone item is found or used for display outside. When stone is stored or used for display on cement, even indoors, water can travel through the cement and into the stone. In these cases, rising dampness can be blocked by placing a water-impermeable material under the stone, or by placing the item on a raised shelf. Low humidity, below 35 percent, can also cause some types of stone like opals to crack as they lose water.

Insects will not attack stone items but may be attracted to residues on the stone, such as paper labels. Lichens often grow on stone outdoors, and these are extremely aggressive weather agents that generally should be removed if the items are to be preserved. Lichens usually look like round patches with a soft or powdery appearance. The use of chemical poisons to control the growth of lichens should be avoided. These chemicals are damaging and will not prevent lichens from reforming. A better solution is to make sure that water, which supports the growth of lichens, is kept away from the item.

Stone, like metal, can acquire a patina after many years of use. While metal patinas often originate from corrosion, patinas on stone are composed of accumulated layers of handling residues, such as oils and dirt. On outdoor stone items, patinas form also from prolonged weathering. To prevent handling residues, handle smooth stone items with clean bare hands or nitrile / latex gloves, as they can be too slippery for cotton gloves. Rough-textured stones can be handled with clean dry hands, although some porous stones easily absorb oils from hands and should be handled with cotton, nitrile, or latex gloves.

Some stone is so soft that it can be scratched with a fingernail. Certain types of stone, such a blue celestite, turquoise, and brown topaz, can be faded by light. Poor-quality semiprecious stones may have been dyed to accentuate their colors, and these dyes can also fade when exposed to light. This is important to take into consideration when displaying gemstones. Any stone that has been painted, dyed, or otherwise decorated may also be sensitive to light. If you keep these concerns in mind, however, items made of stone can be used for display in higher light levels than those made of other materials.

Stone items require only occasional dusting. Avoid using household sprays or cleaners on stone since they leave harmful residues. Stone items can usually be cleaned safely by dusting them with a soft-bristled brush or soft cotton cloth. Some stone items can be cleaned with an eraser. Dry cleaning sponges made of vulcanized rubber can also work well for removing fine particulate dirt from relatively smooth surfaces. Avoid using the 
common adhesives such as epoxy resins, superglue. ultraviolet-curing adhesives, and polyester resins because these adhesives are difficult if not impossible to safely remove should that become necessary.

When displaying and storing stone objects, one must remember that the material is heavier than others, oftentimes requiring additional reinforcement to traditional mounts and storage supports. Vibrations from foot or outside traffic can shift items and put them in positions susceptible to damage. Stone items that are heavily weathered or thinly carved can also be very weak and require significant support. It is recommended that stone objects, if stored on metal shelves, be padded with polyethylene foam.

\section{SOURCES USED:}

- Sherelyn Ogden, Caring for American Indian Objects: A Practical and Cultural Guide, (St. Paul: Minnesota Historical Society Press, 2004).

- Ed: Arthur Shultz, Caring for Your Collections, (New York: Harry N. Abrams, Inc. Publishers, 1992).

- Ed: Rebecca Buck and Jean Allman Gilmore, The New Museum Registration Methods, (Washington DC: American Association of Museums, 1998.) 


\section{MEMORANDUM}

TO: $\quad$ Katie Harrison

FROM: $\quad$ Erica Stevenson

DATE: $\quad$ November $14^{\text {th }}, 2009$

RE: $\quad$ Storage of Wood and Birch Bark

\section{STRUCTURAL QUALITIES}

Wood and birch bark is comprised of primarily cellulose and lignin, with minor amounts of waxes and oils. The quantity of lignin varies widely from one type of tree to another, and more lignin is found in the bark of the trees than in the actual wood.

The way a tree grows creates a pattern called the grain, and wood has more strength across this grain. When stress is placed on wooden items parallel to this grain, they are more likely to split.

Recently cut wood is considered "wet" or "green" and requires about six months to a year before it completely dries out. As it dries, wood shrinks slightly and changes shape. These changes will often cause cracks and splits to the form of the wood. After wood ages for several years, this process slows, and new cracks are unlikely to form, unless exposed to high or low humidity. Even after wood is completely dried, however, it can absorb and lose moisture and will expand and contract according to temperature and humidity conditions.

\section{STORAGE AND HANDLING}

Although seemingly stable, wooden objects may be very fragile because of structural damage caused by desiccation, insect infestation, and fungal attack. Stable temperatures and moisture levels are the most effective way to prevent structural problems, as fluctuation can lead to expansion and contraction that can produce cracking and, in the case of birch bark, curling. Birch bark's multiple layers are susceptible to expansion and contraction at different rates, leading to this curling and oftentimes cracking.

Wood and birch bark are materials that highly attract mold, insects, and other pests if not cared for. To avoid pests, wood items are best stored in an environment that has a cool 
temperature and a relative humidity below 60 percent. When stored at a relative humidity below 30 percent, wood can split and crack and birch bark can curl and split into many layers. A fluctuating environment also harms wood and birch-bark items that are held together with adhesives, stitching, nails, dowels, and other joining methods, as these may become loose and the items can fall apart. If possible, store such items in a stable environment with a relative humidity between 50 and 55 percent.

If an item of wood is comprised of many pieces, it is particularly prone to damage from expansion and contraction unless it has been constructed in a way that allows pieces of wood to move independently.

Wood is often painted or coated with resin or varnish. These applied layers are more fragile than the wood, often decomposing, fading, and flaking. When painted wood is in this condition, avoid moving it. It should be handled very carefully, kept in a stable environment, and exposed to as little light as possible. As discussed previously, wood is an attractive food for many insects, and some traditional paints are made of natural products and may make these items even more attractive to insects. Once again, climate control is essential in avoiding infestation.

In regards to light exposure, wood and birch bark are easily degraded by overexposure to light and may darken or turn yellow. Paint on wood and birch bark easily fades with exposure to light as well. Light levels, therefore, should be minimized and displays times should be kept as short as possible.

When handling these items, wear clean gloves made of cotton, nitrile, or latex. Because they are highly porous, wood and birch bark easily absorb hand oils when they are touched. The resulting stains can be difficult if not impossible to remove. Additionally, layers of paint may be powdery and should be handled as little as possible to reduce the chance of damage.

While displaying and storing wooden objects, mounts should not prevent the items from expanding and contracting with changes in relative humidity. They must, however, adequately support the object. It should be allowed to move slightly to accommodate expansion and contraction. Items made of birch bark should be displayed in a position similar to how they are used in real life. Do not prop them up or hang them unless that is how they were used on a regular basis. Small three-dimensional items like boxes, bowls, and baskets, can be supported with a soft foam pad or a cloth pillow filled with polyester batting or raw cotton. Pads or pillows should be covered with a soft clean cloth to prevent the polyester or cotton fibers from snagging on the items.

It is recommended that birch bark scrolls are stored in shallow curved-bottomed trays. Theses can be made out of acid-free corrugated cardboard. Curved bottoms can be formed by carefully slitting along all the corrugations on one side of the three-ply corrugated acid-free cardboard. Cut in this manner, corrugated cardboard will flex in one direction to form a curved shape. This cut cardboard can be placed inside a tray, padded 
with polyethylene foam, polyester batting or raw cotton, and covered with a soft, clean cloth. Acid-free paper, mat board, or cardboard are the most affordable and compatible materials from which to make storage boxes and display supports for wood and birch bark. Stable plastics can also be good materials for display and storage supports, although they can be expensive.

Any effort to clean wood objects requires careful consideration, as items can prove to be extremely fragile. To remove dirt and debris, wooden and birch bark items can be dusted lightly with a soft brush. Avoid using water to clean these items, as it stains and causes them to change form. Solvents such as alcohol and acetone will not leave a mark on wood and can work well to remove oily or greasy deposits such as those left by hands. The use of solvent on birch bark should be considered carefully, because solvents can affect the moisture content and cause it to dry out, crack, or curl. Avoid the use of commercial wood waxes and polishes, as these can damage the wood finish and leave layers of residue that are difficult to remove.

\section{SOURCES USED:}

- Sherelyn Ogden, Caring for American Indian Objects: A Practical and Cultural Guide, (St. Paul: Minnesota Historical Society Press, 2004).

- Ed: Arthur Shultz, Caring for Your Collections, (New York: Harry N. Abrams, Inc. Publishers, 1992).

- Ed: Rebecca Buck and Jean Allman Gilmore, The New Museum Registration Methods, (Washington DC: American Association of Museums, 1998.) 


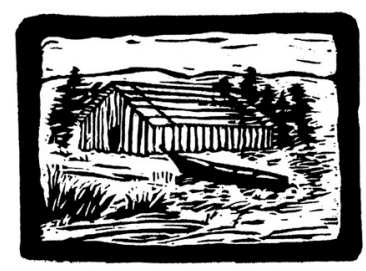

DEED OF GIFT

\section{ACCESSION \#:}

DONOR:

TELEPHONE:

\section{ADDRESS:}

I hereby give, convey and assign to the Cathlapotle Plankhouse all of my right, title and interest in the property hereafter described, to be used or disposed of by the Plankhouse in its sole discretion.

I hereby affirm that the materials contained in this gift were, to the best of my knowledge, acquired legally and without encumbrance, and that I have the proper legal authority to transfer ownership.

It is clearly understood by me that it is my purpose and intention to vest any and all the incidents of absolute ownership, as well as all rights of copyright of the property described below in the Cathlapotle Plankhouse from the date of this document forward.

DESCRIPTION OF GIFT(S):

(Make as specific as possible, including any visible damage to the object(s).)

In witness whereof I have executed this deed at Ridgefield, WA on

Date

Donor's signature

Received by Museum Official 


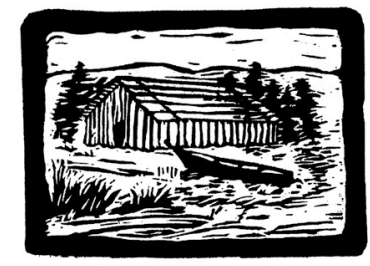

Cathlapotle Plankhouse

[Date]

[Name / Address]

Dear [Name],

The Cathlapotle Plankhouse acknowledges with sincere thanks your recent generous gift of one [object name]. We appreciate your thoughtfulness in placing this material with the Plankhouse.

Enclosed is a Deed of Gift in duplicate covering your donation, as well as a self-address stamped envelope. Please sign and return one copy, necessary for our permanent records.

Thank you for thinking of the Plankhouse. A detailed description of your gift will appear in the Plankhouse's records. If you have any questions, please contact me.

Best regards,

[Director of Collections]

[Title]

[Phone number]

[Email address] 


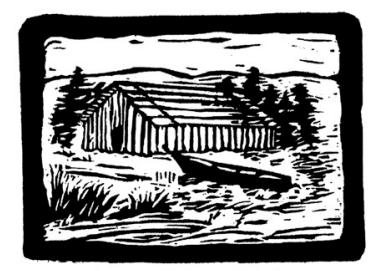

TEMPORARY RECEIPT

Date Received:

Date to be Returned:

(not to exceed 90 days from date of receipt)

Source:

Telephone:

Address:

City:

State:

ZIP:

Email Address:

PURPOSE

Examination for Possible:

Loan

Gift

Purchase

Identification:

Other:

\section{DESCRIPTION OF ITEMS RECEIVED}

-- The Cathlapotle Plankhouse agrees to notify the owner of the above described property of the Plankhouse's decision concerning the item(s) within 60 days of the above date.

-- Place initials here if you do not wish to have item(s) returned:

-- If the Plankhouse decides not to accept the item(s), the owner has 30 days from the date of notification to reclaim the item(s). If the item(s) is not reclaimed at that time, the item(s) becomes property of the Cathlapotle Plankhouse, and the Plankhouse may govern its disposition.

(Owner)

(Received by) 


\section{CATHLAPOTLE ACCESSIONING WORKSHEET} GENERAL COLLECTION

\section{ACQUISITION AND STORAGE:}

Accession Number:

Object Name:

Category / Class:

Acquisition Date:

Gift Purchase

Bequest

Source:

Location:

Size (cm/inches):

L:

D:

W:

DIA: (image)

Ethnographic:

Maker / Artist:

H:

Associated Activities:

Related Artifacts:

DESCRIPTION:

Material(s):

Technique(s):

Description:

Inscription / Markings:

REMARKS:

Provenance:

Condition \& Notes:

Catalogued By:

Date:

Data Entry By:

Date:

Photographed By:

Date: 
CATHLAPOTLE ACCESSIONING WORKSHEET

GENERAL COLLECTION

\section{ACQUISITION AND STORAGE:}

Accession Number:

(image)

Object Name: Beaver Tooth Knife

Category / Class: Permanent Collection

Acquisition Date: December, 2008

Gift $\square$ Purchase $\square$ Bequest $\square$

Source: Lyle Deschand

$\cdot$

Location: La Center, WA

Maker / Artist: Lyle Deschand

Size (cm/inches):
L: 9.5 inches
W: 0.75 inches
H: 1 inch
D:
DIA:

Associated Activities: Fine wood working

Related Artifacts: D Adze, elbow adze

\section{DESCRIPTION:}

Material(s): Antler, pigment, beaver tooth, pitch

Technique(s):

Description: Beaver tooth knife with an antler handle and a beaver tooth affixed to one end with a pitch. Red and black paints were used to add to the design on both ends of the antler.

Inscription / Markings: None.

\section{REMARKS:}

Provenance: Mady by Lyle Deschand, a volunteer who helped to build the Plankhouse.

Condition \& Notes: Good condition.

Catalogued By: ELS

Photographed By:
Date: $11 / 29 / 09$

Date:
Data Entry By:

Date: 
CATHLAPOTLE ACCESSIONING WORKSHEET GENERAL COLLEC'TION

\section{ACQUISITION AND STORAGE:}

Accession Number:

Object Name: Bentwood Box

Category / Class: Permanent Collection

Acquisition Date:

Gift $\square$ Purchase $\square$ Bequest $\square$

Source: John Todd

Location: Portland, OR

Size (cm/inches):
L: 6 inches
W: 6 inches
D:
DIA:

(image)

Ethnographic:

Maker / Artist: John Todd

H: 5.5 inches

Associated Activities: Storage of liquids, food, and personal goods.

Related Artifacts:

\section{DESCRIPTION:}

Material(s): Cedar, pigment

Technique(s):

Description: A long, rectangular length of cedar, scored in three places and bent to bring the two ends together. A square board was inserted to create the bottom of the box. The ends of pegs were used to hold the two ends together and can be seen on one corner of the box. The exterior shows the scars from smoothing the surface of the wood that were left when carving the hourglass shapes. Each hourglass is painted red, in relief, on all four sides of the box.

Inscription / Markings: None.

\section{REMARKS:}

Provenance: Made by John Todd, a Plankhouse volunteer and docent who enjoys woodworking as a hobby

Condition \& Notes: Good.

$$
\text { NOTE: This box was modeled off a bentwood box found on Sauvie Island. }
$$

Catalogued By: ELS

Photographed By:
Date: $11 / 29 / 09$

Date:
Data Entry By:

Date: 
CATHLAPOTLE ACCESSIONING WORKSHEET

GENERAL COLLEC'TION

\section{ACQUISITION AND STORAGE:}

Accession Number:

Object Name: Canoe Bailer

Category / Class: Permanent Collection

Acquisition Date:

Gift $\checkmark$ Purchase $\square$ Bequest $\square$

Source: Kate Mueller-Wille

Location:

Size (cm/inches):
L: 17.25 inches
D:
W: 9 inches
DIA:

(image)

Ethnographic:

Maker / Artist: Kate Mueller-Wille

Associated Activities: Bailing water out of canoes

Related Artifacts:

\section{DESCRIPTION:}

Material(s): Cedar bark, cedar wood

Technique(s):

Description: A canoe bailer made of a single slab of cedar bark with the outer bark removed on the ends to make it more pliable. It has been scored in two places to fold up the sides. Sides are then pleated and the handle is set into a split existing in the pleated bark. The handle is then lashed in place with cedar withes.

Inscription / Markings: None.

\section{REMARKS:}

Provenance: Made by Kate Mueller-Wille, an active volunteer and former program coordinator for the Plankhouse.

Condition \& Notes: Good condition.

Catalogued By: ELS

Photographed By:
Date: $11 / 29 / 09$

Date:
Data Entry By:

Date: 
CATHLAPOTLE ACCESSIONING WORKSHEET GENERAL COLLECTION

\section{ACQUISITION AND STORAGE:}

Accession Number:

Object Name: Chinook Canoe Paddle

Category / Class: Permanent Collection

Acquisition Date:

Gift

Source:

Location:

Size (cm/inches):

L: 62 inches

D:

Purchase

Bequest (image)

Ethnographic:

Maker / Artist:

Associated Activities: Paddling canoes, pushing off bottom of waterway

Related Artifacts: Canoe paddle (wood and black colored); canoe paddle (leaf-shaped head, wood color)

\section{DESCRIPTION:}

Material(s): Wood, pigment

Technique(s):

Description: Wooden paddle with a t-shaped handle and a flared end that has a concave, U-shaped edge. Flared end is painted with red and black paint in a striped pattern. The handle remains wooden in color, except at the base where the t-shape of the handle is painted black. NOTE: Chinookan-style paddle. The U-shaped end, opposite to the handle, is the primary indicator of this. While red and black are not exclusive to Chinookan culture, the colors are highly symbolic and used in contemporary Chinookan design.

Inscription / Markings: None.

REMARKS:

Provenance:

Condition \& Notes: Good condition.

Catalogued By: ELS

Photographed By:
Date: $11 / 29 / 09$

Date:
Data Entry By:

Date: 


\section{CATHLAPOTLE ACCESSIONING WORKSHEET GENERAL COLLECTION}

\section{ACQUISITION AND STORAGE:}

Accession Number:

Object Name: Chinook Canoe Paddle

Category / Class: Permanent Collection

Acquisition Date:

Gift $\square$ Purchase $\square$ Bequest $\square$

Source:

Location:

Size (cm/inches):

L: 55.5 inches

W: 5 inches

D:

DIA: (image)

Ethnographic:

Maker / Artist:

Associated Activities: Paddling canoes; pushing off bottom of waterway

Related Artifacts: Canoe paddle (red and black); canoe paddle (leaf-shaped head, wood color)

\section{DESCRIPTION:}

Material(s): Wood, pigment

Technique(s):

Description: Wooden paddle with a t-shaped handle and a flared end that has a concave, U-shaped edge. Flared end remains wooden in color and the handle and stem of the paddle are painted black. NOTE: Paddle is made in Chinookan style. The U-shaped end, opposite to the handle, is the primary indicator of this style.

Inscription / Markings: None.

REMARKS:

Provenance:

Condition \& Notes: Good condition.

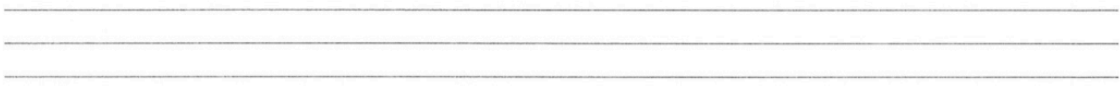

Catalogued By: ELS

Date: 11/29/09

Data Entry By:

Date:

Photographed By:

Date: 
CATHLAPOTLE ACCESSIONING WORKSHEET GENERAL COLLECTION

\section{ACQUISITION AND STORAGE:}

Accession Number:

Object Name: Canoe Paddle

Category / Class: Permanent Collection

Acquisition Date:

Gift $\square$ Purchase $\square$ Bequest $\square$

Source:

Location:

Size (cm/inches):

L: 63 inches

W: 8.25 inches

D:

DIA: (image)

Ethnographic:

Maker / Artist:

H: 3.5 inches

Associated Activities: Paddling canoes

Related Artifacts: Canoe paddle (black and red colored); canoe paddle (black and wood colored)

DESCRIPTION:

Material(s): Wood (yew, yellow cedar?)

Technique(s):

Description: Wooden paddle with a t-shaped handle, a curved stem, and an oval-shaped end that tapers to a point (resembles a leaf). Paddle remains a wooden color. Identified to be a "West Coast" style of paddle.

Inscription / Markings: None.

\section{REMARKS:}

Provenance:

Condition \& Notes: Good condition.

Indentified as "West Coast" paddle in Hilary Stewart's "Cedar."

Catalogued By: ELS

Date: $11 / 29 / 09$

Data Entry By:

Date:

Photographed By:

Date: 
CATHLAPOTLE ACCESSIONING WORKSHEET

GENERAL COLLEC"IION

\section{ACQUISITION AND STORAGE:}

Accession Number:

(image)

Object Name: Cedar Bark Basket

Category / Class: Permanent Collection

Acquisition Date:

Gift $\square$ Purchase $\square$ Bequest $\square$

Source: Bill Bridges

Location:

Size ( $\mathrm{cm} /$ inches $)$ :
L: 11 inches
W: 8.5 inches
D:
DIA:

Associated Activities: Gathering, specifically berry collection

Related Artifacts:

\section{DESCRIPTION:}

Material(s): Cedar wood, cedar bark

Technique(s):

Description: Cedar wood basket with continual sides and bottom. Rectangular slab of outer cedar bark that has been scored on the bottom to enable folding up of the sides. The sides have been sewn together with cedar withes. An elliptical opening is reinforced with a cedar twig and is held in place with a sewn cedar withes. A cedar back cordage handle is attached above the two seams.

Inscription / Markings: None.

\section{REMARKS:}

Provenance:

Condition \& Notes: Good.

NOTE: This type of basket is considered "disposable" compared to woven baskets. It could be made while out gathering foods such as berries. The hard sides keep delicate food in tact.

Catalogued By: ELS

Date: $11 / 29 / 09$

Data Entry By:

Date:

Photographed By:

Date: 


\section{CATHLAPOTLE ACCESSIONING WORKSHEET GENERAL COLLECTION}

\section{ACQUISITION AND STORAGE:}

Accession Number:

Object Name: D Adze

Category / Class: Permanent Collection

Acquisition Date: December 2008

Gift $\square$ Purchase $\checkmark$ Bequest $\square$

Source: Lyle Deschand

Location:

Size (cm/inches):

L: 9 inches

D:

Associated Activities: Cutting, shaping, and finishing wood

DESCRIPTION:

Material(s): Wood, nephrite, pitch, rawhide

Technique(s):

Description: A D-adze comprised of a wooden haft carved to represent a ram holding a nephrite blade attached with pitch and wrapped with rawhide. Rawhide is red in color, while nephrite blade is green. Wood is a reddish-brown with black coloring in areas of the wood.

Inscription / Markings: None.

\section{REMARKS}

Provenance: Mady by Lyle Deschand, a volunteer who helped build the Plankhouse. Funds for purchase provided by the National Park Service.

Condition \& Notes: Good condition.

Adze used to carve the Plankhouse posts, front entrance and wealth boards, as well as select artifacts within the Plankhouse.

Catalogued By: ELS

Date: 11/29/09

Data Entry By: Date:

Photographed By: Date: 
CATHLAPOTLE ACCESSIONING WORKSHEET GENERAL COLLECTION

\section{ACQUISITION AND STORAGE:}

Accession Number:

Object Name: Effigy Spoon

Category / Class: Permanent Collection

Acquisition Date:

Gift $\square$ Purchase $\square$ Bequest $\square$

Source: John Todd

Location: Portland, OR

Size (cm/inches):

L: 7.5 inches

W: 3.5 inches

D:

DIA: (image)

Ethnographic:

Maker/Artist: John Todd

H: 2.5 inches

Associated Activities: Cooking, ceremony

Related Artifacts: Effigy bowl

DESCRIPTION:

Material(s): Wood

Technique(s):

Description: Hand-carved wooden spoon with a three-dimensional animal effigy at the top of a very short and thick handle.

Inscription / Markings: None

REMARKS:

Provenance: Made by John Todd, a volunteer and docent who enjoys woodworking as a hobby.

Condition \& Notes: Good condition.

Catalogued By: ELS

Photographed By:
Date: $11 / 29 / 09$

Date:
Data Entry By:

Date: 


\section{CATHLAPOTLE ACCESSIONING WORKSHEET GENERAL COLLECTION}

\section{ACQUISITION AND STORAGE:}

Accession Number:

Object Name: Elbow Adze

Category / Class: Permanent Collection

Acquisition Date: December 2008

Gift $\square$ Purchase $\square$ Bequest $\square$

Source: Lyle Deschand

Location: La Center, WA

Size (cm/inches):
L: 17.5 inches
W: 6.5 inches
D:
DIA:
H: 2 inches

Ethnographic: (image)

Maker / Artist: Lyle Deschand

Associated Activities: Woodworking, chopping, carving basic shapes in large objects like posts/canoes.

Related Artifacts: $D$ adze, beaver tooth knife

\section{DESCRIPTION:}

Material(s): Wood, pigment, pitch, nephrite, rawhide

Technique(s):

Description: Elbow adze with a long handle that turns shy of a 90 degree angle. A nephrite blade is attached with pitch and rawhide to the top of the bend. A design on the adze includes a yellow circle with black dots on both sides of the top of the handle. Where it angles to the blade is a band of red pigment with linear yellow dots. There is a red band at the tip of the handle.

Inscription / Markings: None

\section{REMARKS:}

Provenance: Made by Lyle Deschand, a volunteer who helped to build the Plankhouse.

Condition \& Notes: Good

NOTE: Object commonly used for rough shaping and chopping, including removing branches from a log or carving out the basic shape for a canoe. Also assists with the initial stages of design on poles, boards, or posts.

Catalogued By: ELS

Date: $11 / 29 / 09$

Data Entry By:

Date:

Photographed By:

Date: 


\section{CATHLAPOTLE ACCESSIONING WORKSHEET} GENERAL COLLECTION

\section{ACQUISITION AND STORAGE:}

Accession Number:

Object Name: Ladle

Category / Class: Permanent Collection

Acquisition Date:

Gift $\square$ Purchase $\square$ Bequest $\square$

Source: John Todd

Location: Portland, OR

Size (cm/inches):
L: 12 inches
D:
W: 3 inches
DIA:

(image)

Ethnographic:

Maker / Artist: John Todd

H: 5 inches

Associated Activities: Cooking

Related Artifacts:

\section{DESCRIPTION:}

Material(s): Wood

Technique(s):

Description: Wooden ladle. Ladle has a flat, wide handle with slight curvature towards the end. An ovalshaped bowl is attached to the flat handle. Some darkening of the wood on the outside of the spoon area.

Inscription / Markings: None.

\section{REMARKS:}

Provenance: Made by John Tood, a Plankhouse volunteer and docent who enjoys wood working as a hobby.

Condition \& Notes: Good condition.

Catalogued By: ELS

Photographed By:
Date: $11 / 29 / 09$

Date:
Data Entry By:

Date: 


\section{CATHLAPOTLE ACCESSIONING WORKSHEET GENERAL COLLECTION}

\section{ACQUISITION AND STORAGE:}

Accession Number:

Object Name: Obsidian Blade

Category / Class: Permanent Collection

Acquisition Date:

Gift $\square$ Purchase $\square$ Bequest $\square$

Source: Dennis Torresdale

Location:

Size (cm/inches):

L:

D:

W:

DIA:

Associated Activities: Hunting tool, cutting cool

Related Artifacts:

\section{DESCRIPTION}

Material(s): Obsidian

Technique(s): Flint knapping (see attached for further detail)

Description: Black, shiny obsidian blade. Has a pointed tip and a body that widens as you approach the blade's center from both the top and the bottom. A straight, flat edge exists at the bottom of the blade.

Inscription / Markings: None.

\section{REMARKS:}

Provenance:

Condition \& Notes: Missing from collection.

Catalogued By: Date:

Data Entry By: Date:

Photographed By:

Date: 
CATHLAPOTLE ACCESSIONING WORKSHEET GENERAL COLLECTION

\section{ACQUISITION AND STORAGE:}

Accession Number:

Object Name: Stone Bowl

Category / Class: Permanent Collection

Acquisition Date: December, 2008

Gift $\square$ Purchase $\checkmark$ Bequest $\square$

Source: Lyle Deschand

Location: La Center, WA

Size (cm/inches):

L: 1.5 inches

W:

D:

DIA: 6.5 inches (image)

Ethnographic:

Maker / Artist: Lyle Deschand

H: 4 inches

Associated Activities: Cooking activities, mixing, storage

Related Artifacts:

\section{DESCRIPTION:}

Material(s): Stone

Technique(s):

Description: An oval-shaped piece of stone with a concave depression in the top. The depression is deep enough to allow for storage of liquid and solid objects. The stone material is grey in color with subtle hints of white and tan coloring in surface depressions.

Inscription / Markings: None.

\section{REMARKS:}

Provenance: Funds for the purchase of this object were made possible by the National Park Service.

Condition \& Notes: Good condition.

Catalogued By: ELS

Photographed By:
Date: $11 / 29 / 09$

Date:
Data Entry By:

Date: 


\section{CATHLAPOTLE ACCESSIONING WORKSHEET GENERAL COLLECTION}

\section{ACQUISITION AND STORAGE:}

Accession Number:

Object Name: Wooden Effigy Bowl

Category / Class: Permanent Collection

Acquisition Date: January 17, 2009

Gift $\square$ Purchase $\checkmark$ Bequest $\square$

Source: Greg Robinson

Location: Vancouver, WA

Size (cm/inches):

L:

D:
W: 10 inches

DIA: 25 inches (image)

Ethnographic:

Maker / Artist: Greg Robinson

Associated Activities: Serving food

Related Artifacts: Effigy spoon

\section{DESCRIPTION:}

Material(s): Cedar wood, seal oil

Technique(s):

Description: A cedar conical-shaped bowl that is wider at the top and has two handles or grips on opposing sides. Handles extend 2 inches above the rim of the bowl. They also extend to the base of the bowl and have carved effigy figures on each side. NOTE: The effigy figure is a human effigy patterned after old figurines in Chinookan stories or personal tamanawas. A bowl of this type would have been used for serving or holding oil for dipping food into. Often used to serve meals for special guests or the headman's family.

Inscription / Markings: None.

\section{REMARKS:}

Provenance: Carved by Greg Robinson, a Chinookan carver and Project Coordinator for the Plankhouse. Funds provided by NPS and the Clark County Historic Promotions Grant.

Condition \& Notes: Good condition.

NOTE: Cedar wood used is old growth cedar that is between 600 and 1,000 years old. Object donated at the Chinook Winter Gathering held at the Plankhouse on January 17 , 2009.

Catalogued By: ELS

Date: $11 / 29 / 09$

Data Entry By:

Date:

Photographed By:

Date: 
APPENDIX B

IMAGES OF THE CATHLAPOTLE PLANKHOUSE

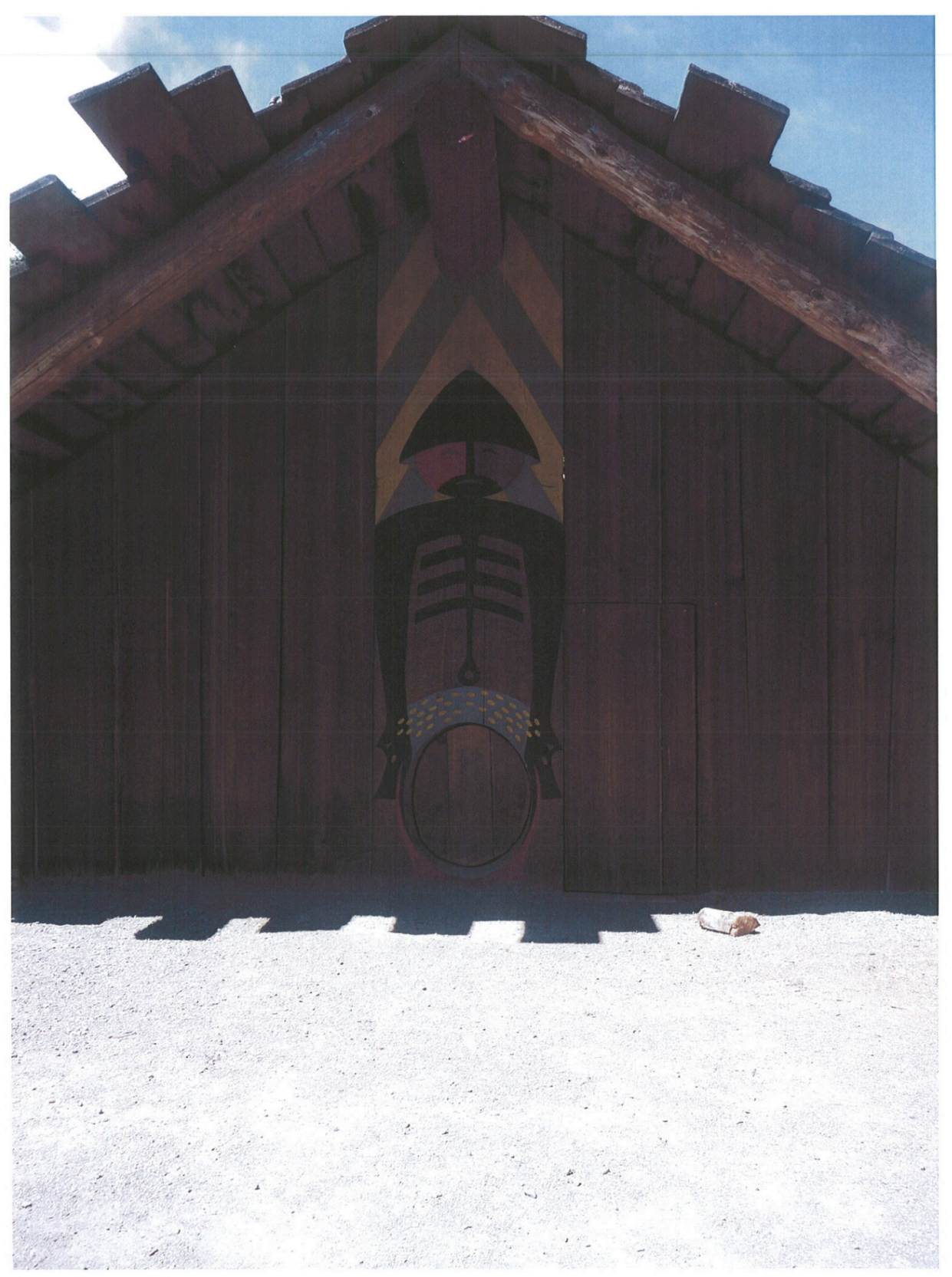

Traditional Chinookan entryway of the Cathlapotle Plankhouse.

Photo credit: Erica Boyne 


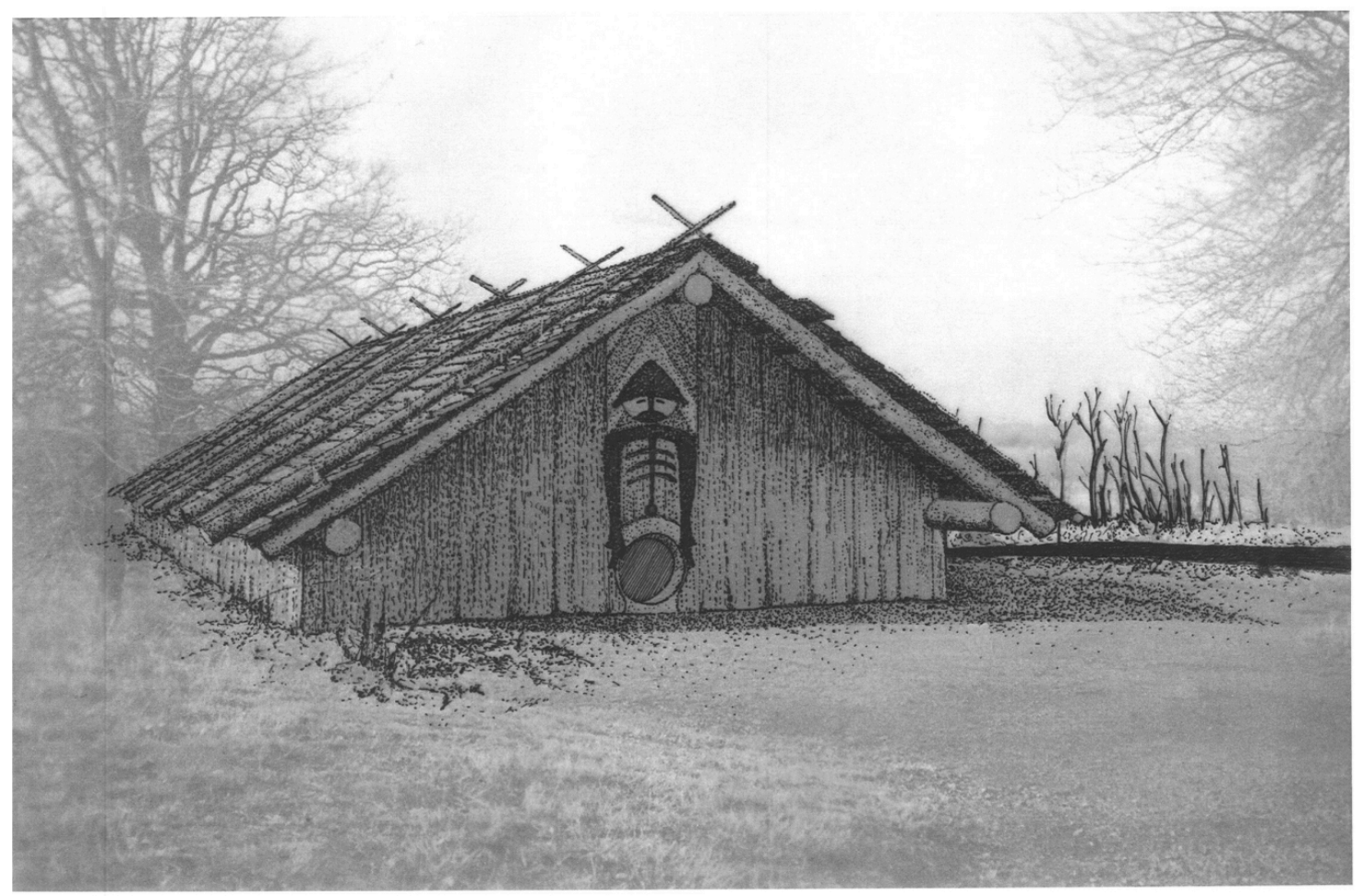

Illustration of the Cathlapotle Plankhouse

Illustration credit: Andrew T. Boyne 


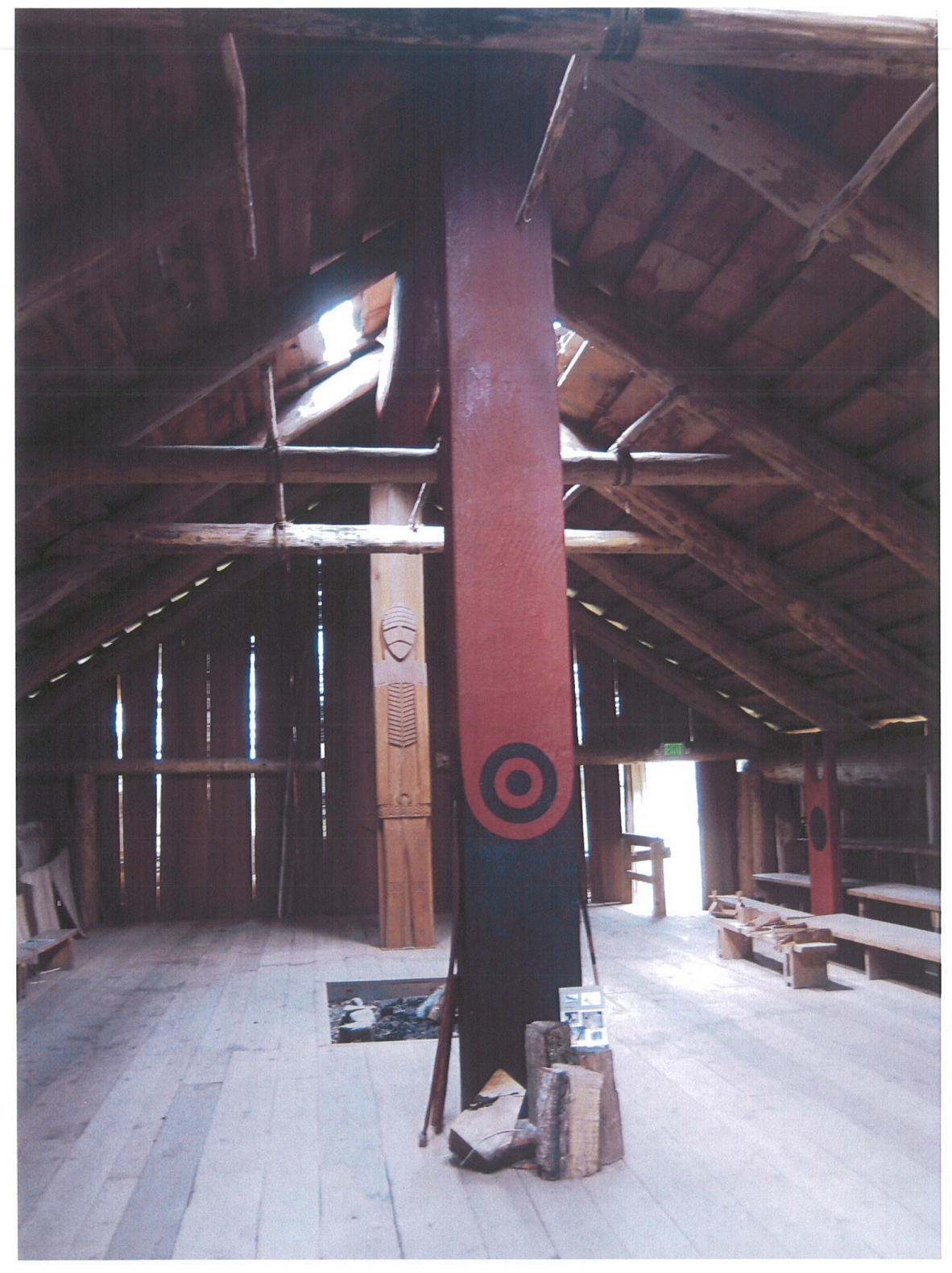

Internal view of the Cathlapotle Plankhouse looking away from the traditional entryway. Photo credit: Erica Boyne 


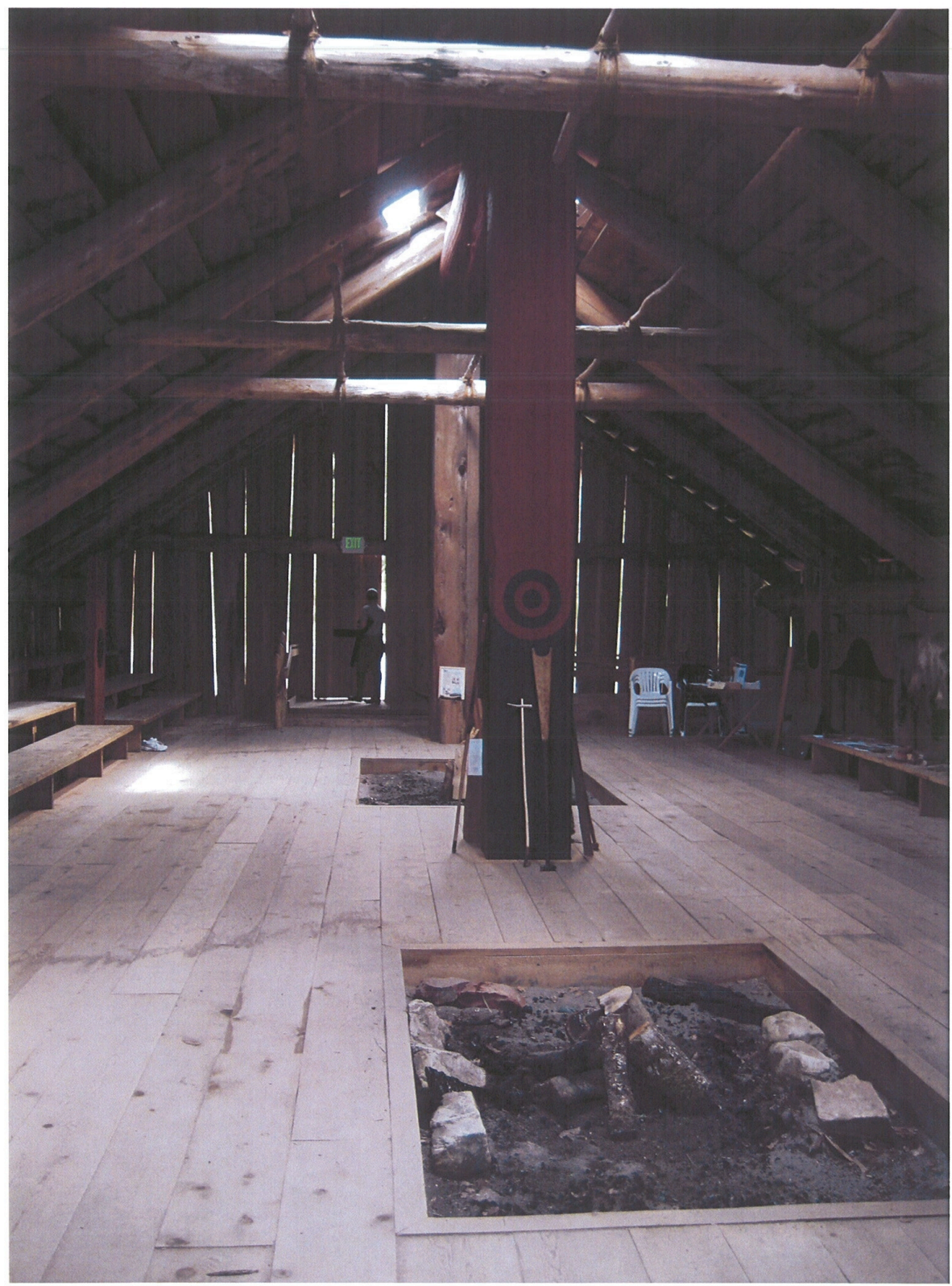

Internal view of the Cathlapotle Plankhouse, looking towards the traditional entryway. Photo credit: Erica Boyne 


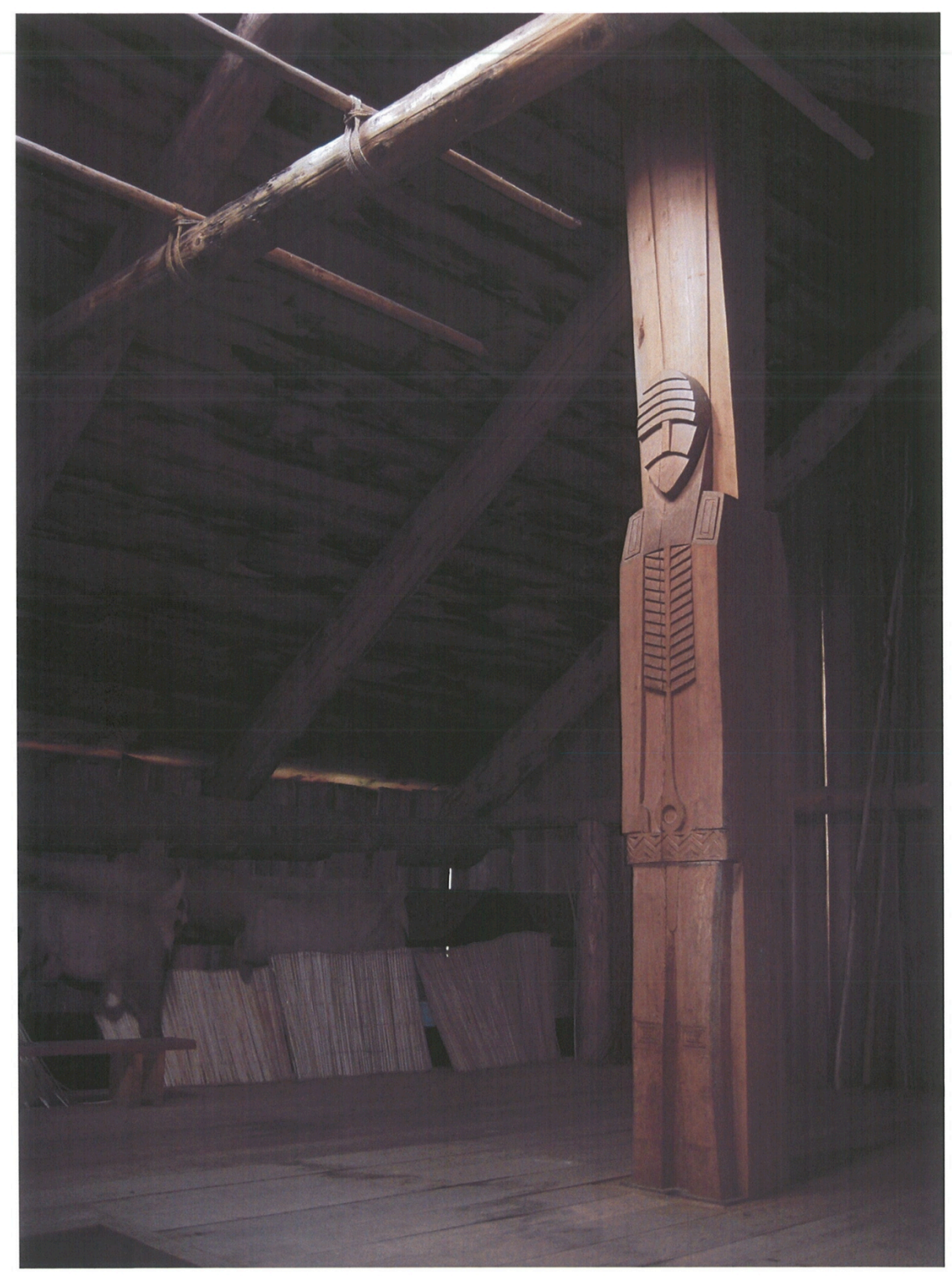

Carved ridge beam support in the Cathlapotle Plankhouse.

Photo credit: Erica Boyne 


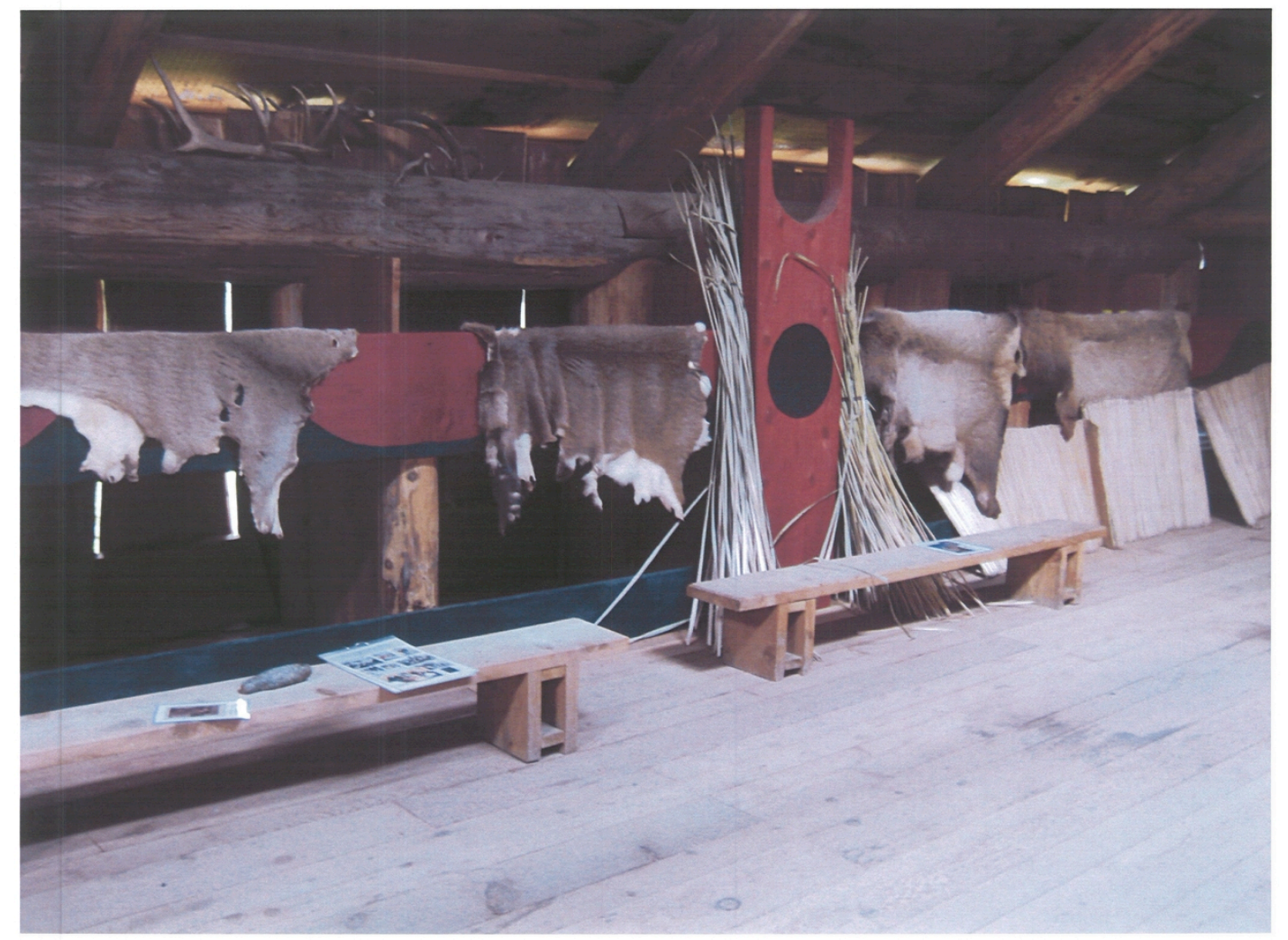

Internal furnishings of the Cathlapotle Plankhouse.

Photo credit: Erica Boyne 


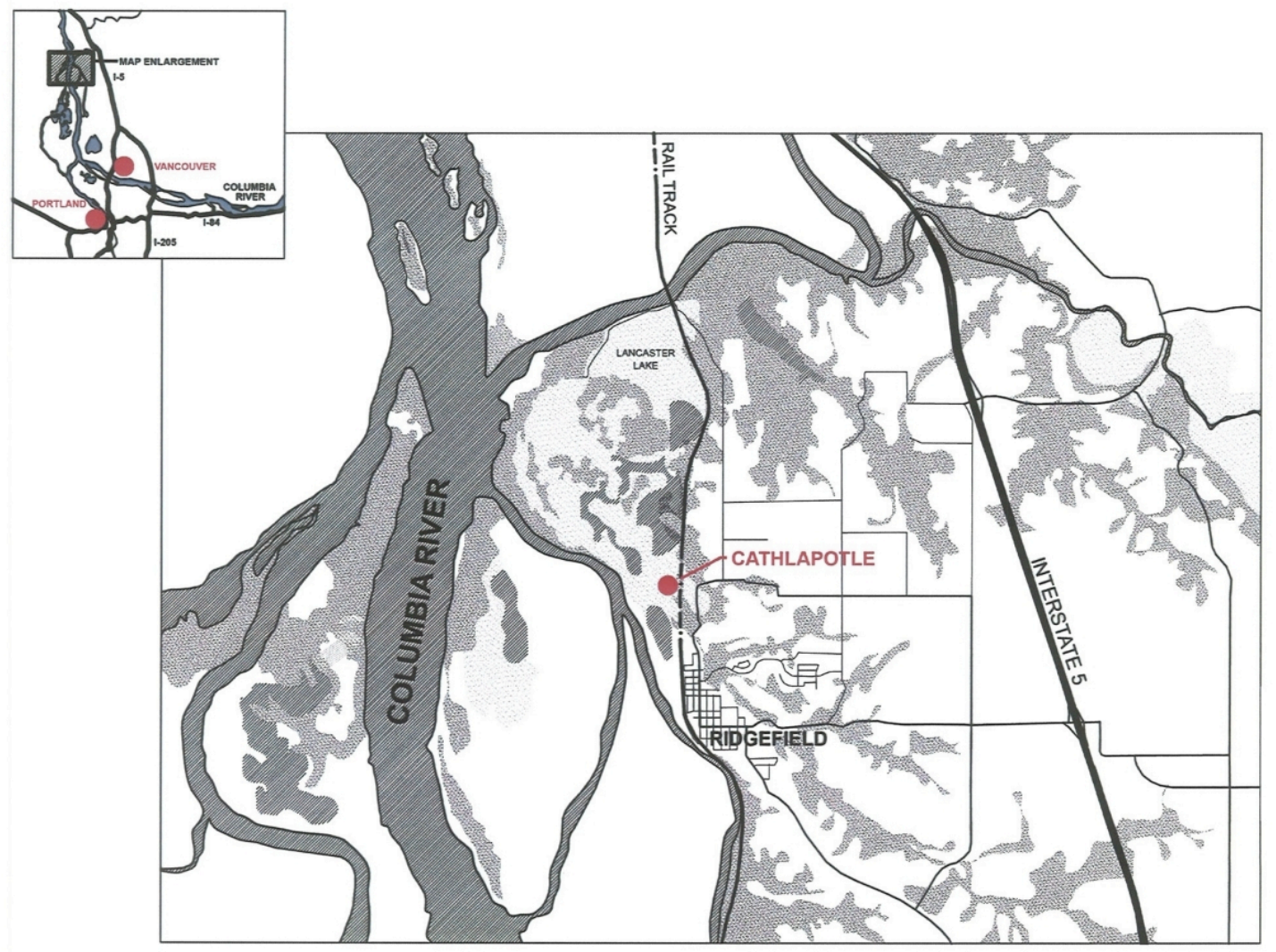

Map of the Ridgefield, Washington area.

Map credit: Andrew T. Boyne 